\title{
A genome wide scan for familial high myopia suggests a novel locus on chromosome 7q36
}

\author{
L Naiglin, C Gazagne, F Dallongeville, C Thalamas, A Idder, O Rascol, F Malecaze, \\ P Calvas
}

J Med Genet 2002;39:1 18-124

$\mathrm{H}$ igh myopia often appears as a familial disease. It is usually defined as a refraction error equal to or below -6 diopters (D) in each eye. ${ }^{1}$ Highly myopic patients represent $27-33 \%$ of the myopic population. ${ }^{2}$ The prevalence of the disease in the general population varies according to the country, from $2.1 \%$ in the USA, ${ }^{2}$ to $3.2 \%$ in France, ${ }^{3}$ and up to $9.6 \%$ in Spain. ${ }^{3}$ High myopia is also termed "pathological" myopia because of its potential complications. The highly myopic eye is usually characterised by an abnormal lengthening and a posterior staphyloma. It is often accompanied by glaucoma, cataracts, macular degeneration, and retinal detachment, leading to blindness when the damage to the retina is extremely severe.

Both genetic and environmental factors, such as close work, are known to play a role in the aetiology of high myopia. The inheritance of the disease is equivocal. Several genealogical studies have shown autosomal dominant or autosomal recessive modes of inheritance. ${ }^{45}$ Rare cases of sex linked transmission have been observed. ${ }^{6}$

In a previous study, ${ }^{7}$ we showed that, assuming a single gene model, autosomal dominant transmission with weak penetrance was largely present in the families that we studied. Young et al have recently reported linkage of familial high myopia to chromosome regions $18 \mathrm{p}^{8}$ and $12 \mathrm{q} .{ }^{9}$ We previously found no evidence for linkage to the former chromosomal region in the families of our study. Several putative candidate loci were excluded as well in these families, such as the locus for Stickler syndrome types 1 and 2, versican and aggregan genes, Marfan 1 syndrome, and a Marfan-like disorder localised to 3p24.2-p25.

In order to find new loci implicated in high myopia, we conducted a genome screen in 23 families following an autosomal dominant mode of inheritance with weak penetrance. Here, we provide further evidence for genetic heterogeneity by excluding the chromosome $12 \mathrm{q}$ and $18 \mathrm{p}$ regions, previously linked to familial high myopia, ${ }^{8}$ and report suggestive evidence for the presence of a third autosomal locus on chromosome $7 \mathrm{q}$.

If you have a burning desire to respond to a paper published in Journal of Medical Genetics, why not make use of our "rapid response" option?

Log on to our website (www.jmedgenet.com), find the paper that interests you, and send your response via email by clicking on the "eletters" option in the box at the top right hand corner.

Providing it isn't libellous or obscene, it will be posted within seven days. You can retrieve it by clicking on "read eletters" on our homepage.

The editors will decide as before whether to publish it in a future paper issue as well.

\section{SUBJECTS, MATERIALS, AND METHODS Subjects}

Medical history and ophthalmic assessment were obtained from 140 participants from 21 French families and two Algerian families, after informed consent according to French law. We focused our study on isolated bilateral high myopia. Families with unilateral high myopia, syndromes with high myopia, and myopia of prematurity were excluded.

For each patient, subjective refraction and keratometry were performed. Axial lengths were also measured for almost all of the subjects. Objective refraction was measured by automatic refractometry. The refraction defect in spherical equivalent was the criterion chosen to classify subjects into two groups, high myopes and unaffected persons. A subject was considered to be highly myopic if the refraction error in the lesser affected eye was $-6 \mathrm{D}$ or below. We considered low myopes (myopia between -6 and -1 D), emmetropes (refraction status between -1 and 1 D), and patients with hyperopia (refraction status greater than I D) as unaffected subjects. Details of refractive status are summarised in table 1 .

\section{DNA analysis/marker typing}

Venous blood samples were collected in EDTA for DNA extraction according to standard methods..$^{10}$ The genome screen used 400 highly polymorphic fluorescently labelled microsatellite markers, with an average spacing of $10 \mathrm{cM}$, from the ABI PRISM Linkage Mapping Set MD-10 (Perkin-Elmer, Warrington, UK). The map positions were generated from the CEPH genotype data used for the Généthon map. For fine mapping, we selected those regions with a two point lod score $>1$. This is clearly well below the threshold for statistical significance but provided a convenient cut off for identification of regions meriting higher density genotyping. Additional polymorphic markers (heterozygosity $\geqslant 75 \%$ ) were selected from the Généthon and the CHLC genetic maps and were fluorescently labelled. All labels were either 6FAM, HEX, or NED 5' end labels.

All PCR reactions were carried out using $25 \mathrm{ng}$ of genomic DNA as a template in a mixture of $1 \times$ Perkin-Elmer PCR buffer, $2.5 \mathrm{mmol} / \mathrm{l} \mathrm{MgCl}, 200 \mathrm{nmol} / \mathrm{l}$ of each dNTP, $5 \mathrm{pmol}$ of each primer, and $0.1 \mu \mathrm{l}$ of TaqGold polymerase (Perkin-Elmer, Warrington, UK) in a final volume of $15 \mu \mathrm{l}$. The thermocycling conditions were $95^{\circ} \mathrm{C}$ for 18 minutes, followed by 38 cycles at $94^{\circ} \mathrm{C}$ for one second, $55^{\circ} \mathrm{C}$ for 25 seconds, and $72^{\circ} \mathrm{C}$ for five seconds, followed by a 10 minute final extension step at $72^{\circ} \mathrm{C}$. PCR products were pooled with regard to their size range and labelling, mixed with a formamide sample buffer, and electrophoresed through preheated $6 \%$ acrylamide $/ 50 \%(\mathrm{~W} / \mathrm{V})$ urea gels on an ABI 373 DNA sequencer XL upgrade (PE Applied Biosystems, Foster City, CA, USA) according to the manufacturer's recommendations. All amplimers were sized by the GeneScan Analysis 3.1 software (PE Applied Biosystems, Foster City, CA, USA) and scored by the Genotyper 2.1 software (PE Applied Biosystems, Foster City, CA, USA) with respect to the CEPH control genotype No 1347-02. 


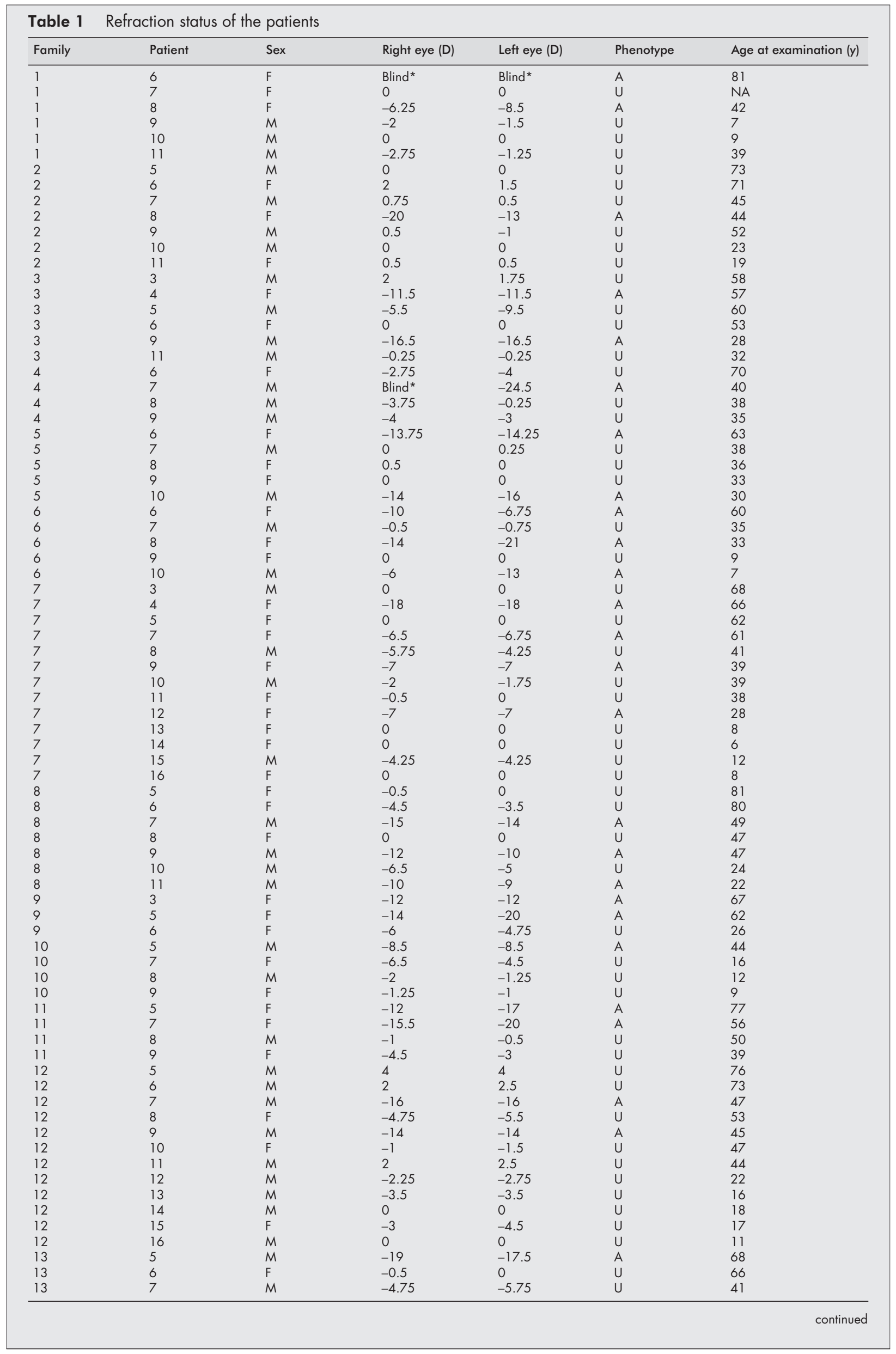




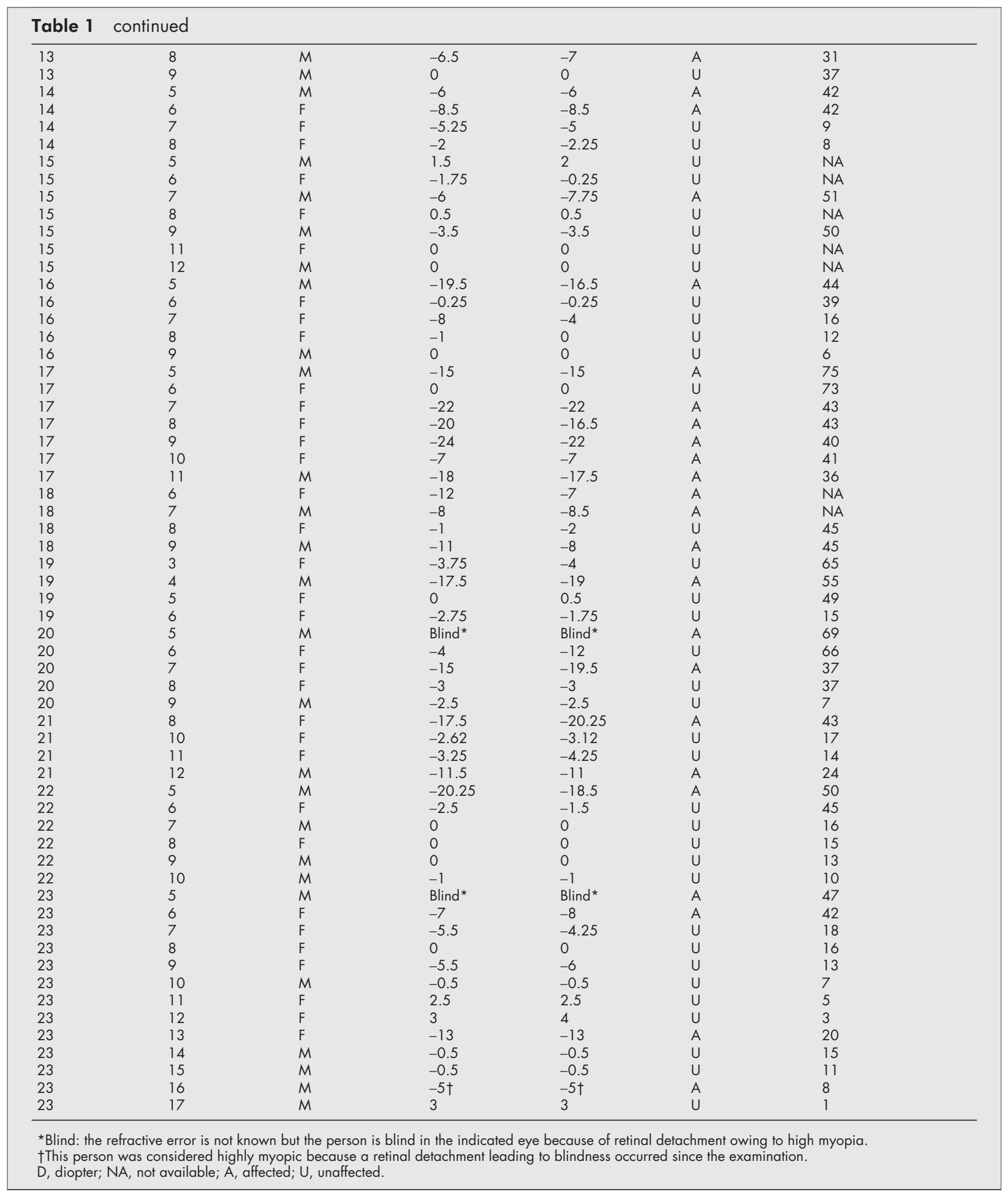

\section{Statistical analysis}

In parametric statistics, we assumed an autosomal dominant mode of inheritance with $58.4 \%$ penetrance and a myopia gene frequency of 0.013 , as they were established in a previous study. ${ }^{7}$ Data were simulated using the program SLINK ${ }^{11}$ in order to determine the power to detect linkage. Two point lod scores and maximum lod scores (Zmax) were calculated using the MLINK and ILINK routines of the FASTLINK program ${ }^{12}$ and genetic heterogeneity was tested using the HOMOG program. Marker allele frequencies were estimated from the non-inbred founders in the data. The two Algerian pedigrees were included in the whole population to calculate a unique set of allele frequencies.

Multipoint lod score analysis of the genome screen was performed with the GENEHUNTER computer package ${ }^{13}$ under the parametric model previously defined (lod) and the non-parametric option. In addition, lod scores were calculated under the locus heterogeneity hypothesis (hlod). The proportion of the families linked (alpha) was allowed to vary until the hlod was maximised. Map order and genetic distances between markers were determined from the Généthon Human Linkage Map. ${ }^{14}$ 


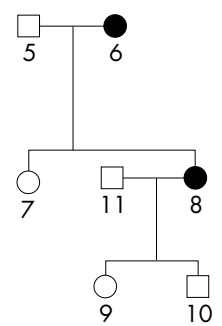

Family 1
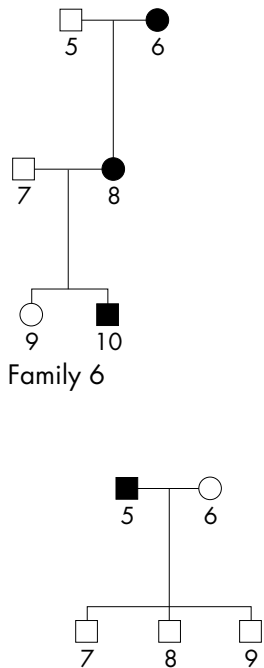

Family 10

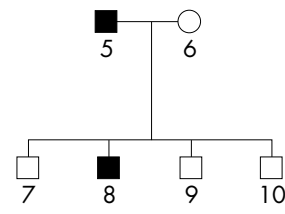

Family 13

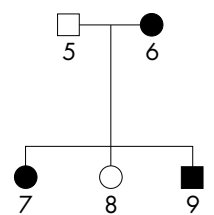

Family 18

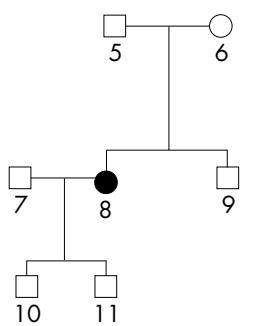

Family 2

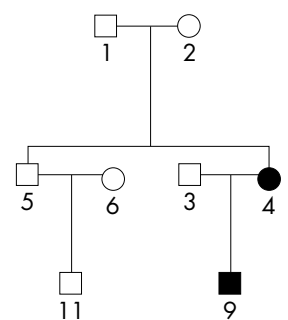

Family 3
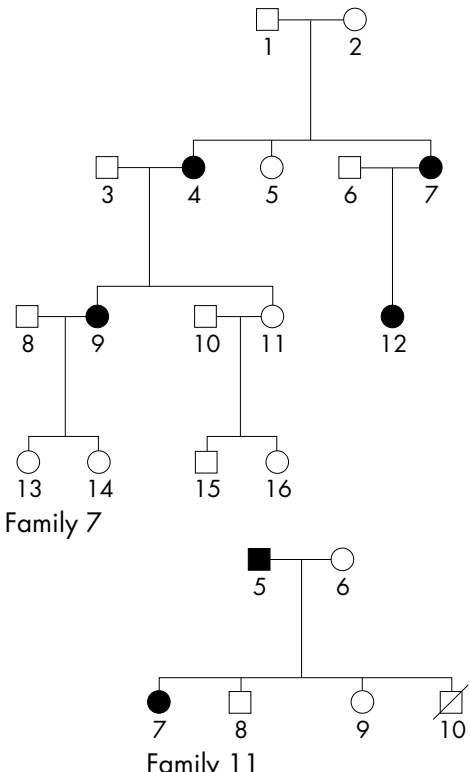

Family 11
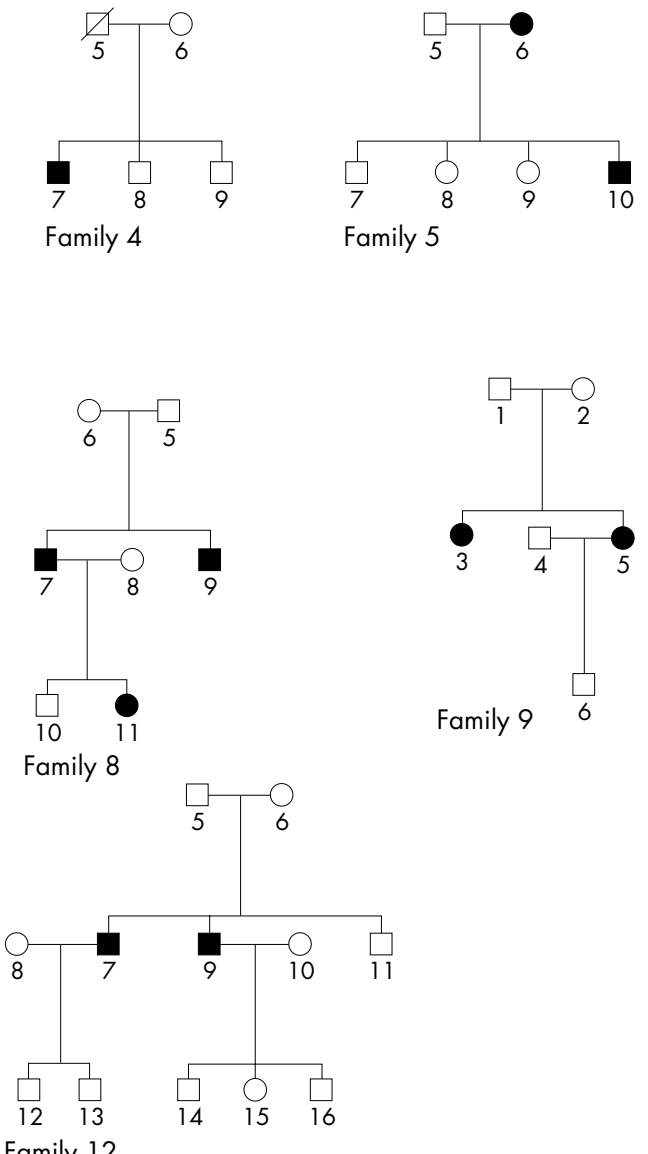

Family 12
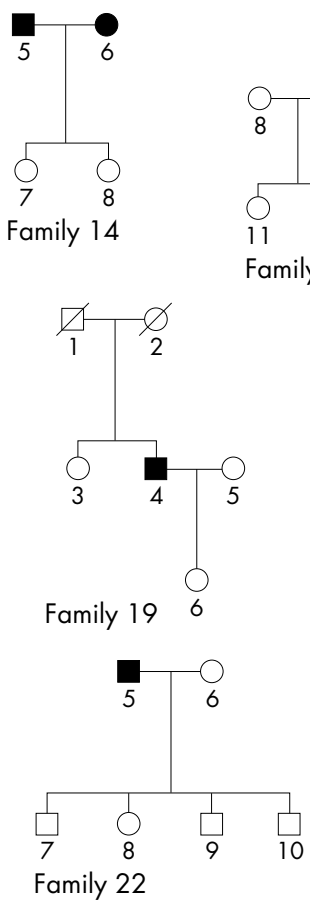

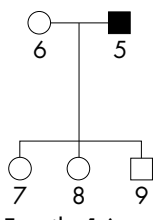

Family 16

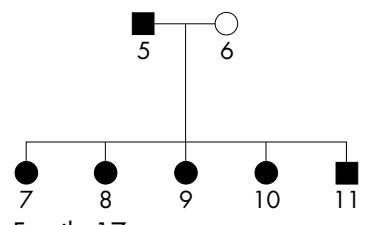

Family 17
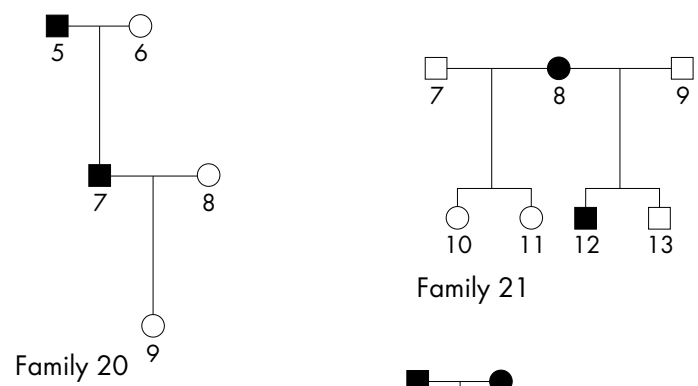

Family 21

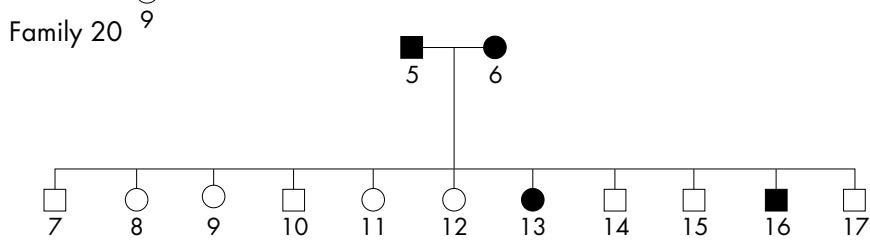

Family 23

Figure 1 Pedigrees of the 23 families studied with familial high myopia. Filled symbols denote affected subjects (myopia $\leqslant-6 \mathrm{D}$ ).

\section{RESULTS}

Twenty-three families were included in the genome scan (fig 1). They were not selected a priori, in order to avoid a bias in favour of dominance. They only had to have at least one highly myopic subject in their pedigree. Fifty highly myopic patients with a sex ratio of 1 were studied. The mean refraction value was -13.05 (SD 4.92) D for high myopes versus - 1.32 (SD 2.43) D for nonhighly myopic subjects. The mean axial lengths were 27.87 (SD 2.92) $\mathrm{mm}$ and 23.52 (SD 1.26) mm for highly myopic and nonhighly myopic subjects, respectively. 

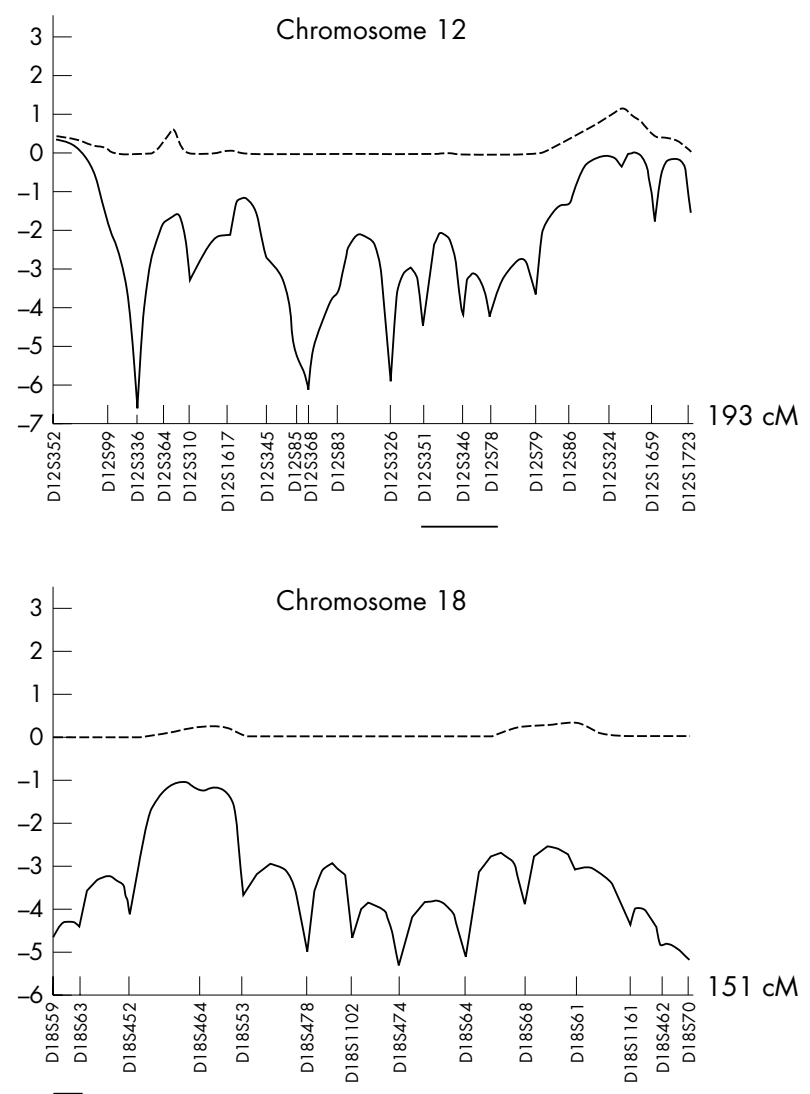

Figure 2 Multipoint lod score (continuous line) and hlod score (dashed line) statistics for chromosomes 12 and 18. The regions of the locus for familial high myopia are underlined.

The simulation test found a power of $41.6 \%$ to obtain significant evidence for linkage $(Z \max >3)$ and a power of $70.6 \%$ to obtain suggestive evidence of linkage (Zmax $>2$ ) when a recombination fraction $(\theta)$ of 0.01 between the marker tested and the disease locus was assumed.

Some markers implicated in familial high myopia on chromosome 12q (D12S351, D12S346, and D12S78) and chromosome 18p (D18S59 and D18S63) by Young et al ${ }^{8}{ }^{9}$ were tested during our initial genome scan and showed negative lod scores (data not shown). The multipoint analysis also excluded both regions and under the heterogeneity hypothesis no evidence for linkage to these regions was found (fig 2).

The initial $10 \mathrm{cM}$ genome screen did not show any suggestive evidence of linkage even under the heterogeneity hypothesis. Indeed, no lod score above 2 was obtained. No significantdifferences were observed when allowing genetic heterogeneity in the initial screen. However, five chromosomal regions, on 4q, 5p, 7q, 13q, and 15q, were identified as having Zmax $>1$. In each region, additional highly polymorphic markers were genotyped and analysed by two point and multipoint linkage analysis. The new markers for chromosome 4q, 5p, 13q, and 15q gave similar or lower two point lod scores. The multipoint analysis confirmed the exclusion of these regions (fig 3). In contrast, the maximum two point lod score with chromosome 7q markers reached 1.87 at $\theta=0$ (table 2). The multipoint analysis showed suggestive evidence of linkage with a maximum multipoint lod score of 2.81 (fig 3), whereas no locus heterogeneity could be detected. The implicated region extended from D7S798 to D7S2423, the latter marker being located in the immediate vicinity of the telomere. A recombination event between D7S798 and D7S2546 in family 17 (fig 4) allowed us to set this interval in an $11.7 \mathrm{cM}$ region extending from D7S798 to the telomeric end of the chromosome.

\section{DISCUSSION}

In our previous study, ${ }^{7}$ we have shown that genetic factors were of decisive importance in the aetiology of familial high myopia. By segregation analysis, we showed that an autosomal dominant mode of inheritance with weak penetrance was largely favoured in the families that we studied. Nevertheless, some families (family 2) showed an autosomal recessive mode of transmission. The weak penetrance of a dominant allele may give the appearance of recessive transmission which could not be totally excluded in some families.

The pathophysiology of isolated high myopia remains unknown. Besides heredity, the trait depends on environmental factors and, moreover, the genetic component is also complex. Indeed, we found that the locus for familial high myopia on chromosome 18p11.31, recently reported by Young et al, ${ }^{8}$ was probably not implicated in our families. This indicates that the disease is genetically heterogeneous as there were no obvious phenotypic differences between our patients and the ones reported by these authors.

We now confirm the locus heterogeneity of the disease with the families we have studied by excluding the loci for familial high myopia on chromosomes 12q21-23 and 18p11.31. Moreover, the results obtained during our genome scan suggest the presence of a new susceptibility locus for familial high myopia on chromosome 7q36 within a $11.7 \mathrm{cM}$ interval. Evidence for locus heterogeneity could not be detected, even if some families, when the data were examined in detail, did not seem to be linked. The added high resolution markers were informative in our population and gave results in keeping with the simulation test, which predicted a power of only $41.6 \%$ to obtain a lod score above 3. Furthermore, the complexity of the high myopia trait probably leads to the decrease in the power to detect significant linkage.

The non-parametric lod score curve of the genome scan (data not shown) showed the same variations as the lod score curve but remained less powerful. This strongly suggested that our parametric segregation model was correct and that our results were not due to a possible error in the model.

Myopia is commonly considered as a complex, multifactorial trait, where several genes could act together in a quantitative way. To date, in single families or limited familial series,

Table 2 Two point linkage analysis of high myopia and markers on chromosome $7 q$

\begin{tabular}{llllllllll}
\hline & \multicolumn{9}{l}{ Total lod score at $\theta=$} \\
\cline { 2 - 9 } Marker* & 0 & 0.05 & 0.1 & 0.15 & 0.2 & 0.3 & 0.4 & $\begin{array}{c}\text { Maximum lod } \\
\text { score (Zmax) }\end{array}$ & $\theta$ at Zmax \\
\hline D7S798 & 1.01 & 1.26 & 1.17 & 1.01 & 0.83 & 0.4 & 0.17 & 1.26 & 0.047 \\
D7S2546 & 0.44 & 0.53 & 0.55 & 0.53 & 0.47 & 0.30 & 0.12 & 0.55 & 0.096 \\
D7S550 & 1.87 & 1.67 & 1.44 & 1.21 & 0.97 & 0.52 & 0.18 & 1.87 & 0.001 \\
D7S2465 & 1.54 & 1.45 & 1.31 & 1.15 & 0.95 & 0.55 & 0.19 & 1.54 & 0.001 \\
D7S2423 & 0.90 & 0.84 & 0.75 & 0.64 & 0.52 & 0.27 & 0.08 & 0.90 & 0.001 \\
\hline
\end{tabular}

*Order is shown from centromere to telomere. 

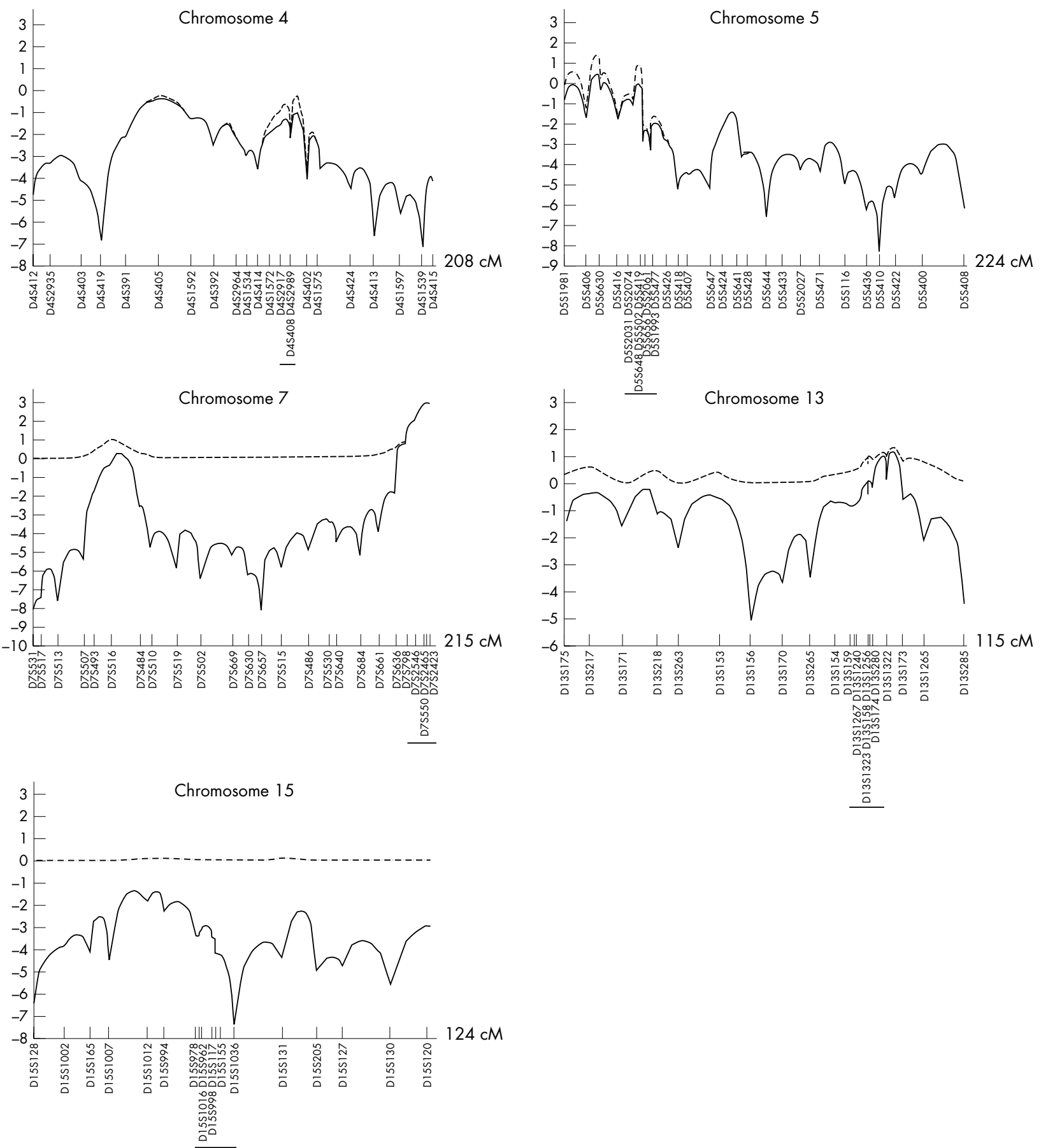

Figure 3 Multipoint lod score (continuous line) and hlod score (dashed line) statistics for each chromosome of interest in the genome scan of 23 families genotyped with $10 \mathrm{cM}$ spaced polymorphic markers ( $x$ axis). The names (in Généthon map position order) of the added high resolution markers are as follows: chromosome 4: D4S2917, D4S2989; chromosome 5: D5S2031, D5S2074, D5S648, D5S502, D5S661, D5S2061, D5S1993, D5S477; chromosome 7: D7S2546, D7S550, D7S2423; chromosome 13: D13S1267, D13S1240, D13S1323, D13S1256, D13S174, D13S280, D13S1322; and chromosome 15: D15S1016, D15S962, D15S998, D15S155, D15S1036. The refined regions are underlined.

single loci have been identified. Our data suggest that a new locus triggers or participates in familial high myopia. The computational search for genes and/or expressed sequence tags physically mapped between markers D7S798 and the telomere showed numerous unidentified transcripts, mRNAs for an open reading frame, and several genes. None of these appeared to be good candidate genes on the basis of their known function. In addition, there is no evidence of any closely related genes shared by the regions of interest on chromosomes 7q36, 12q21-23, and 18p11.31.
A majority of the families that we studied contained low myopic persons whom we considered as being unaffected, in order to preserve phenotypic homogeneity. The -6 diopter limit for high myopia that was chosen for the current clinical definition cannot be considered perfectly biologically accurate. Consequently, it would be interesting to analyse high myopia as a quantitative trait.

In summary, we provide suggestive evidence for the presence of a third autosomal locus for familial high myopia on chromosome 7q36. Studies are currently under way in our 


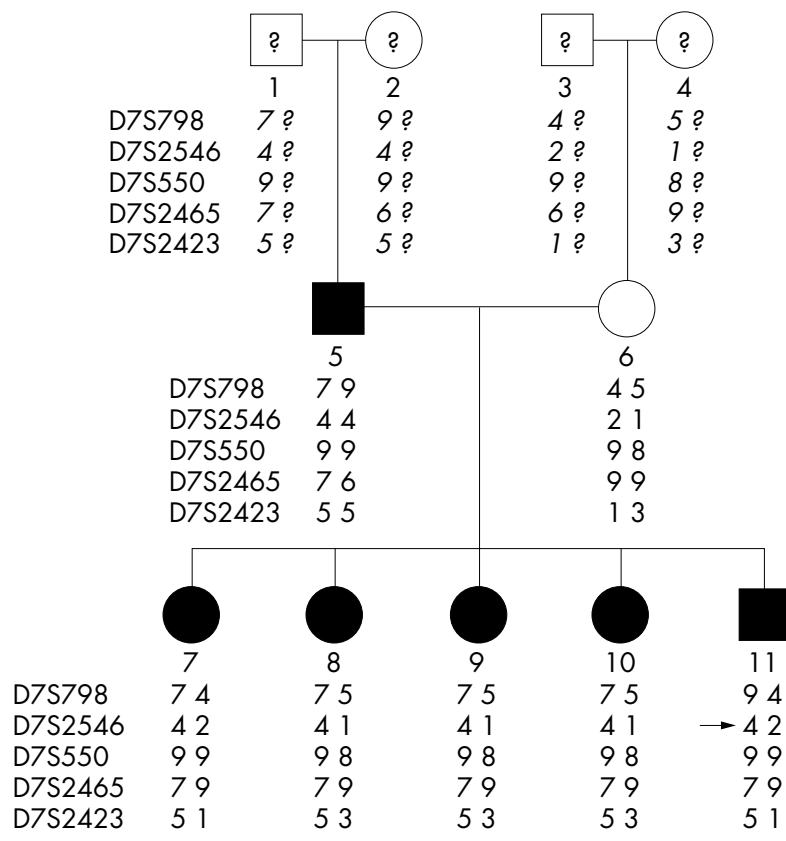

Figure 4 Recombination event in family 17. The alleles for D7S798, D7S2546, D7S550, D7S2465, and D7S2423 are shown for each subject. Filled symbols denote affected subjects. Subjects 1 2,3 , and 4 (symbols with a question mark) in generation I were not accessible for genotyping and their haplotypes were deduced. The recombination event in subject 11 in generation III is denoted by an arrow.

laboratory, in order to validate these results and to reduce the critical region for high myopia. The recruitment and analysis of new families and/or new members of the families already studied are needed before starting gene isolation experiments. The characterisation of the genes implicated in this common eye disorder will lead to a better understanding of the molecular mechanisms contributing to eye shape and growth.

\section{ACKNOWLEDGEMENTS}

Electronic database information. URLs for data in this paper are as follows: Perkin-Elmer, http://www.pebio.com/ga/ (for ABI PRISM Linkage Mapping Set MD-10). Généthon, http://genethon.fr (for additional polymorphic markers). CHLC Genetic maps, http://chlc.org/ ChlcMaps.html (for additional polymorphic markers). Human Gene Map '99, http://www.ncbi.nlm.nih.gov/genemap99 (for genes and expressed sequence tags in the region of interest within the interval between marker D7S798 and the telomere). We thank Dr L Cardon for his helpful discussion and for contributing actively to the statistical part of this work and Professor A Hovnanian for his critical review and comments on the manuscript. We also extend many thanks to the members of the myopia families. This work was supported by grants from the Association Retina France and from INSERM: Programme de Recherche en Santé No 4P015D.

\section{Authors' affiliations}

L Naiglin, P Calvas, Laboratoire d'Immuno-Génétique Moléculaire, Université Paul Sabatier, Hôpital Purpan, Place du Dr Baylac, 31059
- Familial high myopia, defined as a refraction error equal to or below -6 diopters for each eye, is a major problem for public health because of its frequency and its potential severity.

- Assuming an autosomal dominant mode of inheritance with weak penetrance, which we had previously characterised, we conducted a $10 \mathrm{cM}$ resolution genome scan in 23 families.

- We provided evidence for genetic heterogeneity of the disease by excluding the loci for familial high myopia reported elsewhere on chromosomes 12q21-23 and $18 \mathrm{p} 11.31$.

- Moreover, we identified a new suggestive locus on chromosome $7 q 36$, the multipoint lod score being 2.81 , in a $11.7 \mathrm{cM}$ region extending from the marker D7S798 to the telomeric end of the chromosome.

Toulouse cedex, France

C Gazagne, F Malecaze, Clinique d'Ophtalmologie, CHU de Toulouse, Hôpital Purpan, Toulouse, France

F Dallongeville, P Calvas, Service de Génétique Médicale, Hôpital Purpan, Pavillon Lefebvre, Toulouse, France

C Thalamas, $\mathrm{O}$ Rascol, Centre d'Investigation Clinique, $\mathrm{CHU}$ de

Toulouse, Hôpital Purpan, Toulouse, France

A Idder, INESSMO Clinique Ophtalmologique, EHS d'Oran, Algeria

F Malecaze, Laboratoire d'Ophtalmologie, Université Paul Sabatier,

Toulouse, France

Correspondence to: Dr P Calvas, Laboratoire d'Immuno-Génétique Moléculaire, Université Paul Sabatier, Hôpital Purpan, Place du Dr Baylac, 31059 Toulouse cedex, France; patrick.calvas@mipnet.fr

\section{REFERENCES}

1 Mondon H, Metge P. La myopie forte. Paris: Société Française d'Ophtalmologie et Masson, 1994.

2 Curtin BJ. The myopias: basic science and clinical management. Philadelphia: Harper \& Row, 1985

3 Fuchs A. Frequency of myopia gravis. Am J Ophthalmol 1960:49:1418.

4 Waardenburg PJ. Genetics in ophthalmology. Vol 2. Springfield, IL: C C Thomas, 1963:1201-85.

5 Sorsby A, Benjamin B. Modes of inheritance of errors of refraction. J Med Genet 1973;10:161-4.

6 Barstocas CS, Kastrantas AD. X-linked form of myopia. Hum Hered 1981;31:199-200.

7 Naiglin L, Clayton J, Gazagne C, Dallongeville F, Malecaze F, Calvas P. Familial high myopia: evidence of an autosomal dominant mode of inheritance and genetic heterogeneity. Ann Genet 1999;42:140-6.

8 Young TL, Ronan SM, Drahozal LA, Wildenberg SC, Alvear AB, Oetting WS, Atwood LD, Wilkin DJ, King RA. Evidence that a locus for familial high myopia maps to chromosome 18p. Am J Hum Genet 1998;63:109-19.

9 Young TL, Ronan SM, Alvear AB, Wildenberg SC, Oetting WS, Atwood LD, Wilkin DJ, King RA. A second locus for familial high myopia maps to chromosome 12q. Am J Hum Genet 1998;63:1419-24

10 Sambrook J, Fritsch EF, Maniatis T, eds. Molecular cloning, a laboratory manual. 2nd ed. New York: Cold Spring Harbor Laboratory Press, 1989.

11 Weeks DE, Ott J, Lathrop GM. SLINK: a general simulation program for linkage analysis. Am J Hum Genet Suppl 1990;47:A204.

12 Cottingham RWJ, Idury RM, Schaffer AA. Faster sequential genetic linkage computations. Am J Hum Genet 1983;53:252-63.

13 Kruglyak L, Daly M, Reeve-Daly MP, Lander ES. Parametric and nonparametric linkage analysis: a unified multipoint approach. Am J Hum Genet 1996;58:1347-63.

14 Dib C, Faure S, Fizames C, Samson D, Drouot N, Vignal A, Millasseau P, Marc S, Hazan J, Seboun E, Lathrop M, Gyapay G, Morissette J, Weissenbach J. A comprehensive genetic map of the human genome based on 5,264 microsatellites. Nature 1996;380:152-4. 


\title{
Supportive evidence for the DYX3 dyslexia susceptibility gene in Canadian families
}

\author{
T L Petryshen, B J Kaplan, M L Hughes, J Tzenova, L L Field
}

J Med Genet 2002;39:125-126

A previous report in the Journal by Fagerheim et al identified a dyslexia locus (DYX3) on chromosome 2p15-p16 in a large Norwegian family with autosomal dominant inheritance of dyslexia. Parametric linkage analyses using three diagnostic schemes found significant evidence for linkage in this family (maximum lod $=4.3$ at D2S378), which was supported by non-parametric linkage analysis $(p=0.0009$ between D2S2352 and D2S1337). Furthermore, identification of a three marker haplotype cosegregating with dyslexia in the family defined a 2 cM region between D2S2352 and D2S1337 that probably harbours the DYX3 gene. Replication of this linkage in other families would confirm the existence of the locus. We therefore examined our independent sample of dyslexia families and found preliminary evidence for linkage to the DYX3 locus. ${ }^{2}$ Here, we report the results of more comprehensive analyses, which provide further evidence for the chromosome $2 \mathrm{p}$ dyslexia locus.

\section{METHODS}

As described in detail elsewhere, ${ }^{34}$ our sample consists of 96 Canadian families (877 subjects), each containing two or more sibs diagnosed with phonological coding dyslexia (PCD). This diagnosis was used since the key problem in most reading disabled subjects is a specific difficulty in the phonological coding component of reading, where written words are sounded out using grapheme-phoneme (letter-sound) rules. The PCD diagnosis (affected, unaffected, or uncertain) was determined for all subjects primarily based on psychometric test results for phonological coding. Test results for phonological awareness, which is the ability to recognise and manipulate phonemes, and for spelling, which requires phonological and orthographic (recognition of letter patterns) coding, were used to assist in diagnosis, as was reading history for adults. The PCD phenotype was used for parametric and non-parametric linkage analyses. Scores from the phonological awareness, phonological coding, and spelling tests were used in quantitative trait variance component linkage analyses, after conversion to standard scores (for phonological coding and spelling) or age adjustment (for phonological awareness). Of the 96 families, 46 were nuclear families consisting of both parents, two or more affected children, and unaffected children if available, with an average family size of five members. The remaining 50 families were extended kindreds consisting of a nuclear family and other branches with affected and unaffected relatives, ranging in size from six to 107 members (average 18 members). Seven microsatellite markers spanning the DYX3 region were selected from the report of Fagerheim et al ${ }^{1}$ and automated genotyping was performed using a LI-COR 4200S-2 Gene ReadIR DNA Analyzer. Marker allele frequencies were calculated from the parents of one nuclear family per pedigree. The Genethon genetic map ${ }^{5}$ was used for intermarker order and distances: (pter) D2S1352 - 4 cM - D2S2352 - 1 cM - D2S378 - 0 cM - D2S2279 - 0 cM D2S2183 - 1 cM - D2S1337 - 2 cM - D2S393 (cen). This marker order corresponded to the order from the human genome sequence. ${ }^{6}$

Two point parametric linkage analysis was performed using FASTLINK (version 4.1P) from the LINKAGE programs, ${ }^{7-11}$ and multipoint parametric linkage analysis under genetic heterogeneity was performed using the GENEHUNTER program (version 2.0). ${ }^{12}$ Parametric analyses were performed under a dominant model with $1 \%$ disease allele frequency and penetrances of 0.04, 0.99, and 0.99 for aa, Aa, AA genotypes for males and $0.01,0.85,0.85$ for females. These values were chosen to match those in the models used by Fagerheim et al. ${ }^{1}$ Multipoint non-parametric linkage analysis (NPL) was performed using GENEHUNTER by analysing all affected family members. Multipoint variance component analysis was also performed using GENEHUNTER ${ }^{13}$ under four models that all included QTL additive variance, polygenic additive variance, and environmental variance, and with dominance variance at neither, both, or either the QTL or polygenes. Note that GENEHUNTER can only accommodate pedigrees of a limited size, so it was necessary to subdivide 10 large pedigrees, probably reducing the power to detect linkage. Marker haplotypes were constructed using GENEHUNTER to determine whether any families possessed the Norwegian cosegregating haplotype.

\section{RESULTS}

Results of two point and multipoint parametric linkage analyses provided weak evidence for linkage between PCD and the $D Y X 3$ region (maximum two point lod score $=0.77, \theta=0.3$ at D2S1352; multipoint peak hlod $=0.07$ at D2S1352). NPL analysis provided stronger evidence for linkage to $D Y X 3$, with a peak NPL $\mathrm{Z}_{\text {all }}$ score of $2.33(\mathrm{p}=0.0087)$ at $\mathrm{D} 2 \mathrm{~S} 1352$, and $\mathrm{p}<0.05$ from D2S1352 to D2S2352, thus surpassing the recommended $p=0.01$ required to claim significant evidence for linkage in a replication study. ${ }^{14}$ The discrepancy between the parametric and NPL results suggested that our parametric analysis model (based on that of Fagerheim et al ${ }^{1}$ ) may not have been the most appropriate for our Canadian sample. We therefore subsequently performed two point linkage analyses using recessive, intermediate, and dominant inheritance models, all with reduced penetrance. The strongest evidence for linkage (lod $=1.42, \theta=0.1$ ) was found to D2S378 under an intermediate model (penetrances of 0, 0.4, 0.6 for aa, Aa, AA genotypes, frequency of $25 \%$ for disease allele " $\mathrm{A}$ "), supporting the notion that the assumptions of the model of Fagerheim et $^{1} \mathrm{l}^{1}$ were less accurate for our sample. Multipoint variance component linkage analyses of the phonological awareness, phonological coding, and spelling measures produced the most significant results under a model that included QTL additive and dominance variance, polygenic additive variance, and environmental variance. The peak lod scores were 3.82 between D2S2352 and D2S378 for spelling, 1.13 at D2S378 for phonological coding, and 1.01 at D2S378 for phonological awareness. These lod scores were generated under two degrees of freedom, owing to inclusion of QTL additive and dominance variance. To allow for comparison with a traditional linkage threshold of lod $=3.0$, the lod scores

Abbreviations: PCD, phonological coding dyslexia; NPL, non-parametric linkage analysis 
under one degree of freedom were estimated to be 3.12 for spelling, 0.69 for phonological coding, and 0.60 for phonological awareness. Investigation of haplotypes in affected subjects failed to identify the D2S378/D2S2279/D2S2183 haplotype that cosegregated with dyslexia in the Norwegian family; however, the D2S378 allele in the Norwegian haplotype was rare in our sample (observed in only two of 877 subjects).

\section{CONCLUSION}

In conclusion, linkage analyses of dyslexia and quantitative reading measures in a large Canadian family sample have provided the first independent evidence for the DYX3 dyslexia locus on chromosome 2 p15-pl6, originally reported in a large Norwegian family.

\section{ACKNOWLEDGEMENTS}

We thank Dr Toril Fagerheim for Norwegian DNA samples and haplotype information, Rose Tobias, Elzbieta Swiergala, and Malgorzata Zapala for technical assistance, and the Multimedia Advanced Computational Infrastructure (MACI) cluster for computing service. This work was supported by the Alberta Mental Health Research Fund, the Alberta Children's Hospital Foundation, the Network of Centres of Excellence Programme, grant MT-15661 from the Canadian Institutes of Health Research (formerly MRC Canada), and scholarships to TLP from the Natural Sciences and Engineering Research Council and the Alberta Heritage Foundation for Medical Research. LLF was an Alberta Heritage Medical Scientist while at the University of Calgary.

\section{Authors' affiliations}

T L Petryshen, M L Hughes, L L Field, Department of Medical Genetics, University of Calgary, Calgary, Canada

B J Kaplan, Department of Paediatrics, University of Calgary, and Alberta Children's Hospital, Calgary, Canada

J Tzenova, L L Field, Department of Medical Genetics, University of British Columbia and British Columbia Research Institute for Women's and Children's Health, Vancouver, Canada
Correspondence to: Dr L L Field, Department of Medical Genetics, British Columbia Research Institute for Women's and Children's Health, 950 West 28th Avenue, Vancouver, British Columbia, Canada V5Z 4H4;

Ilfield@interchange.ubc.ca

\section{REFERENCES}

1 Fagerheim T, Raeymaekers $P$, Tonnessen FE, Pedersen M, Tranebjaerg L, Lubs HA. A new gene (DYX3) for dyslexia is located on chromosome 2. J Med Genet 1999;36:664-9.

2 Petryshen TL, Kaplan BJ, Hughes ML Field LL. Evidence for the chromosome 2p15-pl6 dyslexia susceptibility locus (DYX3) in a large Canadian data set. Am J Med Genet (Neuropsychiatr Genet) 2000;96:472.

3 Field LL, Kaplan BJ. Absence of linkage of phonological coding dyslexia to chromosome 6p23-p21.3 in a large family data set. Am J Hum Genet 1998:63:1448-56 (erratum 1999:64:334)

4 Petryshen TL, Kaplan BJ, Liu MF, Schmill de French N, Tobias R, Hughes ML, Field LL. Evidence for a susceptibility locus on chromosome $6 q$ influencing phonological coding dyslexia. Am J Med Genet (in press).

5 Dib C, Faure S, Fizames C, Samson D, Drouot N, Vignal A, Millasseau P, Marc S, Hazan J, Seboun E, Lathrop M, Gyapay G, Morissette J, Weissenbach J. A comprehensive genetic map of the human genome based on 5,264 microsatellites. Nature 1996;380:152-4.

6 International Human Genome Sequencing Consortium. Initial sequencing and analysis of the human genome. Nature $2001 \cdot 409: 860-921$.

7 Lathrop GM, Lalouel JM. Easy calculations of lod scores and genetic risks on small computers. Am J Hum Genet 1984;36:460-5.

8 Lathrop GM, Lalouel JM, Julier C, Ott J. Strategies for multilocus analysis in humans. Proc Natl Acad Sci USA 1984;81:3443-6.

9 Lathrop GM, Lalouel JM, White RL. Construction of human genetic linkage maps: likelihood calculations for multilocus analysis. Genet Epidemiol 1986;3:39-52.

10 Cottingham RW Jr, Idury RM, Schaffer AA. Faster sequential genetic linkage computations. Am J Hum Genet 1993:53:252-63.

11 Schaffer AA, Gupta SK, Shriram K, Cottingham RW Jr. Avoiding recomputation in genetic linkage analysis. Hum Hered 1994;44:225-37.

12 Kruglyak L, Daly M, Reeve-Daly MP, Lander ES. Parametric and nonparametric linkage analysis: a unified multipoint approach. Am J Hum Genet 1996:58:1347-63.

13 Pratt SC, Daly M, Kruglyak L. Exact multipoint quantitative-trait linkage analysis in pedigrees by variance components. Am J Hum Genet 2000;66: 1153-7.

14 Lander ES, Kruglyak L. Genetic dissection of complex traits: guidelines for interpreting and reporting linkage results. Nat Genet 1995;11:241-7.

\title{
Unique de novo mutation of $B R C A 2$ in a woman with early onset breast cancer
}

\author{
M Robson, L Scheuer, K Nafa, N Ellis, K Offit
}

A though it is widely stated that $5-10 \%$ of all breast cancers arise as the result of an inherited predisposition, the prevalence of mutations in BRCA1 or BRCA2 in unselected ascertainments of women with breast cancer is somewhat lower. In two population based series from the United States, presumably deleterious BRCAl mutations were identified in only 14 female breast cancer patients out of a combined total of 884 women (1.6\%). ${ }^{12}$ In two European series, BRCA1 or BRCA2 mutations were identified in 19/1035 (1.6\%) Finnish breast cancer patients ${ }^{3}$ and 24/1220 (2.0\%) breast cancer patients from the UK. ${ }^{4}$ Because of the low prevalence of detectable mutations, screening of unselected breast cancer patients has not been recommended. Mutation analysis is more often suggested for specific groups of breast cancer patients in whom mutations are more likely to be detected. The decision whether or not to offer genetic testing usually revolves around the presence or absence of a significant family history of breast or ovarian cancer, although age at diagnosis, bilaterality, and ethnicity may be important considerations. A negative family history, however, clearly does not exclude the presence of a germline mutation in $B R C A 1$ or $B R C A 2$. In a population based series from the United Kingdom, none of the 13 mutation carriers diagnosed with breast cancer before the age of 36 was reported to have had a family history of breast or ovarian cancer in first degree relatives. ${ }^{5}$ In contrast, in a series from the United States, most mutation carriers in a group of women with early onset breast cancer had a history of breast cancer in either first or second degree relatives. ${ }^{6}$ However, even in this series, one of the mutation carriers had no family history of breast cancer. The lack of a family history among mutation carriers may reflect 
small family size, non-penetrance, premature death of at risk women, or inadequacy of the history information itself.

Some affected mutation carriers without a family history may represent new mutations. The proportion of $B R C A$ mutations that arise de novo is unknown. The two cases that have been reported to date appear to be recurrent mutations occurring at sites that may be predisposed to alteration. ${ }^{78} \mathrm{~A}$ woman with early onset breast cancer with no family history of breast or ovarian cancer was found to carry both the BRCAl mutation 3888delGA and the BRCA2 mutation 6174delT. ${ }^{7}$ While the father of the proband was shown to carry the BRCA2 6174delT mutation, which is known to be a founder mutation in people of Ashkenazi descent, neither parent carried the BRCAl 3888delGA mutation, indicating that this alteration most likely arose de novo. Interestingly, an Ashkenazi woman with both early onset breast cancer and ovarian cancer had previously been reported to carry both the BRCA1 3888delGA mutation and the BRCA2 6174delT mutation," suggesting that the BRCAl 3888delGA mutation may, in fact, be a recurrent alteration developing at a mutational hot spot. Further evidence for such areas of predisposition to mutation comes from the recent report of a woman with early onset breast cancer who carried the BRCA2 mutation 3034del4. ${ }^{8}$ Although this particular mutation has been described many times in families of various ethnic origins, ${ }^{10}$ neither of the proband's parents carried the alteration, again suggesting a de novo origin at a genomic site prone to small deletions.

Both of the de novo BRCA1 or BRCA2 mutations that have been reported to date have been identified in other families. We now report a unique, previously undescribed de novo mutation, identified in a woman with early onset breast cancer.

\section{CASE REPORT}

The proband was a woman of Irish, Scots, and Welsh ancestry who was diagnosed at the age of 35 with bilateral infiltrating ductal carcinoma after investigation of abnormalities noted at the time of baseline mammography. She was treated with bilateral modified radical mastectomies and CMF chemotherapy. She had no family history of breast or ovarian cancer. Her mother was alive and without cancer at 71 years of age. She had five sisters, aged 32 to 47, none of whom had been diagnosed with either breast or ovarian cancer. Her father was diagnosed with colon cancer at the age of 57 and died of metastatic disease at 62 . At 41 years of age, the proband enrolled in an Institutional Review Board approved study of genetic testing for hereditary breast cancer risk. After giving informed consent, she provided a sample of peripheral blood, from which DNA was extracted using standard techniques. Testing was performed at Myriad Genetic Laboratories (Salt Lake City, UT). Aliquots of DNA were subjected to polymerase chain reaction amplification and full sequence determination in both forward and reverse directions of the 23 exons of $B R C A 1$, along with approximately $800 \mathrm{bp}$ of intronic sequence surrounding the intron-exon boundaries. In addition, full sequence determination was performed of the 26 exons of $B R C A 2$, along with approximately $900 \mathrm{bp}$ of intronic sequence surrounding the intron-exon boundaries of this gene. Sequence analysis showed a single nucleotide insertion at nucleotide 7260 of BRCA2. The 7260insA insertion in exon 14 results in premature termination at codon 2359. Other than the proband, there are no reports of this alteration in the Breast Cancer Information Core database (http://www.nhgri .nih.gov/Intramural research/Lab transfer/Bic/accessed 13 December 2001). The presence of the mutation was confirmed on a separate blood sample. Testing was then carried out on DNA samples obtained from the proband's mother and five sisters, none of whom was found to carry the mutation. Repeat testing of each of these family members was performed and confirmed the absence of the mutation in all.

To investigate the possibility of a de novo mutation, the paraffin embedded samples of the proband's father's colon cancer specimen were retrieved. DNA was extracted using standard techniques and analysed for the presence of the BRCA2 7260insA mutation. The mutation was not identified in the father's sample on initial or repeat analysis. To establish paternity, both parents and all sibs who had donated samples for DNA analysis were genotyped at three polymorphic loci (MYC-L1, D2S123, D17S250). The results of this genotyping are consistent with the reported paternity.

\section{DISCUSSION}

To our knowledge, this is the first report of a unique de novo mutation in either BRCA1 or BRCA2. Although this specific mutation has not previously been described, several other presumably deleterious alterations have been reported in its vicinity in exon 14. Examples include BRCA2 7253delAA (reported four times), 7297delCT (reported five times), and $7252 \mathrm{C} \rightarrow \mathrm{T}$ (Q2342X, reported once). This portion of the BRCA2 gene may therefore represent an area of susceptibility to mutation. The prevalence of de novo mutations in BRCAl and $B R C A 2$ is unknown. Although one would hypothesise that previously unreported mutations would be more likely to be the result of new mutational events, the recurrent nature of the two previously reported de novo alterations indicates that this criterion is not a reliable discriminator.

The identification of this mutation illustrates that analysis of BRCAI and BRCA2 may be productive in the absence of a family history of breast or ovarian cancer. Empirical models estimating the likelihood of identifying germline mutations, such as BRCAPRO, are based upon the pattern of diagnoses within a family as a whole and have not been validated in women without a family history. Studies from the United Kingdom and United States have indicated that 5.9-9.4\% of women diagnosed with breast cancer at the age of 35 or younger will have a detectable germline BRCA mutation. ${ }^{56}$ While many of these women will have a family history of breast or ovarian cancer, it is clear from the reported series that some will either have no such history ${ }^{5}$ or will only report breast cancer diagnoses in relatives of second or greater degree. ${ }^{6}$ Women with $B R C A$ mutations are at increased risk of metachronous contralateral cancer, and it is therefore logical to assume that the presence of bilateral disease would increase the likelihood of detecting a germline mutation. However, the degree to which the presence of bilateral disease influences this probability has not been defined. Other factors, such as lack of hormone receptor expression, medullary histology, or high histological grade may also indicate an increased probability of germline mutation, although none of these are absolute discriminants.

The information derived from genetic testing of women with very early onset breast cancer may substantially influence clinical management. For example, after the mutation was identified, the proband underwent bilateral salpingo-oophorectomy in an attempt to reduce her ovarian cancer risk. Other women may elect to forego breast conservation therapy and undergo bilateral risk reducing mastectomy to address the substantial risk of metachronous contralateral disease. Because of the significant clinical implications both for the affected subject and for her family, as well as the less than complete sensitivity of a family history of breast cancer, consideration should be given to providing genetic counselling and discussing $B R C A$ genotyping with all women with early onset breast cancer. The existence of de novo BRCA mutations should also be taken into account when generating penetrance estimates from genetic epidemiology studies. For instance, the kin-cohort model assumes that 50\% of unaffected parents are obligate heterozygotes. ${ }^{11}$ The violation of this assumption by occurrence of de novo mutations may lead to underestimation of penetrance by this and similar models. 


\section{Authors' affiliations}

M Robson, L Schever, K Offit, Clinical Genetics Service, Department of Medicine, Memorial Sloan-Kettering Cancer Center, New York, NY, USA K Nafa, N Ellis, Diagnostic Molecular Genetics Laboratory, Department of Medicine, Memorial Sloan-Kettering Cancer Center, New York, NY, USA

Correspondence to: Dr Robson, Clinical Genetics Service, Memorial Sloan-Kettering Cancer Center, 1275 York Avenue, New York, NY 10021, USA; robsonm@mskcc.org

\section{REFERENCES \\ 1 Newman B, Mu H, Butler LM, Millikan RC, Moorman PG, King MC. Frequency of breast cancer attributable to $B R C A 1$ in a population-based series of American women. J Am Med Assoc 1998;279:915-21. \\ 2 Anton-Culver H, Cohen PF, Gildea ME, Ziogas A. Characteristics of $B R C A 1$ mutations in a population-based case series of breast and ovarian cancer. Eur J Cancer 2000;36:1200-8. \\ 3 Syriakoski K, Vahteristo P, Eerola H, Tamminen A, Kivinummi K, Sarantaus L, Holli K, Blomqvist C, Kallioniemi OP, Kainu T, Nevanlinna $\mathrm{H}$. Population-based study of BRCA1 and BRCA2 mutations in 1035 unselected Finnish breast cancer patients. J Natl Cancer Inst 2000;92:1529-31 \\ 4 Anglian Breast Cancer Study Group. Prevalence and penetrance of $B R C A 1$ and $B R C A 2$ mutations in a population-based series of breast cancer cases. Br J Cancer 2000;83:1301-8.}

5 Peto J, Collins N, Barfott R, Seal S, Warren W, Rahman N, Easton D, Evans G, Deacon J, Stratton M. Prevalence of BRCA1 and BRCA2 gene mutations in patients with early-onset breast cancer. J Natl Cancer Inst 1999;91:943-9.

6 Malone KE, Daling JR, Neal C, Suter NM, O'Brien C, Cushing-Haugen $\mathrm{K}$, Jonasdottir TJ, Thompson JD, Ostrander EA. Frequency of $B R C A 1 / B R C A 2$ mutations in a population-based sample of young breast carcinoma cases. Cancer 2000;88:1393-402.

7 Tessoriero A, Andersen C, Southey M, Somers G, McKay M, Armes J, McCredie M, Giles G, Hopper J, Venter D. De novo BRCA 1 mutation in a patient with breast cancer and an inherited BRCA2 mutation. 1999. Am J Hum Genet 1999;65:567-9.

8 Van der Luijt RB, van Zon PHA, Jansen RPM, van der Sijs-Bos CJM, Warlam-Rodenhuis CC, Ausems MGEM. De novo recurrent germline mutation of the BRCA2 gene in a patient with early onset breast cancer. J Med Genet 2001;38:102-5.

9 Randall TC, Bell KA, Rebane BA, Rubin SC, Boyd J. Germline mutations of the $B R C A 1$ and $B R C A 2$ genes in a breast and ovarian cancer patient. 1998. Gynecol Oncol 1998;70:432-4

10 Neuhausen SL, Godwin AK, Gershoni-Baruch R, Schubert E, Garber J, Stoppa-Lyonnet D, Olah E, Csokay B, Serova O, Lalloo F, Osorio A, Stratton M, Offit K, Boyd J, Caligo MA, Scott R, Schofield A, Teugels E, Schwab M, Cannon-Albright L, Bishop T, Easton D, Benitez J, King MC, Ponder BAJ, Weber B, Devilee P, Borg A, Narod SA, Goldgar D. Haplotype and phenotype analysis of nine recurrent BRCA2 mutations in 111 families: results of an international study. Am J Hum Genet 1998;62:1381-8.

11 Wacholder S, Hartge P, Struewing JP, Pee D, McAdams M, Brody L, Tucker $M$. The kin-cohort study for estimating penetrance. Am J Epidemiol 1998; 148:623-30.

\title{
A variant of osteogenesis imperfecta type IV with resolving kyphomelia is caused by a novel COL 1A2 mutation
}

\author{
M T Johnson, S Morrison, S Heeger, S Mooney, P H Byers, N H Robin
}

J Med Genet 2002;39:128-132

C ongenital kyphomelia, or bowing of the femora, is associated with a number of skeletal dysplasias that include campomelic dysplasia, Stüve-Wiedemann dysplasia, Bruck syndrome, Antley-Bixler syndrome, Fuhrmann syndrome, and osteogenesis imperfecta (OI). ${ }^{12}$ In most reported cases, the femora become progressively more angulated with age. However, spontaneous resolution of congenitally bowed femora has been recognised to occur in a small number of cases associated with either OI or a rare skeletal dysplasia known as kyphomelic dysplasia (KD)..$^{3-5}$

Osteogenesis imperfecta is a connective tissue disorder that is caused in more than $90 \%$ of cases by an abnormality of type I collagen. Clinical manifestations of OI may include bone fragility and/or deformities, blue sclerae, short stature, joint laxity, deafness, Wormian bones, and dental abnormalities. Owing to considerable phenotypic variability in OI, a classification system based on clinical, genetic, and radiographic characteristics has been used for the last 20 years to divide this diagnostic category into four broad clinical subtypes. ${ }^{6}$ While all types of OI may present with congenital bowing of the long bones, especially the femora, this finding is most commonly associated with types II and III, the neonatal lethal and progressively deforming types, respectively.

In 1983, Maclean et al described an infant with broad, angulated femora and several minor skeletal abnormalities that included a narrow thorax, platyspondyly, and micrognathia. ${ }^{7}$ An unusual feature of the proband's skeletal deformity was that the bowing improved considerably over the first six months of life. The pattern of skeletal involvement and the atypical natural history were felt to represent a novel skeletal dysplasia that was named "kyphomelic dysplasia" (OMIM 211350 ). Over the subsequent two decades, at least 15 cases with phenotypic similarities to kyphomelic dysplasia have been reported. ${ }^{8}$ Other phenotypic findings noted in some cases of apparent KD include dimpling of the skin overlying long bone deformities, variable bowing of other long bones, rhizomelic shortening, metaphyseal irregularities, a small thorax often with 11 flared ribs, and platyspondyly. ${ }^{9-11}$ The diagnosis of $\mathrm{KD}$ has been periodically challenged since its inception. Pitt ${ }^{12}$ considered a case of apparent KD to represent a variant of femoral hypoplasia-unusual facies syndrome. Cisarik et $a l^{13}$ described four patients with KD with widely variable manifestations including a "classical lethal" form and questioned whether the more severe phenotype could represent either an allelic variant or a distinct entity. More recently, the existence of KD was further challenged following revision of the diagnosis of the index case described by Maclean et al to Schwartz-Jampel syndrome. ${ }^{14}$

This report presents the clinical course and molecular analysis of the type I collagen genes of a 35 year old woman initially thought to have KD, but whose molecular studies have

Abbreviations: $\mathrm{KD}$, kyphomelic dysplasia; Ol, osteogenesis imperfecta 
shown that she has a variant of OI. The histories of her two affected children are also presented to provide insight into the prenatal and neonatal manifestations of this disorder.

\section{CASE REPORTS}

The proband is a 35 year old woman who presented at 23 weeks' gestation following a routine fetal ultrasound that showed generalised rhizomelic and mesomelic shortening of the limbs with severe angulation malformations of the femora (fig 1). In reviewing her past medical history, the proband reported that she was born with severely bowed legs. Review of films from infancy showed that she had rhizomesomelic shortening of the lower extremities with severely bowed femora and fibulae, and Wormian bones in the calvarium (fig $2 \mathrm{~A})$. At the age of 3 months, she was diagnosed with osteogenesis imperfecta after a reportedly normal evaluation for hypophosphatasia. From approximately 3 months to 1 year of age, her legs were maintained in full length plaster casts, which slightly improved the bowing (fig $2 \mathrm{~B}$ ). After starting to walk, her lower limbs showed dramatic improvement over the subsequent year (fig 2C). The proband also has a history of significant dental decay, particularly involving the primary teeth. A recent dental evaluation has shown that her dental abnormalities are consistent with dentinogenesis imperfecta. She bruises easily and has broken three bones in her life time, each after significant trauma. Over the past few years, she has developed worsening lumbar spondylolisthesis. Her intellectual development was normal and she has neither hearing loss nor joint laxity. There is no previous family history of short stature, blue sclerae, poor dentition, osseous fragility, easy bruising, hearing loss, or joint laxity.

At presentation, she had a height of $147 \mathrm{~cm}$ (below the 5 th centile) with a weight and head circumference measuring within the 50th-75th centiles. Her upper to lower segment ratio and arm span to height ratio were on the 95th centile. She had pale blue sclerae and teeth with translucent enamel and multiple caries. Her limbs were normally proportioned without joint laxity or limitation. Her skin had normal elasticity and there were no abnormal scars. A radiological survey of her skeleton showed femora with very mild varus deformities (fig 2D). Other abnormalities noted in the skeletal survey included a malunion fracture of the left clavicle, grade 3 spondylolisthesis involving the L5/S1 vertebral bodies, and

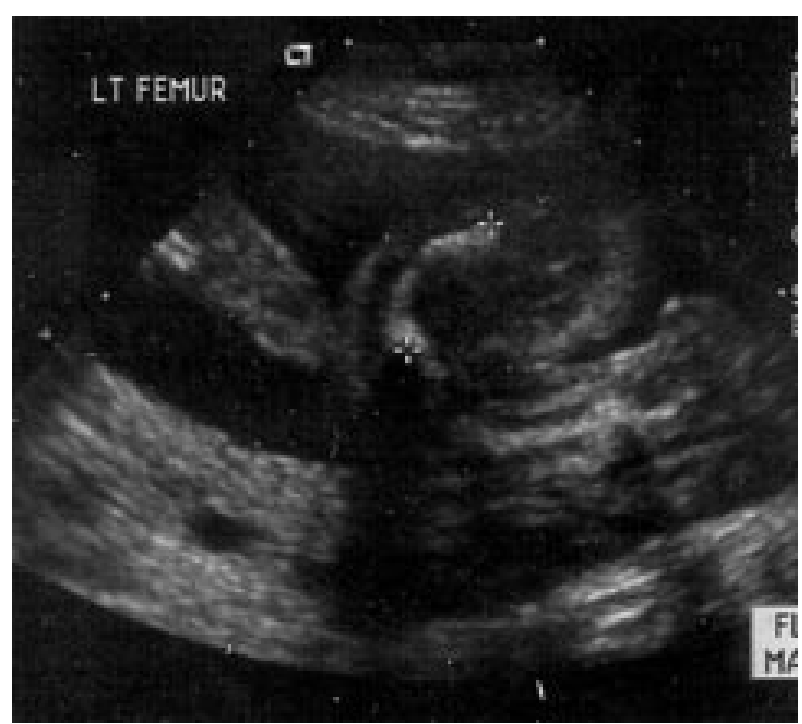

Figure 1 Obstetric ultrasound obtained at 23 weeks' gestation by menstrual history and biparietal diameter. The femur, marked by crosses at the proximal and distal ends, is shortened (corresponding to 16 weeks' gestation) and severely bowed.
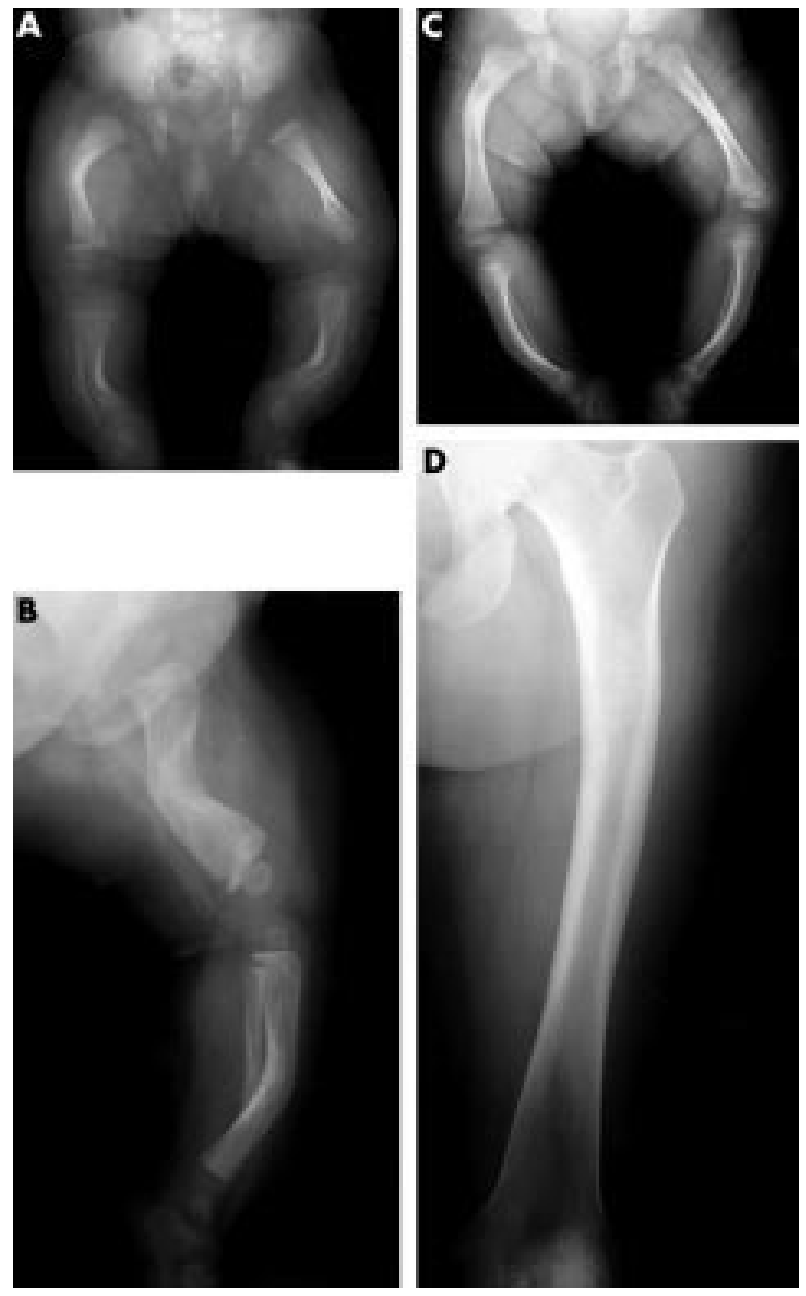

Figure 2 Serial radiographs of lower extremities of the proband. (A) Newborn with significant varus deformities of the femora, tibiae, and fibulae with normal pelvis. (B) One year old with continued bowing of femoral and tibial shafts. (C) Two year old with improved bowing of both lower limbs and normal bone density. (D) Femur at the age of 35 years with only minimal residual bowing.

Wormian bones in the calvarium. She had no radiographic signs of osteopenia or anomalies of the scapulae or vertebrae.

The proband's pregnancy was followed with serial ultrasonographic evaluations at 28 and 32 weeks' gestation. The fetal femora showed worsening of bowing during gestation with lengths following established growth curves, ${ }^{15}$ but remaining below the 3rd centile. In contrast, bilateral tibial and unilateral radial bowing noted in the initial sonogram improved during gestation. The final sonogram also noted slightly decreased echogenicity of the calvarium.

At 39 weeks' gestation, a male infant was delivered by caesarean section because of a history of a previous low transverse caesarean section. The infant weighed $2685 \mathrm{~g}$ (between the 5th and 10th centiles), measured $43.5 \mathrm{~cm}$ in length (below the 5th centile, median height of 33 weeks' gestation), had a crown-rump length of $33.5 \mathrm{~cm}$ (50th centile), and a head circumference of $34.5 \mathrm{~cm}$ (between the 25th and 50th centiles). His sclerae had a faint bluish hue and his face had no appreciable dysmorphic features. The chest was normally shaped with a circumference measuring between the 25 th and 50th centiles. The only anomalies noted on physical examination were severe varus deformities of both thighs without dimpling of the overlying skin. Radiographic skeletal survey showed femoral bowing with slight metaphyseal flaring, Wormian bones, and the presence of only 11 ribs bilaterally (fig 3 ). The 

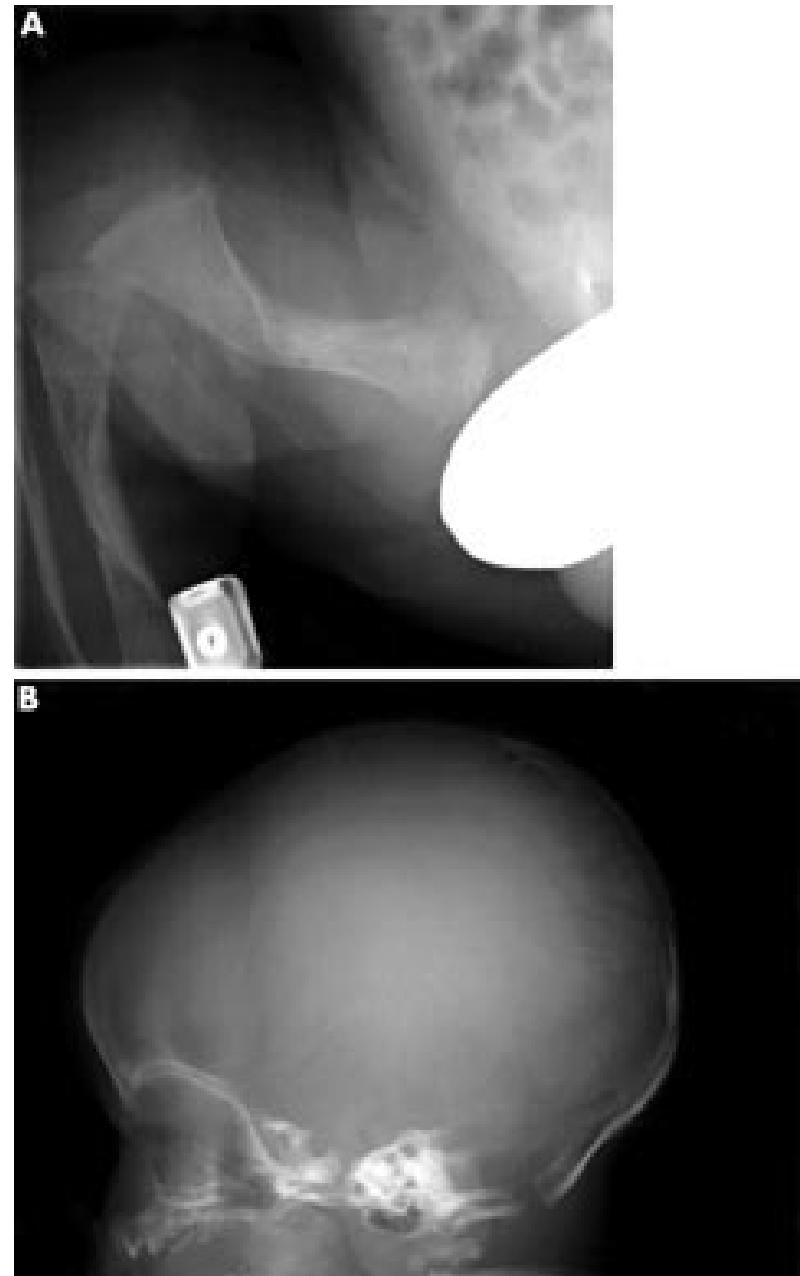

Figure 3 Radiographs of the male infant born to the proband. (A) Lower extremities with angulated femora without fractures and mild metaphyseal flaring. (B) Lateral skull film with multiple Wormian bones in the lambdoid suture.

infant had an uncomplicated course during the neonatal period and was healthy during early infancy. However, he died unexpectedly at 6 weeks of age with the cause of death being attributed to sudden infant death syndrome (SIDS). Necropsy showed abnormal rib morphology with anterior flaring and evidence of a healing left femoral fracture. Histological analysis of samples from the left femur, skull, and ribs showed osteopenia and focal areas of marrow fibrosis.

In a subsequent pregnancy, prenatal ultrasonography at 18 weeks' gestation identified a fractured right femur, bowed right tibia, fractured right humerus, and shortened and bowed left femur. A follow up sonogram at 34 weeks' gestation showed worsening of the bowing of the femora and tibiae. Following a term pregnancy, a female was born by caesarean section with a weight and head circumference falling within the 25th-50th centiles whereas the length of $40.5 \mathrm{~cm}$ fell below the 5 th centile. Physical examination at birth was notable for grey sclerae, rhizomelic shortening of all extremities, and bowing of the femora and tibiae. There was cutaneous dimpling over the lateral aspects of the midshafts of the femora and humeri. A radiographic survey of the skeleton showed diffuse osteopenia, several enlarged costochondral junctions consistent with healing fractures, and bilateral shortening and bowing of the femora and tibiae. A radius to humerus ratio of 0.91 confirmed rhizomelic shortening of the upper extremities according to standard curves. ${ }^{16}$

\section{Molecular studies}

A skin biopsy was obtained from the forearm of the proband with appropriate consent, and fibroblasts were grown by routine methods. The collagens and procollagens synthesised by these cells were analysed as previously described. ${ }^{17}$ The cells were found to produce both a normal and an abnormal species of type I procollagen (fig 4A, B). In the latter, the chains were overmodified along the amino-terminal $40 \%$ of the triple helical domain, consistent with a mutation in either the COL1A1 or COL1A2 gene. Exons 6-52 of the COL1A1 and COL1A2 genes were amplified by PCR and screened for mutations by conformation sensitive gel electrophoresis. ${ }^{18}$ Several heteroduplexes were identified and the sequence of the exon and flanking splice junctions were determined for each. The only pathogenic abnormality identified was a $G$ to $C$ transversion $(1406 \mathrm{G} \rightarrow \mathrm{C})$ with the $\mathrm{A}$ of the initiator methionine as the nucleotide at position 1 of the mRNA, CAGGGCCTC $\rightarrow$ CAGGCCCTC) in one allele (fig 4C). This sequence alteration is predicted to result in substitution of the glycine at position 379 of the triple helical domain of the proo2(I) chain by alanine (G379A, in which the first glycine of the triple helix is referred to as the index position or G469A when the initiator methionine is the reference point). Karyotypic analysis of the male first child showed a normal 46,XY genotype.

\section{DISCUSSION}

The mild skeletal abnormalities, short stature, and dentinogenesis imperfecta combined with the molecular studies confirm that the proband and her children have osteogenesis imperfecta type IVB. The persistent pale blue sclera is uncommon in OI type IV, but can be seen in up to $10 \%$ of affected subjects. The striking improvement of the congenital deformities, to our knowledge, has not been reported in OI type IV. Improvement of femoral bowing in OI has only been described for type I, and there is little documentation of the natural history of the improvement in these cases. ${ }^{319}$ An interesting aspect of the improvement in femoral bowing noted in this report is that it coincided with the start of walking, which may suggest that weight bearing plays a role in the remodelling process.

Before the type I collagen studies, the diagnoses of osteogenesis imperfecta and kyphomelic dysplasia were both considered. Initially, the diagnosis of KD seemed more likely owing to the natural history of the proband's femoral bowing and phenotypic features in her infants, such as cutaneous dimpling over bowed femora, metaphyseal irregularities, and 11 pairs of ribs with flaring at the costochondral junctions. ${ }^{8}$ However, the identification of a type I collagen mutation established the diagnosis of osteogenesis imperfecta type IV for these affected family members. This report provides further evidence that at least some of the cases of apparent kyphomelic dysplasia are actually mild or atypical forms of other skeletal dysplasias. To our knowledge, no other cases of presumed KD have been examined molecularly. As other cases carrying the diagnosis of $\mathrm{KD}$ are analysed for mutations in either the type I collagen genes or Perlecan, the gene recently shown to be mutated in cases of Schwartz-Jampel syndrome, ${ }^{20}$ it should be possible to determine whether $\mathrm{KD}$ exists as a specific diagnostic entity.

Type I collagen is a triple helix composed of two chains encoded by the COL1Al gene and one chain encoded by the COL1A2 gene. In the more than 200 mutations identified in these two genes, there are no predominant mutations and most mutations are restricted to single families. The majority of mutations in both genes result in single amino acid substitutions for glycine residues within the triple helical domain of the chains. In this region, glycine occurs in every third position and substitution by any other amino acid, which introduces a bulkier side chain, is predicted to impair formation of the collagen triple helix. ${ }^{21}$ Of the 55 missense substitutions described 
A

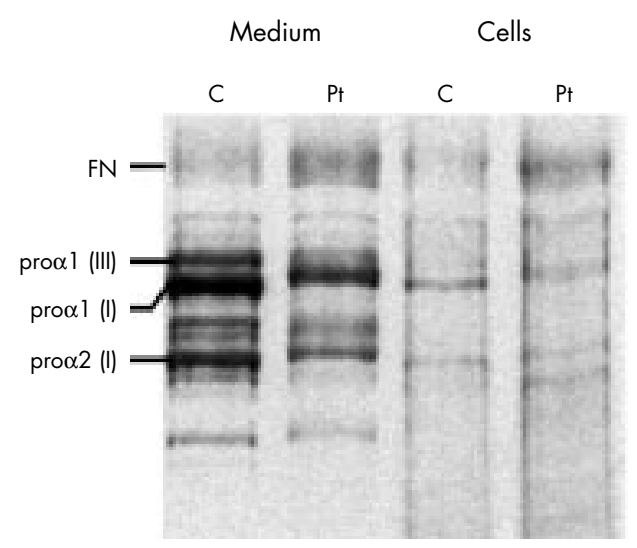

B

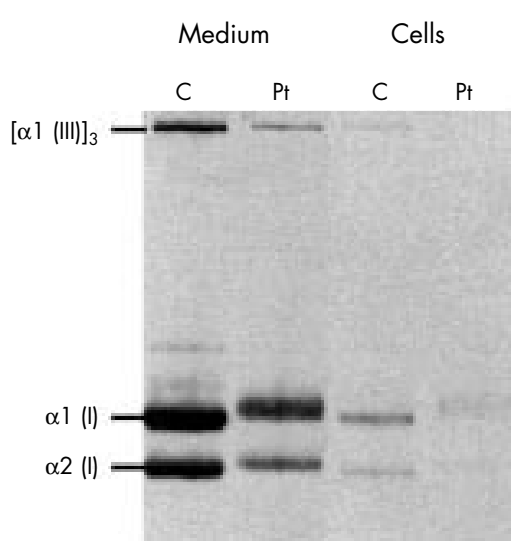

C

COLIA2

Exon 25

Control
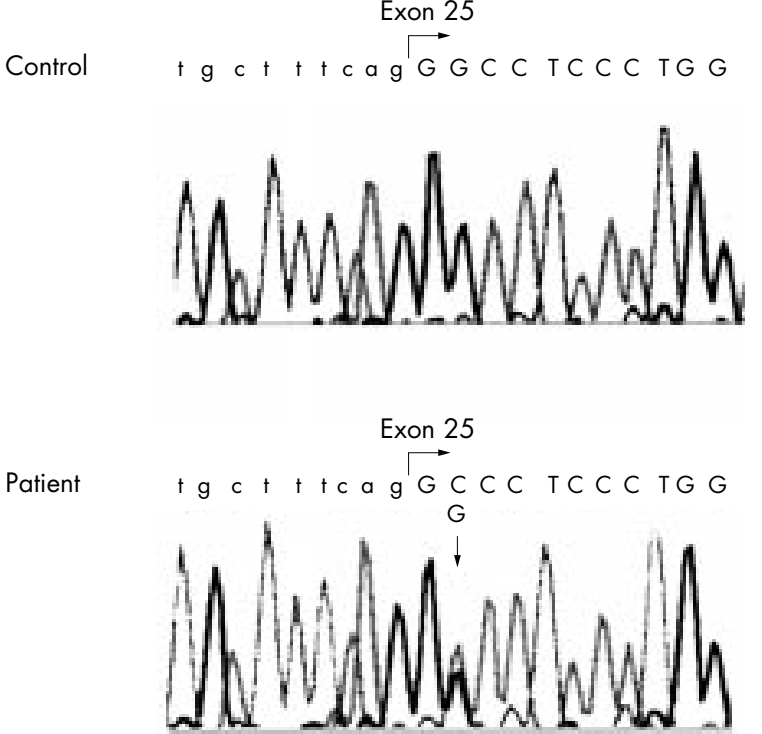

Figure 4 Biochemical and molecular analysis of type I collagen genes. (A) Radiolabelled proteins secreted from fibroblasts were reduced and run on 5\% SDS-polyacrylamide gels. The chains are labelled alongside arrows with several of the chains from the patient sample (Pt) showing delayed migration. (B) To produce the $\alpha$ chains, the labelled procollagens were digested with pepsin before electrophoresis. (C) Sequence analysis of region of COL1A2 gene showing the pathogenic G1406C transversion.

in the COL1A2 gene that replace glycine residues, only two mutations have resulted in substitutions with alanine (at positions 199 which results in OI type IV $^{22}$ and 1006 which results in OI type $\left.\mathrm{III}^{23}\right)$. Alanine codons result from substitutions for the second position $\mathrm{G}$ by $\mathrm{C}$ in all glycine codons (GGN). These substitutions are rare in both type I collagen genes and in the type III collagen gene (COL3Al), mutations which result in Ehlers-Danlos syndrome type IV phenotype. ${ }^{24}$ There appear to be two possible explanations for the low frequency of these substitutions: either the phenotypes do not correspond to those produced by other substitutions for glycine because of the low bulk of the side chain methyl group, or $\mathrm{G} \rightarrow \mathrm{C}$ transversions in these codons are uncommon. There are insufficient data to distinguish between these two possibilities, although substitutions for glycines at positions $910^{25}$ and $928^{26}$ in the COL1Al gene both result in the classical lethal OI type II phenotype, and neither of these cases, to our knowledge, has features of resolving kyphomelia. Thus, mutation frequency may be the more likely explanation.
The clinical courses of the infants presented in this report raise several important points. First, the significant prenatal bowing at 18 weeks' gestation would have raised a greater degree of concern for a more severe form of OI or other skeletal dysplasia had it not been for the natural history of the mother. The lack of multiple fractures in the femora and the absence of significant demineralisation of the calvaria in the early stages of both pregnancies argued against a lethal form of a skeletal dysplasia, ${ }^{27}$ but the significant deformities with progression throughout pregnancy were felt to be consistent with a number of more severe syndromes, such as OI type III, Stüve-Wiedemann syndrome, or Schwartz-Jampel type 2 syndrome. ${ }^{28}$ This case suggests that a potentially mild clinical course can follow when angulated femora are detected in early pregnancy or at birth. Second, the early death of the male infant in this report prompted a review of infant mortality in cases of apparent KD and OI. A recent review of the majority of reported cases with presumed KD noted that four out of 12 babies died between 2 and 13 months of age with the cause of 
death being unclear in several cases. ${ }^{4}$ Temple et $a l^{10}$ described a single case of an infant with apparent KD who had documented episodes if apnoea, including one life threatening episode, between the ages of 4-6 months. In contrast, there were no cases of infant mortality in a review of causes of death in 79 patients with confirmed OI (type II excluded). ${ }^{29}$ The risk of infant mortality in variants of OI with resolving kyphomelia will only become established as more cases are identified.

This case report expands the phenotypic and molecular spectrum of OI type IV. This phenotype with its remarkable natural history is important to appreciate for clinicians who encounter fetuses or neonates with bowing of the femora. The incorporation of this phenotype into the diagnostic category of OI supports the view that congenital bowing of the femora, even if there is striking resolution during infancy, should be considered as a symptom rather than a specific disease. The expanding range of prognoses associated with congenital bowing of long bones provides an impetus for pursuing genotype-phenotype correlations in these cases.

\section{ACKNOWLEDGEMENTS}

This work was supported in part by a grant from the National Institutes of Health, AR41223.

\section{Authors' affiliations}

M T Johnson, S Heeger, N H Robin, Center for Human Genetics, University Hospitals of Cleveland, Cleveland, OH, USA

M T Johnson, N H Robin, Department of Pediatrics, University Hospitals of Cleveland, Cleveland, $\mathrm{OH}$, USA

S Morrison, Department of Radiology, Cleveland Clinic Foundation, Cleveland, OH, USA

S Mooney, P H Byers, Departments of Pathology and Medicine,

University of Washington, Seattle, WA, USA

Correspondence to: $\mathrm{Dr} \mathrm{N}$ H Robin, Center for Human Genetics, Lakeside 1500, Cleveland, OH 44106-6506, USA; nhr2@po.cwru.edu

\section{REFERENCES}

1 Kozlowski K, Butzler HO, Galatius-Jensen F, Tulloch A. Syndromes of congenital bowing of the long bones. Pediatr Radiol 1978;7:40-8.

2 Hall BD, Spranger JW. Familial congenital bowing with short bones. Radiology 1979;132:611-14.

3 Spranger JW, Cremin B, Beighton P. Osteogenesis imperfecta congenita. Pediatr Radiol 1982;12:21-7.

4 Pallotta R, Ehresmann T, Roggini M, Fusilli P. Kyphomelic dysplasia: clinical and radiologic long-term follow-up of one case and review of the literature. Radiology 1999;212:847-52.

5 Toledo C, Navarro-Barros R, Alba L, Munoz E. Kyphomelic dysplasia: a report of a family with an autosomal dominant pattern. Ann Genet 1999:42:170-3.

6 Sillence DO, Senn A, Danks DM. Genetic heterogeneity in osteogenesis imperfecta. J Med Genet 1979;16:101-16.

7 Maclean RN, Prater WK, Lozzio CB. Skeletal dysplasia with short, angulated femora (kyphomelic dysplasia). Am J Med Genet 1983:14:373-80.

8 Prasad C, Cramer BC, Pushpanathan C, Crowley MC, Ives EJ. Kyphomelic dysplasia: a rare form of semilethal skeletal dysplasia. Clin Genet 2000;58:390-5.
9 Khajavi A, Lachman R, Rimoin D, Schimke N, Dorst J, Handemaker S, Ebbin A, Perreault G. Heterogeneity in camptomelic syndromes: long and short bone varieties. Radiology 1976;120:641-7.

10 Temple IK, Thompson EM, Hall CM, Bridgeman G, Pembrey M Kyphomelic dysplasia. J Med Genet 1989:26:457-68.

11 Turnpenny PD, Dakwar RA, Boulos FN. Kyphomelic dysplasia: the first 10 cases. J Med Genet 1990;27:269-72.

12 Pitt D. Kyphomelic dysplasia versus femoral hypoplasia unusual facies syndrome. Am J Med Genet 1986;24:365-6.

13 Cisarik F, Kozlowski K, Masel J, Sillence DO. Variability in kyphomelic dysplasia. Pediatr Radiol 1999;29:551-7

14 Spranger JW, Hall BD, Hane B, Srivastava A, Stevenson RE. Spectrum of Schwartz-Jampel syndrome includes micromelic chondrodysplasia, kyphomelic dysplasia and Burton disease. Am J Med Genet 2000;94:287-95

15 Jeanty P, Dramaix-Wilmet M, van Kerkem J, Petroons P, Schwers J. Ultrasonic evaluation of fetal limb growth: part II. Radiology 1982;143:751-4.

16 Robinow M, Chumlea WC. Standards for limb bone length ratios in children. Pediatr Radiol 1982;143:433-5.

17 Bonadio J, Holbrook KA, Gelinas RE, Jacob J, Byers PH. Altered triple helical structure of type I procollagen in lethal perinatal osteogenesis imperfecta. J Biol Chem 1985;260: 1734-42.

18 Korkko J, Ala-Kokko L, De Paepe A, Nuytinck L, Earley J, Prockop DJ. Analysis of the COLIA1 and COLIA2 genes by PCR amplification and scanning by conformation-sensitive gel electrophoresis identifies only COLIAl mutations in 15 patients with osteogenesis imperfecta type l: identification of common sequences in null-allele mutations. Am J Med Genet 1998;62:98-110.

19 Stephan MS, Coll EJ, Greenberg CR, Freedenberg DL, Byers PH. Congenital bowing of the femurs as a presentation of osteogenesis imperfecta type I. Proc Greenwood Genet Center 1992;11:113-14.

20 Nicole S, Davoine CS, Topaloglu H, Cattolico L, Barral D, Beighton P, Hamida CB, Hammouda H, Cruaud C, White PS, Samson D, Urtizberea JA, Lehmann-Horn F, Weissenbach J, Hentati F, Fontaine B. Perlecan, the major proteoglycan of basement membranes, is altered in patients with Schwartz-Jampel syndrome (chondrodystrophic myotonia). Nat Genet 2000;26:480-3

21 Byers PH. Disorders of collagen biosynthesis and structure. In: Scriver CR, Beaudet AL, Sly WS, Valle D, eds. Metabolic and molecular bases of inherited disease. New York: McGraw-Hill, 2000:5241-85.

22 Krakow D, Wilcox WR, Lachman RS, King LM, Cohn DH. Mutation analysis in osteogenesis imperfecta patients with normal type I procollagen biochemical studies. Am J Hum Genet Suppl 1996:59:A266

23 Lu J, Costa T, Cole WG. A novel G1006A substitution in the alpha 2(l) chain of type I collagen produces osteogenesis imperfecta type III. Hum Mutat 1995; 5: 175-8

24 Pepin MS, Schwarze U, Superti-Furga A, Byers PH. Clinical and genetic features of Ehlers-Danlos syndrome type IV, the vascular type. N Engl J Med 2000;342:673-80

25 Valli M, Sangalli A, Rossi A, Mottes M, Forlino A, Tenni R, Pignatti PF, Cetta $G$. Osteogenesis imperfecta and type I collagen mutations. A lethal variant caused by Gly910-Ala substitution in the $\alpha 1$ (1) chain. Eur J Biochem 1993;211:415-19.

26 Lamande SR, Dahl HHM, Cole WG, Bateman JF. Characterization of point mutations in the collagen $\mathrm{COLIA1}$ and $\mathrm{COL} 1 \mathrm{~A} 2$ genes causing lethal perinatal osteogenesis imperfecta. J Biol Chem 1989-264:15809-12

27 Munoz C, Filly RA, Golbus MS. Osteogenesis imperfecta type II: prenatal sonographic diagnosis. Radiology 1990;174:181-5

28 Sigaudy S, Moncia A, Fredouille C, Bourliere B, Lambert JC, Philip N. Congenital bowing of the long bones in two fetuses presenting features of Stuve-Wiedemann syndrome and Schwartz-Jampel syndrome type 2. Clin Dysmorphol 1998;7:257-62

29 McAllison SJ, Paterson CR. Causes of death in osteogenesis imperfecta. J Clin Pathol 1996;49:627-230.

\section{Functional characterisation of MeCP2 mutations found in male patients with $X$ linked mental retardation}

\section{S Kudo, Y Nomura, M Segawa, N Fujita, M Nakao, S Hammer, C Schanen, I Terai, M Tamura}

J Med Genet 2002;39:132-136

$\mathrm{R}$ ett syndrome $^{1}$ is a neurodevelopmental disorder that primarily affects females and is characterised by a period of normal growth and development, followed by severe neurological dysfunction including dementia, autistic features, loss of purposeful use of the hands, jerky truncal ataxia, and seizures. ${ }^{2}$ Systematic genetic analyses have shown that mutations in the methyl-CpG binding protein gene $\mathrm{MeCP}^{3}$ are associated with Rett syndrome. ${ }^{4}$ Recently, MeCP2 mutations 
$\left(\mathrm{Al} 140 \mathrm{~V}^{5}{ }^{6}\right.$ and $\left.\mathrm{E} 137 \mathrm{G}^{6}\right)$ were also found in male patients with non-specific $X$ linked mental retardation that is clinically distinct from Rett syndrome. To elucidate the functional significance of these mutations, we used transient expression assays to compare the effects of these mutations on MeCP2 function with those of Rett syndrome mutations. ${ }^{4}$ Wild type and mutant MeCP2/GFP fusion proteins expressed in mouse L929 cells were analysed to determine the effect of mutations on accumulation of MeCP2 in heterochromatin, where approximately half of the methyl-CpG dinucleotides occurring in the genome are located. ${ }^{7}$ In contrast to an R106W Rett syndrome mutant protein, which has no affinity to heterochromatin, both Al40V and E137G mutants showed a clear focal heterochromatin staining pattern indistinguishable from the wild type protein. The effects of mutations on transcriptional repressive activities were also evaluated in Drosophila SL2 cells, which possess only marginal background activities of methyl-CpG binding proteins. $^{8-10}$ Although R106W expression substantially reduced transcriptional repressive activity, the Al40V and the E137G mutants retained the transcriptional repressive activity. In particular, the Al40V mutant retained such repressive activity at a level comparable to the wild type protein. These results indicate that potential alterations in $\mathrm{MeCP} 2$ function resulting from the Al40V and the E137G mutations are different from those associated with mutations observed in Rett syndrome and may explain why the manifestation of MeCP2 related mental disorder in males is clinically different from Rett syndrome.

\section{MATERIALS AND METHODS}

MeCP2 CDNA bearing missense mutations were generated by site directed mutagenesis using mismatched primers as described previously. ${ }^{11}$ A full length $\mathrm{MeCP} 2 \mathrm{CDNA}^{12}$ was used as a template for PCR. Insert of the $\mathrm{Al} 40 \mathrm{~V}^{56}$ or $\mathrm{E} 137 \mathrm{G}^{6}$ mutant DNA was cloned into the BspEI and XhoI sites of pEGFP$\mathrm{Cl}$ (Clontech), an enhanced fluorescence vector, and the EcoRI and BamHI sites of the Drosophila expression vector pAc5.1/V5His (Invitrogen). Mouse L929 cells were transfected with GFP expression constructs using Superfect (Qiagen). Two days later, cells on chamber slides were fixed with 3.7\% formaldehyde for 10 minutes, permeabilised with $0.5 \%$ Triton X-100 for 20 minutes, and counterstained with 4',6-diamidino-2phenylindole (DAPI) (Sigma). The specimens were observed under an Olympus fluorescence microscope using the appropriate optical filter. The transient expression analysis using Drosophila SL2 cells was performed as follows. The SNRPN-luciferase reporter construct ${ }^{13}$ was treated with SssI (CpG) methylase (New England Biolabs) in the presence of 5 $\mathrm{mmol} / \mathrm{l} \mathrm{S}$-adenosylmethionine as described previously. ${ }^{14} \mathrm{~A}$ total of $1.4 \times 10^{5} \mathrm{SL} 2$ cells were grown in $0.7 \mathrm{ml}$ of Schneider's Drosophila medium in a 24 well plate. A total of $0.4 \mu \mathrm{g}$ of the luciferase reporter construct was cotransfected with $0.2 \mu \mathrm{g}$ of an Spl expression plasmid, pPacSpl, 0.01 $\mu$ g of pAc5.1-pRL, ${ }^{15}$ and various amounts of expression plasmid (1-100 ng) bearing genes encoding MeCP2 mutants into Drosophila SL2 cells by the calcium phosphate method. The total amount of transfected DNA was adjusted by adding pAc5.1/V5-His vector. After 48 hours, the cells were lysed with $100 \mu$ of lysis buffer and $10 \mu \mathrm{l}$ of lysate was assayed for firefly and Renilla luciferase activities using the Dual-Luciferase reporter assay system (Promega). All transient transfection assays were carried out at least three times independently.

\section{RESULTS}

Recently, novel mutations in the methyl-CpG binding domain (MBD) of MeCP2 were reported in males affected by a mental retardation disorder that is clinically distinct from Rett syndrome. ${ }^{56}$ The E137G mutation was found in a family in which affected males showed profound to mild mental retardation, often associated with speech handicap. ${ }^{6}$ The Al40V mutation was found in a family, four adult, severely mentally retarded brothers, with mild mental retardation in their mother and sister. ${ }^{5}$ The Al40V mutation was also found in sporadic cases of moderate to severe mental retardation in males. ${ }^{6}$ It has been assumed that males who are hemizygous for mutations in $\mathrm{MeCP} 2$ die prenatally or early in infancy with a severe congenital encephalopathy. Therefore, survival of male patients exhibiting mental retardation into adulthood suggests that the activities of these novel mutant proteins are functionally distinct from that of MeCP2 mutant proteins seen in Rett syndrome. In order to investigate the functional consequences of the Al40V and E137G mutations, we used a heterochromatin staining analysis, which was initially used to characterise Rett syndrome mutations. ${ }^{16}$ This analysis takes advantage of the unique feature of mouse L929 cells, which have approximately half of the methyl-CpG dinucleotides clustered in the pericentromeric heterochromatin. ${ }^{7}$ Thus, exogenously expressed MeCP2 accumulates in this region and can be detected by fluorescence microscopy as distinct foci. ${ }^{37}$ Such accumulation of MeCP2 in heterochromatin is not observed in human or rat cells. ${ }^{3}$ Loss of MBD function leads to a decrease in the intensity of focal staining and an increase in staining throughout the nucleus. ${ }^{16}$ Therefore, the effect of MBD missense mutations on methyl-CpG binding activities can be indirectly assessed. Using this system we compared the activities of the Al40V and the E137G mutant proteins with that of wild type protein and with two common Rett syndrome mutations, R106W and T158M. ${ }^{4}$ A previous study showed that fusing MeCP2 mutant proteins with GFP did not affect their nuclear localisation, ${ }^{16}$ so mutants were expressed as GFP fusion proteins. Mouse L929 cells were transfected with GFP fusions of wild type and mutant proteins, and intranuclear localisations of proteins were examined. The result of this analysis is summarised in fig 1 . MeCP2-GFP was predominantly
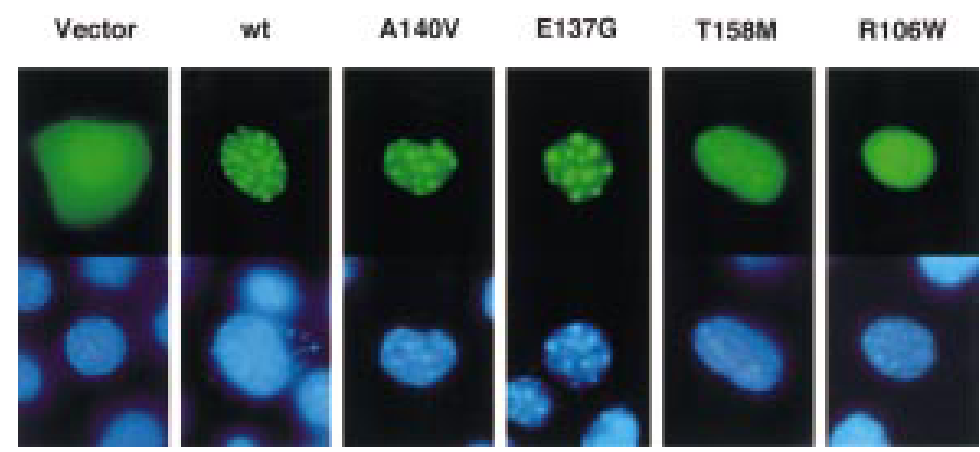

Figure 1 Heterochromatin staining with GFP-MeCP2 mutant proteins. Mouse L929 cells were transiently transfected with constructs expressing GFP fusion protein with MeCP2 (wt) or mutants bearing missense mutations as indicated. After 48 hours, the cells were fixed and permeabilised, and the nucleus was counterstained with DAPI. Intranuclear localisation of GFP fusion proteins was visualised as described in Materials and methods. The same staining pattern was observed in almost all fluorescence stained cells in any field. 

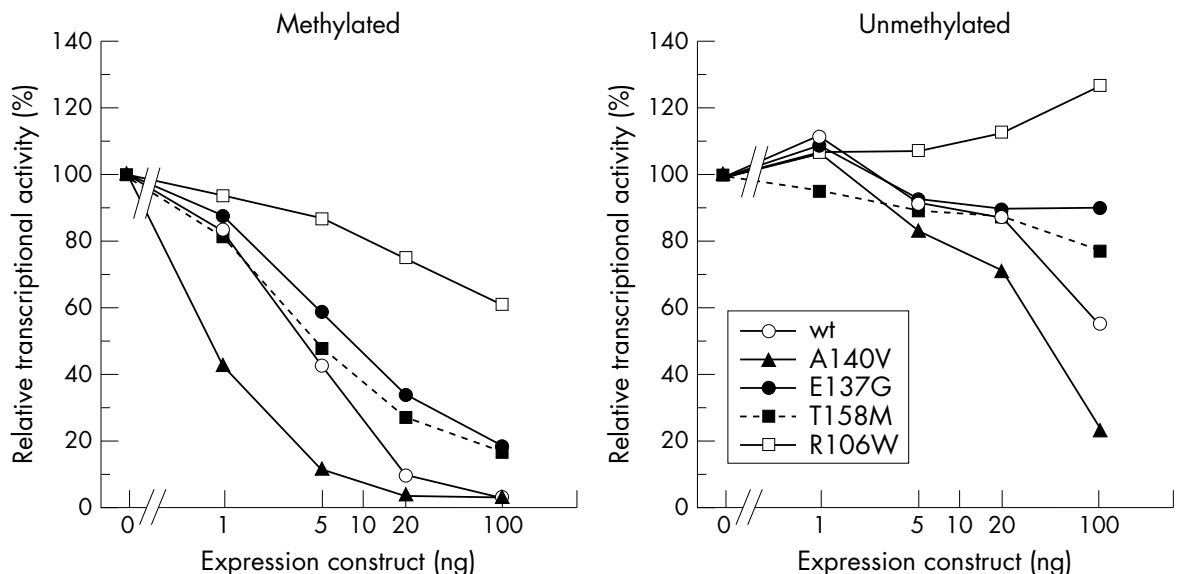

Figure 2 The unmethylated or methylated SNRPN-luciferase construct $(0.4 \mu \mathrm{g})$ was cotransfected with pPacSpl $(0.2 \mu \mathrm{g})$, a Renilla luciferase vector pAc5.1-pRL $(0.01 \mathrm{\mu g})$, and various amounts of expression plasmids $(1-100 \mathrm{ng})$ encoding wild type or mutant MeCP2 into Drosophila SL2 cells. The total amount of transfected DNA was adjusted by adding pAc5.1/V5-His vector. Relative transcriptional activities compared with that of the pAc5.1/V5-His vector only are presented. Renilla luciferase activity was used for normalisation.

localised to heterochromatin regions of mouse L929 cells, which were identified by co-localisation of strong DAPI staining. As reported previously, ${ }^{16}$ Rl06W-GFP showed no clear focal staining in the nucleus and fusion proteins were distributed throughout the nucleus. Impairment of heterochromatin staining was also observed with the T158M-GFP construct, although the effect was milder than that of R106W. Some focal staining in a background of nuclear staining is still apparent. By contrast, both Al40V-GFP and E137G-GFP fusion proteins showed the distinct foci in the nucleus, which matched with DAPI staining, indicating that the mutant proteins were predominantly localised to heterochromatin. These staining patterns are indistinguishable from that of the wild type protein, indicating that the Al40V and the E137G mutants retain substantial affinities for heterochromatin and their abilities to bind methyl-CpG are not obviously affected.

To delineate the effects of the Al40V and the E137G mutations on the transcriptional repressive activity of MeCP2, we used transient expression in a Drosophila cell line. It is known that Drosophila cells have very low levels of DNA methylation ${ }^{18}{ }^{19}$ and exhibit extremely low levels of the DNA methyltransferase activity $^{80}$ and methyl-CpG binding activities. $^{8-10}$ These observations suggest that regulation by DNA methylation is negligible in Drosophila cells. On the other hand, the general transcriptional machinery is thought to be highly conserved between Drosophila and mammals. ${ }^{21}$ Our previous studies indicated that wild type MeCP2 expressed in Drosophila SL2 cells repressed Spl activated transcription on a methylated promoter, ${ }^{14}$ indicating that SL2 cells are suitable to evaluate MeCP2 repressive activity. Here, we used a construct containing the luciferase reporter driven by the promoter of the human imprinted SNRPN gene. This SNRPN promoter provides high transcriptional activity and is highly sensitive to MeCP2 transcriptional repression. ${ }^{13}{ }^{15}$ Drosophila expression constructs encoding wild type or a mutant MeCP2 were cotransfected into SL2 cells with the reporter plasmid and an Spl expression vector, as well as the pAc5.1-pRL control plasmid for normalisation. The results of this analysis are shown in fig 2. As shown previously, ${ }^{16}$ wild type MeCP2 sharply reduced Spl activated transcription in a dose dependent manner. Transcriptional activity was reduced approximately 30 -fold at the highest dose (100 ng). On the other hand, cotransfection with R106W had little effect on transcription from the methylated template; transcription was repressed approximately $40 \%$ at the highest dose, indicating that R106W mutant protein significantly lacks repressive activity.

Intermediate levels of transcriptional repression were seen with the T158M mutant. Transcriptional repressive activity of T158M was slightly stronger than that of R106W, showing five-fold repression of transcription at the highest dose. The E137G mutant showed the transcriptional repressive activity similar to that of the T158M mutant when the promoter was methylated. On the other hand, the Al40V mutant strongly repressed transcriptional activity, showing a steep dose response curve compared to that of the wild type protein. Thus, the Al40V mutant retains substantial repressive activity on a methylated promoter. Interestingly, the ability of the Al40V mutation to repress transcription from an unmethylated SNRPN promoter was also significantly enhanced, reducing luciferase activities by approximately five-fold at the highest dose (100 ng), while the wild type protein reduced transcription by only about $40 \%$ at the same dose. In this study, we also examined expression levels of expressed wild type and mutant MeCP2 proteins by indirect immunofluorescence and western blot analysis, and found that the proteins expressed from these plasmids were produced in the nucleus at similar levels following transfection (data not shown). Table l summarises these two transient expression analyses. Based

\begin{tabular}{|c|c|c|c|}
\hline Mutation & $\begin{array}{l}\text { Nuclear staining in } \\
\text { L929 cells }\end{array}$ & $\begin{array}{l}\text { Transcriptional repressive } \\
\text { activity in SL2 cells }\end{array}$ & Phenotype \\
\hline wt & Distinct foci & Strong & Normal \\
\hline A $140 \mathrm{~V}$ & Distinct foci & Strong & Non-specific $\mathrm{X}$ linked mental retardation \\
\hline E137G & Distinct foci & Moderate & Non-specific $\mathrm{X}$ linked mental retardation \\
\hline $\mathrm{T} 158 \mathrm{M}$ & $\begin{array}{l}\text { Distinct foci + diffuse } \\
\text { staining }\end{array}$ & Moderate & $\begin{array}{l}\text { Rett syndrome } \\
\text { Encephalopathy in boy }\end{array}$ \\
\hline R106W & Diffuse staining & Weak & Rett syndrome \\
\hline
\end{tabular}


on these results, the Al40V and the E137G mutants retain more residual function in terms of heterochromatin binding and transcriptional repression than two common Rett syndrome mutants. This observation may explain why male patients carrying these novel mutations survive into adulthood with mental retardation, a phenotypic manifestation different from that seen in Rett syndrome.

\section{DISCUSSION}

MeCP2 mutations were initially found in patients with Rett syndrome, which occurs almost exclusively in females. ${ }^{4}$ Mosaic expression of normal versus abnormal alleles resulting from $\mathrm{X}$ chromosome inactivation probably contributes to the survival of female patients and also the severity of Rett syndrome, ${ }^{22}$ while males who are hemizygous for mutations in MeCP2 most often present with a severe congenital encephalopathy associated with decreased survival. ${ }^{23}$ Similarly, $M e C P 2$ null mice and mice undergoing conditional knockout of $\mathrm{MeCP} 2$ before birth can survive and develop symptoms characteristic of Rett syndrome after weaning. ${ }^{24} 25$ The recent findings of MBD mutations in adult males with non-specific $X$ linked mental retardation ${ }^{56}$ suggest that the altered activities of these mutant MeCP2 proteins are responsible for these phenotypes. To address this question, the functions of these novel mutant proteins were examined by two assays and the results were compared to similar assays with known Rett syndrome mutant proteins. A previous study showed that most missense mutations in MBD of $\mathrm{MeCP} 2$ substantially reduced the affinity of MeCP2 for heterochromatin in L929 cells. ${ }^{16}$ These mutations also abolished the repressive activity of $\mathrm{MeCP} 2$ on Spl activated transcription from a methylated promoter. ${ }^{16}$ Mouse heterochromatin is known to contain satellite DNA, which possesses highly methylated CpG dinucleotides. ${ }^{7}$ It has been shown that the accumulation of MeCP2 in mouse heterochromatin requires both methylated CpG and the MBD. ${ }^{17}$ Therefore, the accumulation of MeCP2 in heterochromatin depends primarily on the ability of MBD to bind to methylated DNA. Heterochromatin staining analysis of L929 cells showed that Al40V-GFP and E137G-GFP fusion proteins exhibited clear focal staining in the nucleus, a pattern similar to that seen in the wild type protein, indicating that the binding affinities to methylated CpGs are not decreased by these mutations. Transient transfection of Drosophila cells also enabled us to evaluate the consequences of these novel mutations on MBD function. A previous study showed that C-terminal truncated MeCP2, which contains the MBD but not the transcriptional repression domain (TRD), exhibited substantial transcriptional repressive activity in Drosophila cells. ${ }^{12}$ Therefore, it is likely that transcription is repressed primarily by steric hindrance induced by MeCP2 binding to methylated CpGs, making the promoter inaccessible to activators. However, in this system, active transcriptional repression ${ }^{26}{ }^{27}$ may also be partially functional owing to interaction between the TRD and histone deacetylase complex. In fact, the histone deacetylase inhibitor tricostatin A (TSA) relieved the transcriptional potential and the efficiency of recovery varied depending on the promoter context (data not shown). Since binding of the MBD to methylated DNA is a prerequisite for recruitment of histone deacetylase, the effect of the MBD mutation on transcriptional repression can be assessed in our Drosophila system. Transient expression of the A140V mutant in Drosophila SL2 cells showed that this mutant retained considerable ability to repress Spl activated transcription from a methylated reporter. Intriguingly, the Al40V mutant showed stronger repression of transcription from an unmethylated reporter than did the wild type protein. It is noteworthy that the R106W mutant, which had low affinity to heterochromatin, completely failed to repress Spl activated transcription from an unmethylated template (fig 2). It has been shown that the region flanking the carboxy side of MBD is involved in binding to unmethylated DNA. ${ }^{28}$ Our transcription analysis in SL2 cells suggest that in addition to
- Mutations in the MBD of MeCP2 (A140V and E137G) were recently found in male patients affected with non-specific $X$ linked mental retardation.

- We have characterised these mutations by comparing them with the common MBD mutations found in Rett syndrome patients.

- The functional significance of the mutations was analysed by transfection in mouse 1929 cells and Drosophila SL2 cells to investigate the effects of mutations on the affinity to heterochromatin and the transcriptional repressive activity, respectively.

- The A140V and E137G mutations exhibited mild impairment of MeCP2 function, which may be implicated in the manifestation of MeCP2 related mental disorder in males.

that region, the MBD itself contains a region involved in non-specific binding to unmethylated DNA. Although further studies are required to show the significance of MeCP2 affinity to unmethylated DNA, it is possible that higher affinity binding owing to the Al40V mutation affects the proper gene expression although methylated genes are normally controlled. NMR spectroscopy analyses have shown that an alanine at amino acid residue 140 is present in the middle of the $\alpha$ helix of MBD. ${ }^{29} 30$ Therefore, a mutation in this locus may not significantly change the folding of the MBD structure and would barely perturb its binding to methyl-CpG base pairs; however, such a mutation may increase the affinity for unmethylated regions. Although we cannot rule out the possibility that the Al40V mutation is not a disease causing mutation but just a polymorphism, transcriptional repressive effect of this mutation on the unmethylated gene is apparently different from that of wild type. This change of the MeCP 2 function may result in an aberrant pattern of gene expressions in relevant tissues. On the other hand, the E137G mutation exhibited further impairment of the transcriptional repressive function in our Drosophila assay, even though this mutant possessed the mouse heterochromatin affinity comparable to that of wild type. The effect of the E137G mutation on the transcriptional repressive activity to the methylated promoter was almost equal to that of the T158M mutation (fig 2 ). Recently, the T158M mutation was observed in two brothers of a patient with classical Rett syndrome. ${ }^{31}$ Both brothers died within a year of birth, and one suffered from severe encephalopathy. ${ }^{31}$ Our functional analyses show that T158M had intermediate affinity to heterochromatin and moderate effects on transcriptional repressive activity. These results are consistent with reports that the T158M mutant exhibited only slightly lower binding affinity for methylated DNA compared with that of the wild type protein. ${ }^{32}{ }^{33}$ Thus, mild impairment of MeCP2 function owing to mutations may result in MeCP2 associated mental retardation or severe encephalopathy in males. Taken together, these observations suggest that the MeCP2 mutations give rise to a variable range of neurodevelopmental disorders dependent on the functionality of the protein.

\section{ACKNOWLEDGMENTS}

We thank Drs Kei Fujinaga and Takeo Kubota for helpful discussions and Dr Ellen E Lamar for critical reading of the manuscript. This work was supported by the Akiyama Foundation.

Authors' affiliatio

S Kudo, I Terai, M Tamura, Hokkaido Institute of Public Health, Sapporo 060-0819, Japan

Y Nomura, M Segawa, Segawa Neurological Clinic for Children, Tokyo 101-0062, Japan

N Fujita, M Nakao, Department of Tumor Genetics and Biology, Kumamoto University School of Medicine, Kumamoto 860-0811, Japan 
S Hammer, C Schanen, Departments of Human Genetics and Pediatrics and the Mental Retardation Research Center, School of Medicine, University of California at Los Angeles, CA90095-7088, USA

Correspondence to: Dr S Kudo, Hokkaido Institute of Public Health, Kita-19, Nishi-12, Kita-ku, Sapporo 060-0819, Japan

kudos@iph.pref.hokkaido.jp

\section{REFERENCES}

1 Rett A. Uber ein eigenartiges hirnatrophisches Syndrom bei Hyperammonamie im Kindesalter. Wien Med Wochenschr 1966;1 16:723-38

2 Hagberg B, Aicardi J, Dias K, Ramos O. A progressive syndrome of autism, dementia, ataxia and loss of purposeful hand use in girls: Rett's syndrome; report of 35 cases. Ann Neurol 1983;14:471-9.

3 Lewis JD, Meehan RR, Henzel WJ, Maurer-Fogy I, Jeppesen P, Klein F, Bird A. Purification, sequence, and cellular localization of a novel chromosomal protein that binds to methylated DNA. Cell 1992;69:905-14

4 Amir RE, Van den Veyver IB, Wan M, Tran CQ, Francke U, Zoghbi HY Rett syndrome is caused by mutations in X-linked MECP2, encoding methyl-CpG-binding protein 2. Nat Genet 1999;23:185-8.

5 Orrico A, Lam CW, Galli L, Dotti MT, Hayek G, Tong SF, Poon PMK, Zappella M, Federico A, Sorrentino V. MECP2 mutation in male patients with non-specific X-linked mental retardation. FEBS Lett 2000;481:285-8.

6 Couvert P, Bienvenu T, Aquaviva C, Poirier K, Moraine C, Gendrot C, Verloes A, Andres C, Celine Le Fevre A, Souville I, Steffann J, des Portes V, Ropers HH, Yntema HG, Fryns JP, Briault S, Chelly J, Cherif B. MECP2 is highly mutated in X-linked mental retardation. Hum Mol Genet 2001; 10:941-6.

7 Miller LL, Schnoed W, Allen J, Erlanger BF. 5-Methylcytosine localised in mammalian constitutive heterochromatin. Nature 1974;251:636-7.

8 Tweedie S, Ng HH, Barlow AL, Turner BM, Hendrich B, Bird A. Vestiges of a DNA methylation system in Drosophila melanogaster. Nat Genet 1999;23:389-90.

9 Wade PA, Gegonne A, Jones PL, Ballestar E, Aubry F, Wolffe AP. Mi-2 complex couples DNA methylation to chromatin remodelling and histone deacetylation. Nat Genet 1999;23:62-6.

10 Roder K, Hung MS, Lee TL, Lin TY, Xiao H, Isobe KI, Juang JL, Shen CKJ. Transcriptional repression by Drosophila methyl-CpG-binding proteins. $\mathrm{Mol}$ Cell Biol 2000;20:7401-9.

11 Ho SN, Hunt HD, Horton RM, Pullen JK, Pease LR. Site-directed mutagenesis by overlap extension using the polymerase chain reaction. Gene 1989;77:51-9.

12 Kudo S. Methyl-CpG-binding protein MeCP2 represses Sp 1-activated transcription of the human leukosialin gene when the promoter is methylated. Mol Cell Biol 1998; 18:5492-9.

13 Fujita N, Takebayashi S, Okumura K, Kudo S, Chiba T, Saya H, Nakao M. Methylation-mediated transcriptional silencing in euchromatin by methyl-CpG binding protein MBDI isoforms. Mol Cell Biol 1999; 19:6415-26

14 Kudo S, Fukuda $M$. Tissue-specific transcriptional regulation of human leukosialin (CD43) gene is achieved by DNA methylation. J Biol Chem 1995;270:13298-302.
15 Fujita N, Shimotake N, Ohki l, Chiba T, Saya H, Shirakawa M, Nakao M. Mechanism of transcriptional regulation by methyl-CpG binding protein MBD1. Mol Cell Biol 2000;20:5107-18.

16 Kudo S, Nomura Y, Segawa M, Fujita N, Nakao M, Dragich J, Schanen $\mathrm{C}$, Tamura M. Functional analyses of MeCP2 mutations associated with Rett syndrome using transient expression systems. Brain Dev (in press).

17 Nan X, Tate P, Li E, Bird A. DNA methylation specifies chromosomal localization of MeCP2. Mol Cell Biol 1996;16:414-21.

18 Gowher H, Leismann O, Jeltsch A. DNA of Drosophila melanogaster contain 5-methyl cytosine. EMBO J 2000;19:6918-23.

19 Lyko F, Ramsahoye BH, Jaenisch R. DNA methylation in Drosophila melanogaster. Nature 2000:408:538-40.

20 Hung MS, Karthikeyan N, Huang B, Koo HC, Kiger J, Shen CKJ. Drosophila proteins related to vertebrate DNA (5-cytosine)
methyltransferases. Proc Natl Acad Sci USA 1999;96: 1940-5

21 Heiermann R, Pongs $O$. In vitro transcription with extracts of nuclei of Drosophila embryos. Nucleic Acids Res 1985;13:2709-30

22 Wan M, Lee SSJ, Zhang X, Houwink-Manville I, Song H-R, Amir RE, Budden S, Naidu S, Pereira JLP, Lo IFM, Zoghbi HY, Schanen NC Francke U. Rett syndrome and beyond: recurrent spontaneous and familial MECP2 mutations at CpG hotspots. Am J Hum Genet 1999;65: 1520-9.

23 Schanen C, Francke U. A severely affected male born into a Rett syndrome kindred supports X-linked inheritance and allows extension of the exclusion map. Am J Hum Genet 1998:63:267-9.

24 Guy J, Hendrich B, Holmes M, Martin JE, Bird A. A mouse Mecp2-null mutation causes neurological symptoms that mimic Rett syndrome. Nat Genet 2001;27:322-6.

25 Chen RZ, Ákbarian S, Tudor M, Jaenisch R. Deficiency of methyl-CpG binding protein-2 in CNS neurons results in a Rett-like phenotype in mice. Nat Genet 2001:27:327-31.

26 Nan X, Ng HH, Johnson CA, Laherty CD, Turner BM, Eisenman RN, Bird A. Transcriptional repression by the methyl-CpG-binding protein MeCP2 involves a histone deacetylase complex. Nature 1998;393:386-9.

27 Jones PL, Veenstra GJ, Wade PA, Vermaak D, Kass SU, Landsberger N, Strouboulis J, Wolffe AP. Methylated DNA and MeCP2 recruit histone deacetylase to repress transcription. Nat Genet 1998;19:187-9.

28 Nan X, Meehan RR, Bird A. Dissection of the methyl-CpG binding domain from the chromosome protein MeCP2. Nucleic Acids Res 1993:21:4886-92.

29 Wakefield RID, Smith BO, Nan X, Free A, Soteriou A, Uhrin D, Bird AP Barlow PN. The solution structure of the domain from MeCP2 that binds to methylated DNA. J Mol Biol 1999;291:1055-65.

30 Ohki I, Shimotake N, Fujita N, Nakao M, Shirakawa M. Solution structure of the methyl-CpG-binding domain of the methylation-dependent transcriptional repressor MBD 1. EMBO J 1999;18:6653-61.

31 Villard L, Cardoso AK, Chelly PJ, Tardieu PM, Fontes M. Two affected boys in a Rett syndrome family: clinical and molecular findings. Neurology 2000;55: 11 88-93

32 Ballestar E, Yusufzai TM, Wolffe AP. Effects of Rett syndrome mutations of the methyl-CpG binding domain of the transcriptional repressor $\mathrm{MeCP} 2$ on selectivity for association with methylated DNA. Biochemistry 2000:39:7100- 6

33 Free A, Wakefield RID, Smith BO, Dryden DTF, Barlow PN, Bird A. DNA recognition by the methyl-CpG binding domain of MeCP2. J Biol Chem 2000;276:3353-60.

\section{Acrofacial dysostosis in a patient with the TSC2-PKD 1 contiguous gene syndrome}

\section{J G Dauwerse, K Bouman, A J van Essen, A H van der Hout, G Kolsters, M H Breuning, D J M Peters}

$\mathrm{T}$ he acrofacial dysostoses (AFD) are a heterogeneous group of disorders characterised by defects in craniofacial and limb development. The hallmarks include downward slanting palpebral fissures, malar hypoplasia, and receding chin (retrognathia) combined with variable limb malformations. The predominantly preaxial form is called Nager AFD and the predominantly postaxial form is called GenéeWiedeman or Miller syndrome. ${ }^{1}$ A translocation $t(X ; 9)$ suggests the localisation of a gene for Nager AFD on chromosome $9 q 32 .{ }^{2}$ More distally, on $9 q 34$, one of the two major genes for tuberous sclerosis (TSC1) is located. Tuberous sclerosis (TSC) is an autosomal dominant trait with variable expression most frequently characterised by neurological impairment (seizures and learning difficulties), by dermatological manifestations (facial angiofibromas, periungual fibromas, shagreen patches, and hypopigmented macules), and by renal manifestations including angiomyolipomas and cystic disease. $^{3}$

The second gene for TSC, TSC2, maps to chromosome $16 \mathrm{p} 13.3$ tail to tail with the major gene for autosomal dominant polycystic kidney disease (ADPKD), the PKDl gene.

Abbreviations: AFD, acrofacial dysostosis; TSC, tuberous sclerosis $A D P K D$, autosomal dominant polycystic kidney disease 


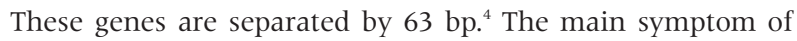
ADPKD is the occurrence of a large number of fluid filled cysts in the kidneys. Cysts can in general be detected by ultrasonography or CT scanning around the second or third decade of life and end stage renal failure occurs at a mean age of 53 years in $P K D 1$ patients. ${ }^{5}$ ADPKD is a systemic disorder with possible extrarenal manifestations such as cysts in other organs (particularly the liver), hypertension, cardiac valve abnormalities, and cerebral aneurysms. Features of TSC and ADPKD have been observed in patients with a TSC2-PKDl contiguous gene syndrome. In these patients, a large portion of the adjacent TSC2 and PKD1 genes has been deleted on one chromosome. In a study by Sampson et al, ${ }^{6} 17$ of 22 patients with such a deletion were diagnosed with a very severe form of polycystic kidney disease, already manifesting within the first year of life.

We present a patient with an acrofacial dysostosis-like phenotype, TSC, and ADPKD. Fluorescence in situ hybridisation (FISH) analysis showed a microdeletion of approximately 280 $\mathrm{kb}$ including the TSC2 and PKD1 genes on chromosome 16p13.3. The deleted region is gene rich and we propose that haploinsufficiency of one of the deleted genes is responsible for acrofacial dysostosis or that the deletion has exposed a mutation in a gene on the non-deleted chromosome. An interesting candidate gene is E4Fl, belonging to the GLIKruppel family of transcription factors.

\section{PATIENT AND METHODS}

\section{Patient}

The patient, 42 years old, had moderate mental retardation with hearing loss and mild renal impairment. Several dysmorphic features were observed (fig 1), including a long face with hypoplastic malae and retrognathia, a low nuchal hairline, downward slanting palpebral fissures, simply formed ears, a large nose with a high nasal bridge, full lips and a high arched palate, adenoma sebaceum on the chin and in the nasolabial region, and a webbed neck. He had finger-like thumbs, clinodactyly of the second finger of the right hand, and a subungual fibroma on the third finger. There was cutaneous syndactyly of the second and third fingers of the left hand. He had a wide space between the first and second toe of his feet and subungual fibroma on the second and third toe of the right foot and on the third toe of the left foot. $X$ rays showed a triphalangeal thumb on the right hand but not on the left hand. The second and third cervical vertebrae were fused. On his back were two shagreen patches. Further investigation, following the tuberous sclerosis protocol including MRI of the brain and echocardiography, was refused. A CT scan of the abdomen was, however, performed at the age of 44 years, showing enlarged cystic kidneys and multiple cysts in the liver, as seen in ADPKD. In the following 14 months plasma creatinine levels increased from 320 to $500 \mu \mathrm{mol} / \mathrm{l}$ indicating decline of renal function. The patient suffered from
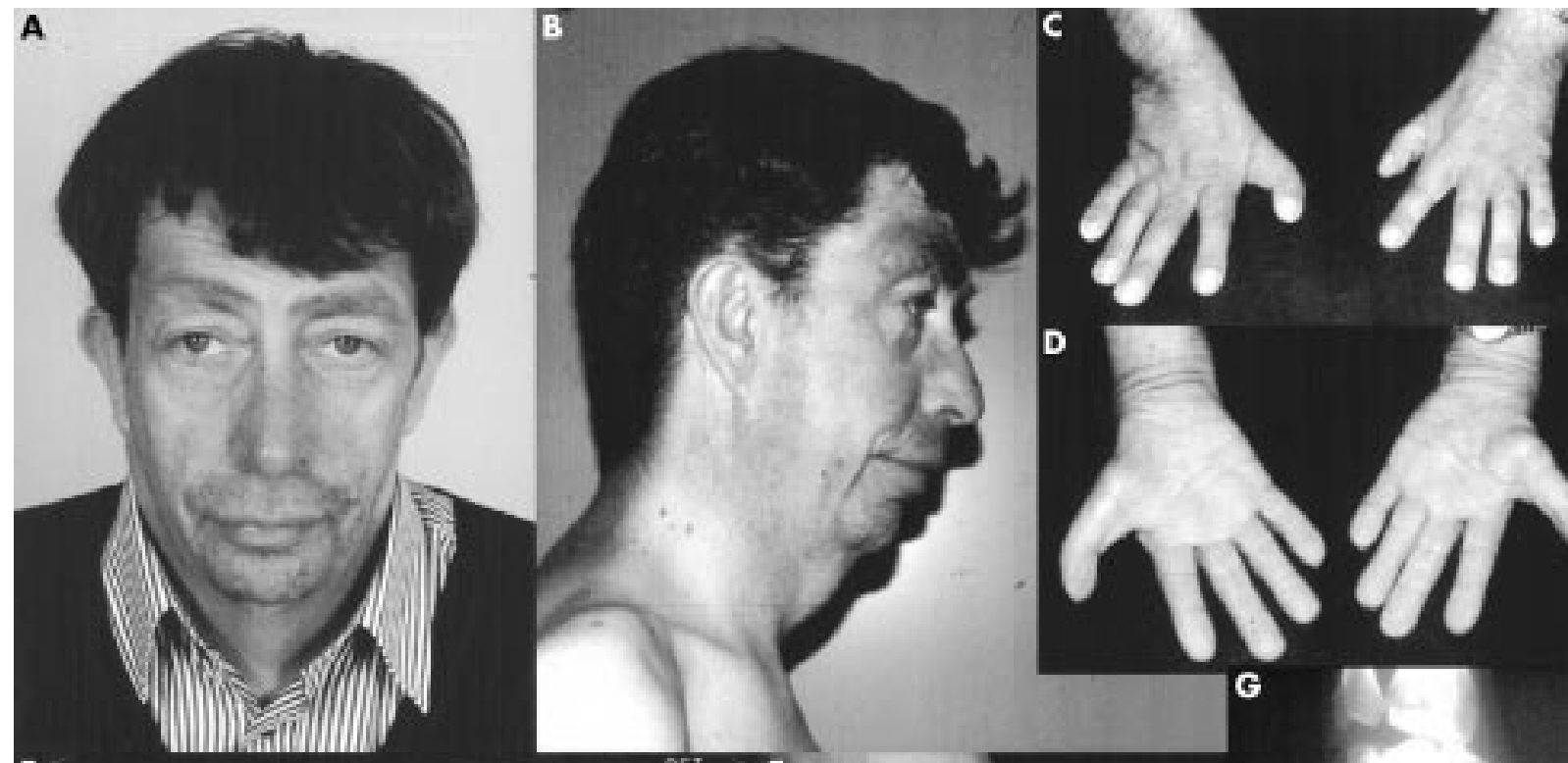

E
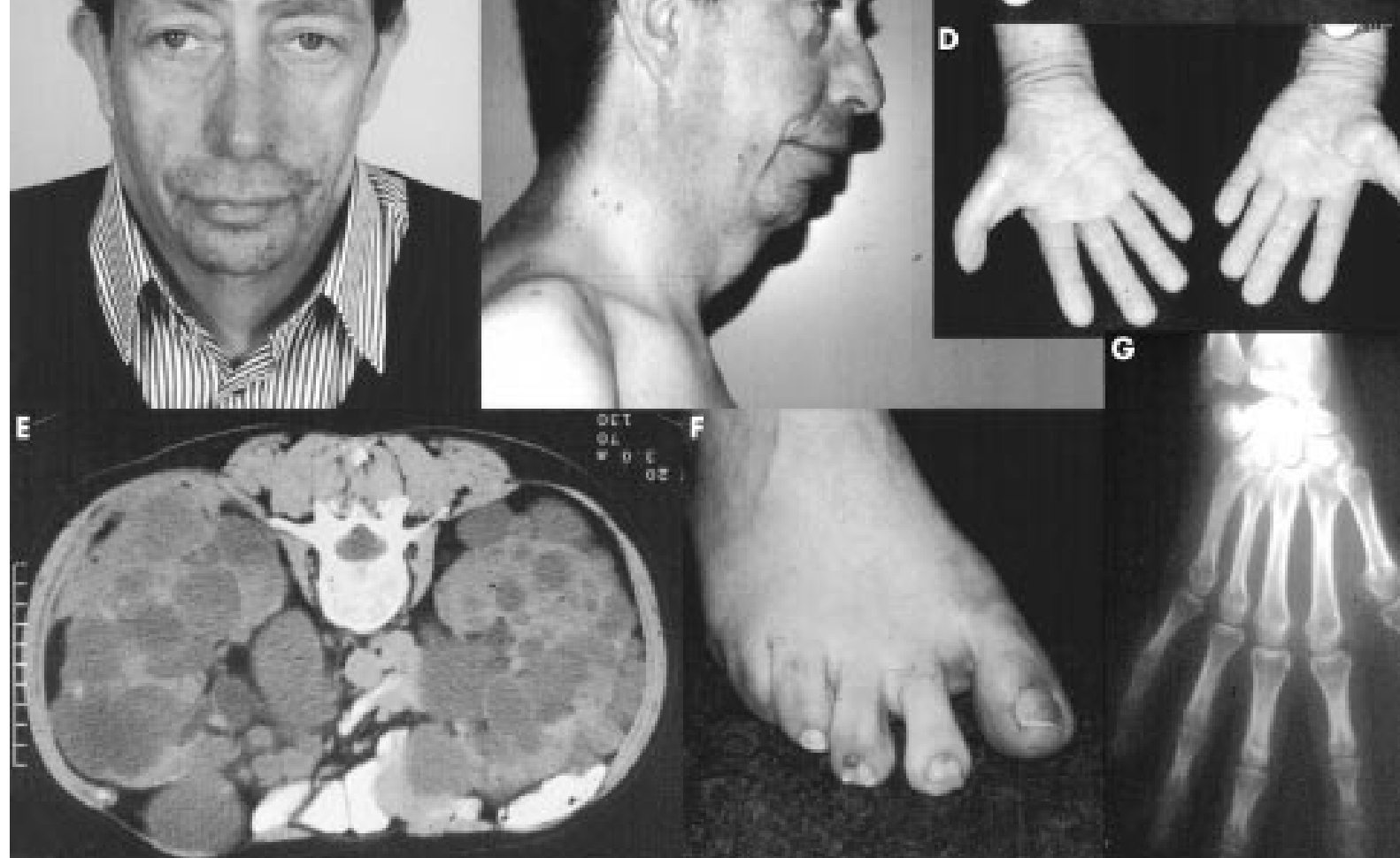

Figure 1 The patient with acrofacial dysostosis, tuberous sclerosis, and polycystic kidney disease. (A, B) Hypoplastic malae, downward slanting palpebral fissures, dysplastic ears, and high nasal bridge can be seen. (C, D) Finger-like thumbs, clinodactyly of the second finger of the right hand, a subungual fibroma on the third finger, and cutaneous syndactyly of the second and third fingers of the left hand. (E) Massive cystic kidneys detected by CT scanning. (F) Subungual fibroma on the second and third toe of the right foot. (G) $X$ ray of the hand showing triphalangeal thumb. 
hypertension and progressive anaemic symptoms. Haemodialysis was started but this treatment was not well tolerated, and the patient died after three months. Necropsy was not performed. Family history was negative for tuberous sclerosis, polycystic kidney disease, and dysmorphic features. A diagnosis of tuberous sclerosis with an acrofacial dysostosis-like phenotype and polycystic kidneys was made.

\section{Cytogenetic analysis}

Chromosome analysis on cultured peripheral blood lymphocytes was performed according to standard $G$ banding procedures.

For fluorescence in situ hybridisation (FISH), metaphase preparations from EBV transformed harvested cells were prepared as described by Landegent et al. ${ }^{7}$ FISH analysis was performed as described previously ${ }^{8}$ with all cosmids and PAC clones. Fine mapping of the deletion breakpoints was done by fibre-FISH using PAC clone $64.12 \mathrm{C}$ and $77.3 \mathrm{D}$ according to the protocol described by Giles et al. ${ }^{9}$

\section{Clones}

Chromosome 16 cosmids encompassed the TSC2 gene $\left(\right.$ LADS4, ZDS $5^{10}$ ), the PKD1 gene (ZDS5, REP59, 2H2 ${ }^{11}{ }^{12}$ ), and cosmids located more proximally ( $\cos 3$, provided by $\operatorname{Dr} \mathrm{S}$ Reeders, Yale, USA, $218+218.10^{13}$ ) or more distally (UW3 +5 , $\cos 2 \mathrm{~B},{ }^{14} \cos 40^{15}$ ) from the region. Chromosome 16 PACs were 109.8C, 77.3D, 91.8B, 97.10G, 1.8F, 96.4B, and 64.12C. ${ }^{16}$

\section{Database analysis}

Blast searches of the databases of the National Center for Biotechnology Information (NCBI, http://www.ncbi.nlm.nih.gov) were performed using the DNA sequences of ESTs or predicted transcripts and to obtain the sequences of PAC clones. The NIX program at www.hgmp.mrc.ac.uk, which is a tool for identifying unknown nucleic acid sequences, was used to analyse the sequences of the PAC clones $1.8 \mathrm{~F}$ and 96.4. Gene predictions are now also available using the map viewer on the NCBI website. (Accession numbers: PAC clone 47-2H, AC005363; PAC clone 109.8C, AC005606; PAC clone 109.9G, AC005600.1; PAC clone 1.8F, AC00711; PAC clone 96.4B,: AC005212.)

\section{RESULTS}

The patient is a man with an acrofacial dysostosis-like phenotype, tuberous sclerosis, and cystic kidneys; the latter were not initially noticed. Cytogenetic analysis showed a normal male karyotype. Whether a chromosomal aberration involving the TSC1 gene on chromosome 9q34 had occurred was initially investigated, as Zori et al described a patient with Nager anomaly and an apparently balanced translocation, $46, X, t(X ; 9)(p 22.1 ; q 32)$. DNA analysis using highly polymorphic microsatellite markers flanking the TSC1 gene on chromosome 9 did not show a deletion (data not shown). After renal impairment and polycystic kidneys had been detected, FISH analysis with cosmids mapped to chromosome $16 \mathrm{pl} 3.3$ was performed, showing that the cosmids encompassing the TSC2 gene (LADS4, $\mathrm{ZDS}^{10}$ ) and the PKDI gene (ZDS5, REP59, $2 \mathrm{H} 2^{11}$ ) were deleted on one copy of chromosome 16. We defined the deletion boundaries using a set of overlapping Pl clones (fig 2$)^{16}$ and observed a deletion of (large parts of) $\mathrm{Pl} 64.12 \mathrm{C}, 96.4 \mathrm{~B}, 1.8 \mathrm{~F}$, 97.10G, 91.8B, and 77.3D. We did, however, detect signals more proximally on chromosome 16p for the Pl clones $97.10 \mathrm{G}$ and $91.8 \mathrm{~B}$ as well as for the cosmids REP59 and $2 \mathrm{H} 2$, as these clones contain (part of) a $40 \mathrm{~kb}$ repeated region within the PKDl gene and recognise several copies of the homologous sequence located on chromosome 16p13.1. ${ }^{11}$

The $\mathrm{Pl}$ clones $64.12 \mathrm{C}, 96.4 \mathrm{~B}$, and $77.3 \mathrm{D}$ gave weaker than expected signals, indicating that part of these clones were deleted. Using fibre-FISH with clones $64.12 \mathrm{C}$ and 77.3D, the deletion breakpoints were precisely mapped. Fig 2 shows a fusion of the signals of these two Pls, which on fibres of the normal chromosome 16 are $200 \mathrm{~kb}$ apart. As several of these clones have been sequenced by the Center for Human Genome Studies (DOE Joint Genome Institute, Los Alamos National Laboratory), we could improve the physical map of this chromosomal region. However, a few small gaps still exist in the sequence and only a draft sequence is available for clone $1.8 \mathrm{~F}$. We concluded that the deletion ranges from the middle of $\mathrm{Pl}$ clone $64.12 \mathrm{C}$ to the middle of $\mathrm{Pl}$ clone $77.3 \mathrm{D}$ and estimated the size to be approximately $280 \mathrm{~kb}$.

\section{Sequence analysis}

The acrofacial dysostosis-like phenotype suggests that besides the PKD1 and TSC2 genes, one or more additional genes are contributing to the patient's phenotype. From centromere to telomere, genes encoding the following proteins are deleted. The ABC3 transporter (L48758, L48760, L75924, L75925) is involved in transport of molecules into or out of cells and across subcellular membranes. ${ }^{17}$ The human $S$ phase prevalent DNA/RNA binding protein RNPS I (accession No L75926 and L75927) is suggested to be involved in splicing or in processing of precursor RNAs into mature mRNA. ${ }^{18}$ Dodecenoylcoenzyme A delta isomerase (DCI) is a mitochondrial 3,2-trans-enoyl-coenzyme A isomerase suggested to have a role in oxidation of unsaturated fatty acids. ${ }^{19}$ The deoxyribonuclease I-like2 (DNASE1L2) gene ${ }^{20}$ is related to deoxyribonuclease I, which plays a role in the breakdown of nucleic acids in the gastrointestinal tract. An additional role for deoxyribonuclease I in apoptosis has also been proposed. ${ }^{21}$ The exact function of DNAS1L2, however, has still to be elucidated. The adenovirus ElA regulated transcription factor E4F1, the human homologue of the transcription factor ФAP3 (accession No L48762, L48763), is a negative regulator of genes encoding proteins responsible for the inhibition of the cell cycle. ${ }^{22}$ The human homologue of the rat RAB26 ras related GTPase (L48770, L48771), which is a GTP binding protein involved in vesicular transport, ${ }^{23}$ is the final deletion.

The following genes are located distally from the PKDI and TSC2 genes. The endonuclease III-like 1 gene (NTLH1) located in the $\mathrm{Pl}$ clone 77.3D but not in 109.8C, encodes an enzyme with DNA glycosylase and DNA lyase activity and could be involved in DNA repair. ${ }^{24}$ NTLH1 is located 5' to 5", "head to head", with the TSC2 gene with only 63 bp in between. Furthermore, the gene is located in a $3^{\prime}$ to $3^{\prime}$, "tail to tail", orientation with the SLC9A3R2 gene. ${ }^{25}$ This gene encodes the regulatory factor 2 of the solute carrier family 9 (sodium/ hydrogen exchanger), but has recently been shown to be a regulator for phospholipase- $\beta 3 .^{26}$ The distal deletion breakpoint is not exactly known. One or both of the genes NTLH1 and $S L C 9 A 3 R 2$ may be deleted or disrupted in the patient.

Exon trapping has previously identified four of the genes located in the $280 \mathrm{~kb}$ deletion interval, $A B C A 3, R N P S 1, E 4 F 1$, and $R A B 26$. The authors identified one additional transcript, "I", located between $E 4 F 1$ and $R A B 26$, with unknown function. ${ }^{27}$

The SazD transducin gene, ${ }^{28}$ the human ERVI gene, ${ }^{29}$ and the gene encoding the ribosomal protein-like $3(R P L 3 L)^{30}$ are located distally from the deletion interval. ${ }^{16}$ The human somatostatin receptor 5 gene $^{31}$ also maps outside the interval, on cosmid 349E16, although in the Puffer fish Fugu, the gene is located within $10 \mathrm{~kb}$ proximal of the PKDl gene. ${ }^{31}$

\section{DISCUSSION}

Tuberous sclerosis (TSC) is a genetically heterogeneous disorder with genes on chromosome 9 (TSCl) and chromosome 16 (TSC2). In the patient presented in this paper, the diagnosis of TSC was based on adenoma sebaceum, nail fibroma, and shagreen patches. Along with TSC, he had dysmorphic features, triphalangeal thumbs, and hearing loss, consistent with a diagnosis of acrofacial dysostosis. A patient with acrofacial dysostosis and a balanced translocation $46, X, t(X ; 9)(p 22.1 ; q 32)$ inherited from a mosaic carrier mother was described by Zori et al, ${ }^{2}$ 

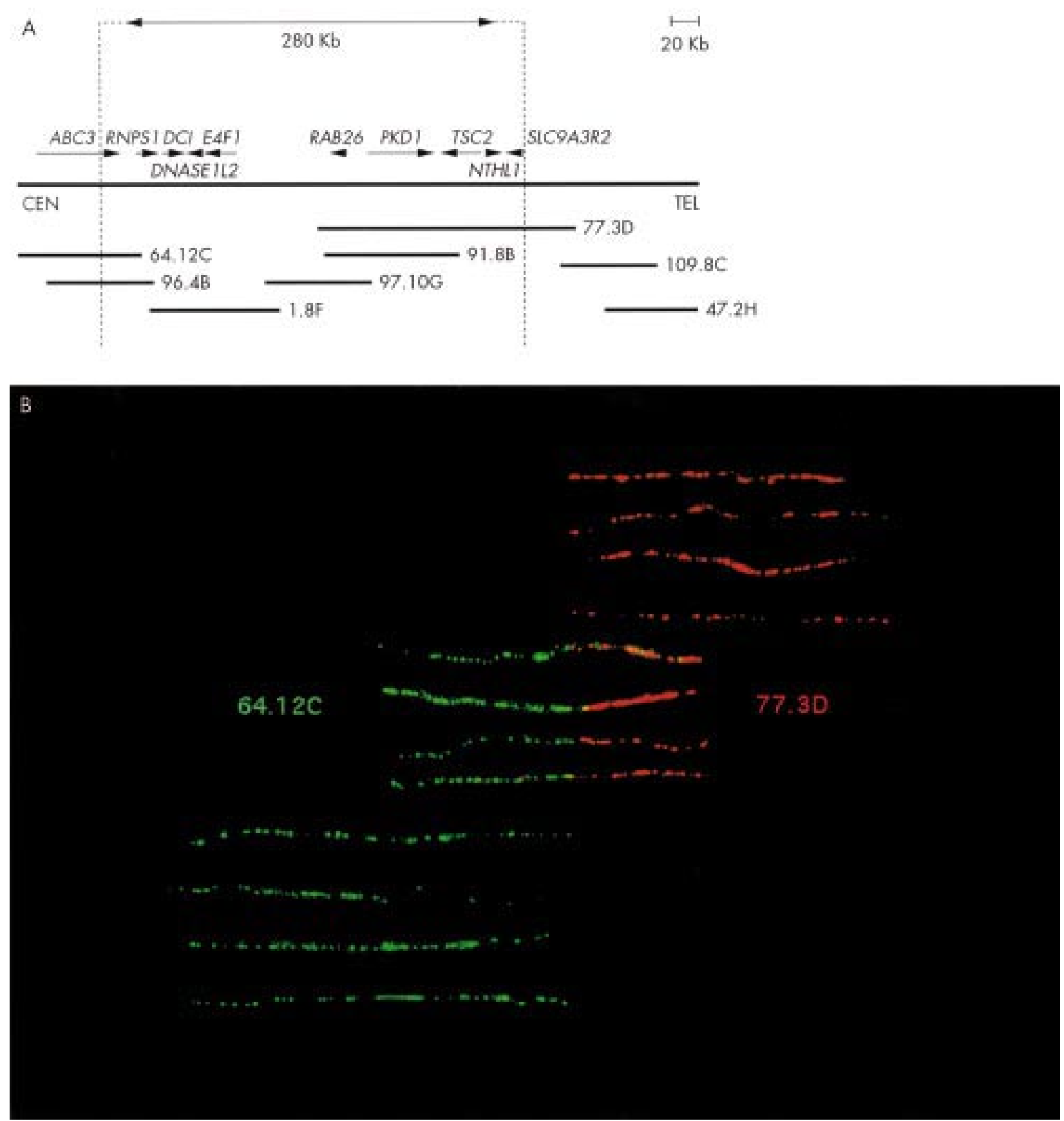

Figure 2 Map of the PKD1-TSC2 region on chromosome 16p13.3. (A) The deletion of approximately $280 \mathrm{~kb}$ is indicated. Orientation of genes in the region is indicated with an arrow. The PAC clones are indicated below the line. (B) Fibre-FISH with clones 64.12C (red) and 77.3D (green) showing a fusion of the signals of these two clones. Separate signals of PACs on the normal chromosome are also shown. Note that because of the deletion they are not only fused, but also reduced in size.

suggesting the location of a gene for acrofacial dysostosis on chromosome 9 or on the $\mathrm{X}$ chromosome. The fact that the TSC1 gene is located on chromosome $9 \mathrm{q} 34$ prompted us to analyse this chromosomal region, but no chromosomal aberration was found. As the patient also had polycystic kidneys, it was a logical step to analyse the short arm of chromosome 16, uncovering a microdeletion of approximately $280 \mathrm{~kb}$. Since dysmorphic facial features are not manifestations of either TSC or ADPKD, we suggest that the region also harbours an acrofacial dysostosis gene. Database analysis showed at least six other genes in the deletion interval.

The acrofacial dysostoses are a heterogeneous group of disorders with craniofacial anomalies and defects in limb development. ${ }^{1}$ For a large number of malformation disorders, disruption or dosage effects of specific transcription factors or transcription enhancers/repressors are known to cause the disease. On this basis the ZFP-37 gene, a putative transcription factor belonging to the GLI-Kruppel gene family, was proposed as a candidate gene for the Nager acrofacial dysostosis syndrome. ${ }^{32}$ Interestingly, E4F1, deleted in our patient, is also a transcription factor related to the GLI-Kruppel family of zinc finger proteins. ${ }^{22}$ There have been reports of other deletions of patients with no dysmorphic phenotype, ${ }^{63}$ which partly overlap with the deletion described here. The most proximal extending deletion extends 80 to $100 \mathrm{~kb}$ proximal from exon 1 of the PKDl gene, ${ }^{6}$ which is probably distal to $E 4 F 1$. Recently, a patient with an unbalanced translocation $\mathrm{t}(8 ; 16)(\mathrm{q} 24.3 ; \mathrm{pl} 3.3)$ with TSC, ADPKD, and hypomelanosis of 
Ito was described. ${ }^{34}$ Downward slanting palpebral fissures, mild malar hypoplasia, and mild retrognathia were present in this patient, but acrodysostosis was not reported. In this patient, however, the most telomeric part of $16 \mathrm{p}$ is deleted, including the PKD1, TSC2, and $\alpha$-globin genes, and the $8 \mathrm{q} 24.3$-qter region is duplicated. The chromosome 16 breakpoint is located in $\mathrm{Pl}$ clone $1.8 \mathrm{~F}$ but the position in relation to E4F2 is not known.

The distal deletion breakpoint is located in the middle of $\mathrm{Pl}$ 77.3D. Two genes are located very close to the breakpoint, the endonuclease III-like 1 gene and the gene encoding the regulatory factor 2 of the solute carrier family 9 (sodium/hydrogen exchanger). ${ }^{25}$ As we did not observe reduced FISH signals for P1 109.8C, the breakpoint is located proximally to or at the beginning of this clone. The proximal breakpoint disrupts the ATP binding cassette transporter $\mathrm{ABC} 3$. The substrate of the transporter is not known but the highest mRNA expression has been seen in lung tissue. ${ }^{17}$

In general, deletions spanning TSC2 and PKDI have been implicated in a severe and infantile form of polycystic kidney disease in TSC..$^{35}$ Progression of renal cystic disease is apparently accelerated when, in addition to inactivation of the PKDl gene, TSC2 function is lost. A patient with neonatal presentation of polycystic kidney disease with paternally inherited ADPKD and maternally inherited TSC supports this observation. ${ }^{36}$

A few other TSC2-PKD1 deletion patients with a milder phenotype have been described. ${ }^{34}$ Sampson et al ${ }^{6}$ observed somatic mosaicism in four of 22 patients with contiguous deletions of TSC2 and PKD1. The relatively mild cystic phenotype found in our patient could be the result of somatic mosaicism. Alternatively, genes in the region counteracting the effect of the PKD1/TSC2 genes or modifying genes located on other chromosomes could explain the milder phenotype of the patient presented here. FISH analysis did not show any mosaicism in the patient presented in this paper, but this was only performed on EBV transformed lymphoblastoid cells. Unfortunately, the patient died from renal failure and inadequate compliance with haemodialysis. For this reason, a fresh blood or tissue sample to test for mosaicism could not be obtained. We therefore cannot definitively conclude whether the mild phenotype was caused by mosaicism or by other genes influencing the phenotype.

The PKD1-TSC2 region on chromosome $16 \mathrm{pl} 3.3$ is particularly gene rich. We propose that haploinsufficiency of one of these genes can cause acrofacial dysostosis or that the deletion has exposed a mutation in a gene on the non-deleted chromosome. The transcription factor $E 4 F 1$ seems to be an interesting candidate gene.

\section{ACKNOWLEDGEMENTS}

We thank G Landes (Genzyme Corporation, Framingham, USA) for the Pl clones. We also thank P Taschner for advice and assistance in database analysis, $\mathrm{S}$ White for critical reading of the manuscript, and the Dutch Kidney Foundation for financial support (C95-1511).

\section{Authors' affiliations}

J G Dauwerse, M H Breuning, D J M Peters, Department of Human and Clinical Genetics, Leiden University Medical Centre, Leiden, The Netherlands

K Bouman, A J van Essen, A H van der Hout, Department of Clinical Genetics, University Hospital, Groningen, The Netherlands G Kolsters, Isala Clinics De Weezenlanden, Zwolle, The Netherlands

Correspondence to: Dr D J M Peters, Department of Human and Clinical Genetics, Leiden University Medical Centre, Sylvius Laboratory, Wassenaarseweg 72, 2333AL Leiden, The Netherlands; d.j.m.peters@lumc.nl

\section{REFERENCES}

1 Opitz JM, Mollica F, Sorge G, Milana G, Cimino G, Caltabiano M Acrofacial dysostoses: review and report of a previously undescribed condition: the autosomal or X-linked dominant Catania form of acrofacial dysostosis. Am J Med Genet 1993;47:660-78.

2 Zori RT, Gray BA, Bent-Williams A, Driscoll DJ, Williams CA, Zackowski JL. Preaxial acrofacial dysostosis (Nager syndrome) associated with an inherited and apparently balanced X:9 translocation: prenatal and postnatal late replication studies. Am J Med Genet 1993;46:379-83.

3 Gomez MR. Tuberous sclerosis. 2nd ed. New York: Raven Press, 1988.

4 Olsson PG, Lohning C, Horsley S, Kearney L, Harris PC, Frischauf A. The mouse homologue of the polycystic kidney disease gene (Pkd1) is a single-copy gene. Genomics 1996:34:233-5.

5 Hateboer N, Dijk MA, Coto E, Saggar-Malik AK, San Millan JL, Torra R, Breuning $M$, Ravine D. Comparison of phenotypes of polycystic kidney disease types 1 and 2. European PKD1-PKD2 Study Group. Lancet 1999;353:103-7

6 Sampson JR, Maheshwar MM, Aspinwall R, Thompson P, Cheadle JP, Ravine D, Roy S, Haan E, Bernstein J, Harris PC. Renal cystic disease in tuberous sclerosis: role of the polycystic kidney disease 1 gene. Am J Hum Genet 1997;61:843-51.

7 Landegent J, Jansen in de Wal N, Dirks RW, Baas F, van der Ploeg M. Use of whole cosmid cloned genomic sequences for chromosomal localization by non-radioactive in situ hybridization. Hum Genet 1987;77:366-70

8 Dauwerse JG, Jumelet EA, Wessels JW, Saris JJ, Hagemeijer A, Beverstock GC, Van Ommen GJB, Breuning MH. Extensive cross-homology between the long and short arm of chromosome 16 may explain leukemic inversions and translocations. Blood 1992; 79:1299-304

9 Giles RH, Petrij F, Dauwerse JG, den Hollander Al, Lushnikova T, Van Ommen GJB, Goodman RH, Deaven LL, Doggett NA, Peters DJM, Breuning $\mathrm{MH}$. Construction of a 1.2-Mb contig surrounding, and molecular analysis of, the human CREB-binding protein (CBP/CREBBP) gene on chromosome 16p13.3. Genomics 1997:42:96-114.

10 The European Chromosome 16 Tuberous Sclerosis Consortium. Identification and characterization of the tuberous sclerosis gene on chromosome 16. Cell 1993;75:1-20.

11 The European Polycystic Kidney Disease Consortium. The polycystic kidney disease 1 gene encodes a 14 kb transcript and lies within a duplicated region on chromosome 16. Cell 1994;77:881-94.

12 Stallings RL, Doggett NA, Callen DF, Apostolou S, Chen LZ, Nancarrow JK, Whitmore SA, Harris PC, Michison H, Breuning MH, Saris JJ, Fickett J, Cinkosky M, Torney DC, Hildebrand CE, Moyzis RK. Evaluation of a cosmid contig physical map of human chromosome 16. Genomics 1992:13:1031-9.

13 Snijdewint FGM, Saris JJ, Dauwerse JG, Breuning MH, Van Ommen GJB. Probe 218 EP6 (D16S246) detects RFLPs close to the locus affecting adult polycystic kidney disease (PKD1) on chromosome 16. Nucleic Acids Res 1990;18:3108.

14 Breuning MH, Snijdewint FGM, Brunner H, Verwest A, IJdo JW, Saris JJ, Dauwerse JG, Blonden LA, Keith T, Callen DF, Hyland VJ, Xiao GH, Scherer G, Higgs DR, Harris P, Bachner L, Reeders ST, Germino GG, Pearson PL, Van Ommen GJB. Map of 16 polymorphic loci on the short arm of chromosome 16 close to the polycystic kidney disease gene (PKD1). J Med Genet 1990;27:603-13.

15 Dauwerse JG, Kievits T, Beverstock GC, van der Keur D, Smit E, Wessels HW, Hagemeijer A, Pearson PL, Van Ommen GJB, Breuning $\mathrm{MH}$. Rapid detection of chromosome 16 inversion in acute nonlymphocytic leukemia, subtype $M 4$, regional localization of the breakpoint in 16p. Cytogenet Cell Genet 1990;53:126-8.

16 Dackowski WR, Connors TD, Bowe AE, Stanton V, Housman D, Dogget $\mathrm{NA}$, Landes GM, Klinger KW. The region surrounding the PKDI gene: a 700-kb Pl contig from a YAC-deficient interval. Genome Res 1996;6:515-24

17 Connors TD, Van Raay TJ, Petry LR, Klinger KW, Landes GM, Burn TC. The cloning of a human $A B C$ gene ( $A B C 3$ ) mapping to chromosome 16p13.3. Genomics 1997;39:231-4.

18 Badolato J, Gardiner E, Morrison N, Eisman J. Identification and characterisation of a novel human RNA-binding protein. Gene 1995; 166:323-7.

19 Janssen U, Fink T, Lichter P, Stoffel W. Human mitochondrial 3,2-trans-enoyl-CoA isomerase (DCI): gene structure and localization to chromosome 16p13.3. Genomics 1994;23:223-8.

20 Rodriquez AM, Rodin D, Nomura H, Morton CC, Weremowicz S, Schneider MC. Identification, localization, and expression of two novel human genes similar to deoxyribonuclease I. Genomics 1997:42:507-13.

21 Baron W, Pan CQ, Spencer SA, Ryan AM, Lazarus RA, Baker KP Cloning and characterization of an actin-resistant DNasel-like endonuclease secreted by macrophages. Gene 1998;215:291-301.

22 Fognani C, Della VG, Babiss LE. Repression of adenovirus ElA enhancer activity by a novel zinc finger-containing DNA-binding protein related to the GLI-Kruppel protein. EMBO J 1993;12:4985-92

23 Wagner AC, Strowski MZ, Goke B, Williams JA. Molecular cloning of a new member of the Rab protein family, Rab 26 , from rat pancreas. Biochem Biophys Res Commun 1995;207:950-6.

24 Sarker AH, Ikeda S, Nakano H, Terato H, Ide H, Imai K, Akiyama K, Tsutsui K, Bo Z, Kubo K, Yamamoto K, Yasui A, Yoshida MC, Seki S. Cloning and characterization of a mouse homologue ( $\mathrm{mNthl} 1)$ of Escherichia coli endonuclease III. J Mol Biol 1998;282:761-74.

25 Imai K, Sarker AH, Akiyama K, Ikeda S, Yao M, Tsutsui K, Shohmori T, Seki S. Genomic structure and sequence of a human homologue (NTHL1/NTH1) of Escherichia coli endonuclease III with those of the adjacent parts of TSC2 and SLC9A3R2 genes. Gene 1998;222:287-95

26 Hwang JI, Heo K, Shin KJ, Kim E, Yun C, Ryu SH, Shin HS, Suh PG. Regulation of phospholipase $\mathrm{C}$-beta 3 activity by $\mathrm{Na}+/ \mathrm{H}+$ exchanger regulatory factor 2. J Biol Chem 2000;275:16632-7.

27 Burn TC, Connors TD, Van Raay TJ, Dackowski WR, Millholland JM, Klinger KW, Landes GM. Generation of a transcriptional map for a 
700-kb region surrounding the polycystic kidney disease 1 (PKD 1) and tuberous sclerosis type 2 (TSC2) disease genes on human chromosome 16p13.3. Genome Res 1996;6:525-37.

28 Weinstat-Saslow DL, Germino GG, Somlo S, Reeders ST. A transducin-like gene maps to the autosomal dominant polycystic kidney disease gene region. Genomics 1993;18:709-11.

29 Lisowsky T, Weinstat-Saslow DL, Barton N, Reeders ST, Schneider MC A new human gene located in the PKDI region of chromosome 16 is a functional homologue to ERV1 of yeast. Genomics 1995;29:690-7.

30 Van Raay TJ, Connors TD, Klinger KW, Landes GM, Burn TC. A novel protein L3-like gene (RPL3L) maps to the autosomal dominant polycystic kidney disease gene region. Genomics 1996;37:172-6.

31 Sandford R, Sgotto B, Burn T, Brenner S. The tuberin (TSC2), autosoma dominant polycystic kidney disease (PKD1), and somatostatin type $\mathrm{V}$ receptor (SSTR5) genes form a synteny group in the Fugu genome. Genomics 1996;38:84-6.

32 Dreyer SD, Zhou L, Machado MA, Horton WA, Zabel B, Winterpacht $A$, Lee B. Cloning, characterization, and chromosomal assignment of the human ortholog of murine Zfp-37, a candidate gene for Nager syndrome. Mamm Genome 1998;9:458-62.
33 Longa L, Brusco A, Carbonara C, Polidoro S, Scolari F, Valzorio B, Riegler P, Tardanico R, Migone N, Maiorca R. A large TSC2 and PKD1 gene deletion is associated with renal and extrarenal signs of autosomal dominant polycystic kidney disease. Contrib Nephrol 1997;1 2:1900-7.

34 Eussen BH, Bartalini G, Bakker L, Balestri P, Di Lucca C, Van Hemel JO, Dauwerse H, van den Ouweland AM, Ris-Stalpers C, Verhoef S, Halley DJ, Fois A. An unbalanced submicroscopic translocation $t(8 ; 16)(q 24.3 ; p 13.3)$ pat associated with tuberous sclerosis complex, adult polycystic kidney disease, and hypomelanosis of Ito. J Med Genet 2000;37:287-91.

35 Brook-Carter PT, Peral B, Ward CJ, Thompson P, Hughes J, Maheshwar MM, Nellist M, Gamble V, Harris PC, Sampson JR. Deletion of the TSC2 and PKDI genes associated with severe infantile polycystic kidney disease - a contiguous gene syndrome. Nat Genet 1994;8:328-32.

36 Griffin MD, Gamble V, Milliner DS, Gomez MR, Harris PC, Torres VE. Neonatal presentation of autosomal dominant polycystic kidney disease with a maternal history of tuberous sclerosis. Nephrol Dial Transplant $1997 ; 12: 2284-8$

\section{Partial trisomy 9p12p21.3 with a normal phenotype}

\section{Stumm, J Müsebeck, H Tönnies, M Volleth, J Lemke, I Chudoba, P Wieacker}

$\mathrm{P}$ artial trisomy or tetrasomy of the short arm of chromosome 9 are among the most common autosomal structural chromosomal anomalies in humans, so the phenotype-genotype correlation of these aneusomies has been well described. Characteristic clinical features of partial trisomy $9 \mathrm{p}$ are mental retardation of various degree, short stature, craniofacial abnormalities, short fingers, simian crease, and single crease of the fifth finger. Additional symptoms like microcephaly, cleft lip and palate, malformed ears, and skeletal, nail, cardiac, and genital anomalies have also been observed. ${ }^{12}$ In 1970, the first case of trisomy 9p was reported by Réthoré et al. Since then, more than 150 patients with partial or complete trisomy $9 p$ have been reported. In most patients, the trisomic segment was transmitted from a parent carrying a reciprocal balanced translocation and only a small number arose from de novo duplications.

Here we report on a three generation family with an interchromosomal insertion of chromosome 9p12-p21 material into the short arm of chromosome 5. One member of the family carried a deletion in the inserted region resulting in cri du chat syndrome, whereas her father is trisomic for the inserted segment owing to an unbalanced segregation of the insertion chromosome. Surprisingly, the unbalanced insertion carrier does not show any morphological or mental abnormalities. The normal phenotype suggests that not all partial trisomies $9 p$ are associated with clinical abnormalities. In particular, the proximal part of the short arm of chromosome 9 seems to be less important for the trisomy $9 \mathrm{p}$ phenotype.

\section{CASE REPORTS}

The female patient, III.1 (fig 1), is the third child of a 27 year old mother and the first child of a 24 year old father. The pregnancy and delivery were uneventful, the birth weight was $2830 \mathrm{~g}$ ( $3 \mathrm{rd}-10$ th centile), and length $48 \mathrm{~cm}$ ( $\sim 3$ th centile). The infant had feeding problems and chromosome analysis was performed because of clinical features of cri du chat syndrome, such as microcephaly, a round face, downward slanting palpebral fissures, deep set ears, microgenia, and atypical crying. Cytogenetic analysis showed the karyotype 46,XX, del(5)(p?).ish del(5)(p?)(D5S23-).

Because about $15 \%$ of cri du chat syndrome cases arise from parental chromosomal aberrations including reciprocal bal- anced translocations and inversions, chromosome analyses were also performed in the mother (II.1) and the father (II.2) of the affected child. The mother had a normal karyotype $(46, X X)$, whereas a derivative chromosome 5 with an enlarged short arm was detected in the father (46,XY,der(5p)) (fig 2). Because the origin of the additional material could not be determined by GTG banding, molecular cytogenetic analyses $(\mathrm{CGH})$ were initiated. Further chromosome analyses of the grandmother (I.2) and the uncle (II.3) of the index patient (III.1) were also performed.

II.2 is a healthy man without any morphological or mental abnormalities. He had normal stature, craniofacial habitus, and dermal ridges of the hands. There were no internal malformations. He had attended a secondary school and learned a technical profession.

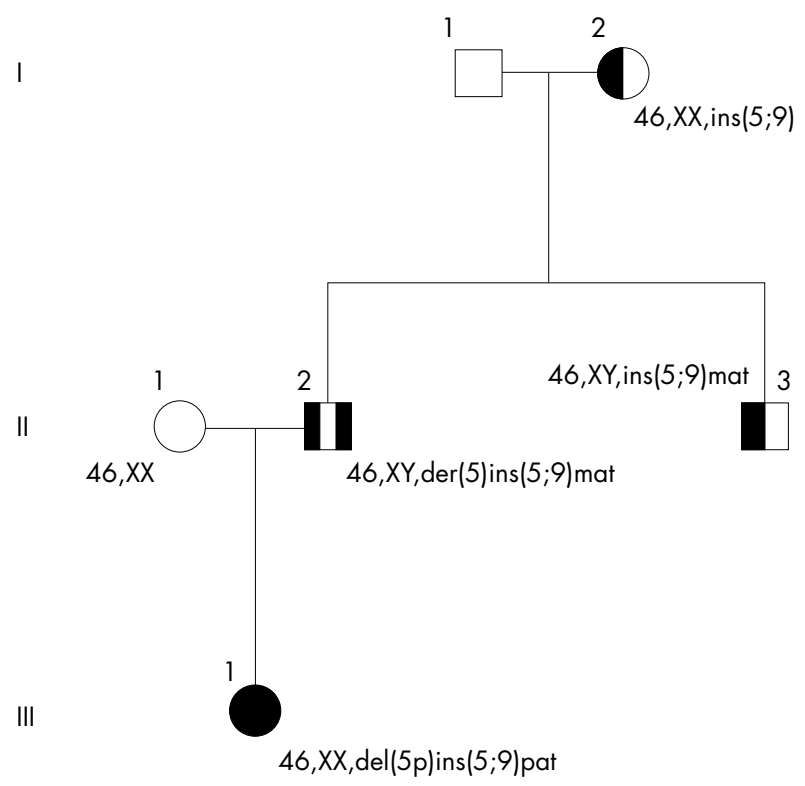

Figure 1 Truncated pedigree of the family, including the important data. 


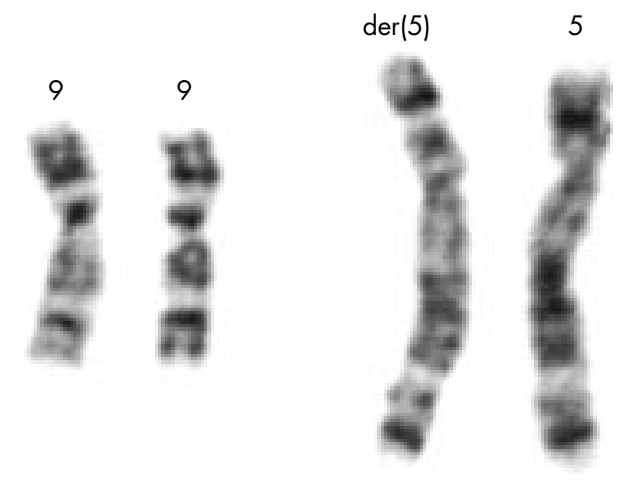

Figure 2 GTG banded chromosomes 9 and 5 from a metaphase of II.2. Both chromosomes 9 and one chromosome 5 are normal. The $\operatorname{der}(5)$ harbours the unbalanced insertion of chromosomal bands (9) (p $12 \mathrm{p} 21.3)$.

\section{METHODS}

Metaphase chromosomes from PHA stimulated peripheral blood lymphocytes of the proband, his daughter, his mother, and his brother were analysed by standard GTG banding procedures and by FISH techniques. Appropriate informed consent was obtained from the family members. FISH studies were performed using the probe D5S23 (ONCOR), which is localised in the cri du chat syndrome critical region in $5 \mathrm{pl5.2}$, and the chromosome painting probes Coatasome 5 dig (ONCOR) and chromosome paint 9 bio (AGS) according to the supplier's protocol. CGH analysis was performed as previously described. ${ }^{4}$ Seven YAC clones from the short arm of chromosome $9 p$ were selected from the website of the Molecular Cytogenetic and Positional Cloning Centre of the Max Planck Institute for Molecular Genetics (Berlin, Germany). YAC-FISH was performed as described by Stumm et al. ${ }^{5}$ Multicolour banding (mBand, Metasystems, Germany) analysis was carried out using seven region specific partial chromosome paints (RPCP) of chromosome 5, which were generated as described by Chudoba et al. ${ }^{6}$

\section{RESULTS}

Because the composition of the derivative chromosome 5 of II. 2 could not be determined by GTG banding (fig 2), a whole

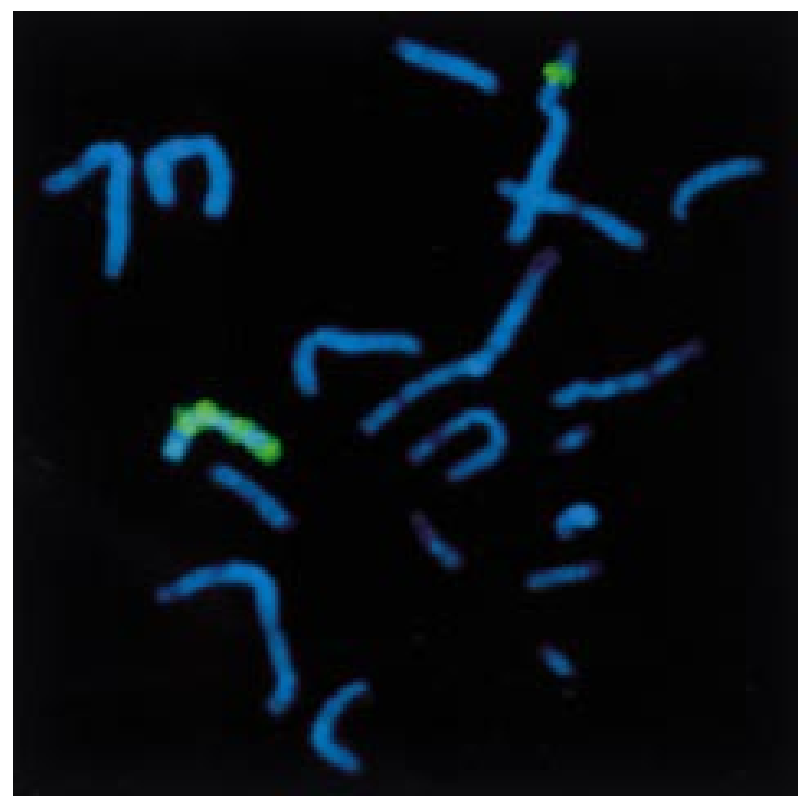

Figure 4 Partial metaphase of II.2 showing whole chromosome painting with a chromosome 9 specific probe. A chromosome 9 specific signal is visible in the short arm of chromosome 5 .

chromosome painting (WCP) with a chromosome 5 specific probe was performed on metaphases of II.2. In the short arm of the derivative chromosome 5, a gap in the painting pattern was detected, indicating an insertion of chromosomal material from a non-homologous chromosome.

Comparative genomic hybridisation (CGH) was applied to identify the additional material inserted in the short arm of chromosome 5. CGH showed a gain of material in the proximal region of the short arm of chromosome 9 (rev ish enh(9)(p12p21)) (fig 3). A further WCP using a chromosome 9 specific probe confirmed the CGH result and detected an insertion of chromosome 9 material in the short arm of chromosome 5 (fig 4).

mBand and WCP analysis on metaphases of the cri du chat syndrome patient (III.1) with chromosome 5 and chromosome 9 specific probes showed that the breakpoint of the
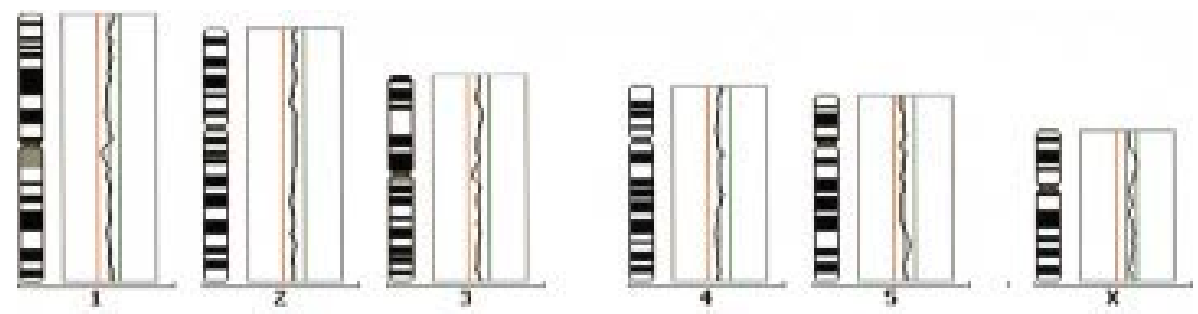

Figure $3 \mathrm{CGH}$ profiles of the proband's (Il. 2) chromosomes. The thin vertical lines represent ration profile value of 0.5 and 1.5 . The average profile of chromosome 9 shows amplification of proximal 9p.
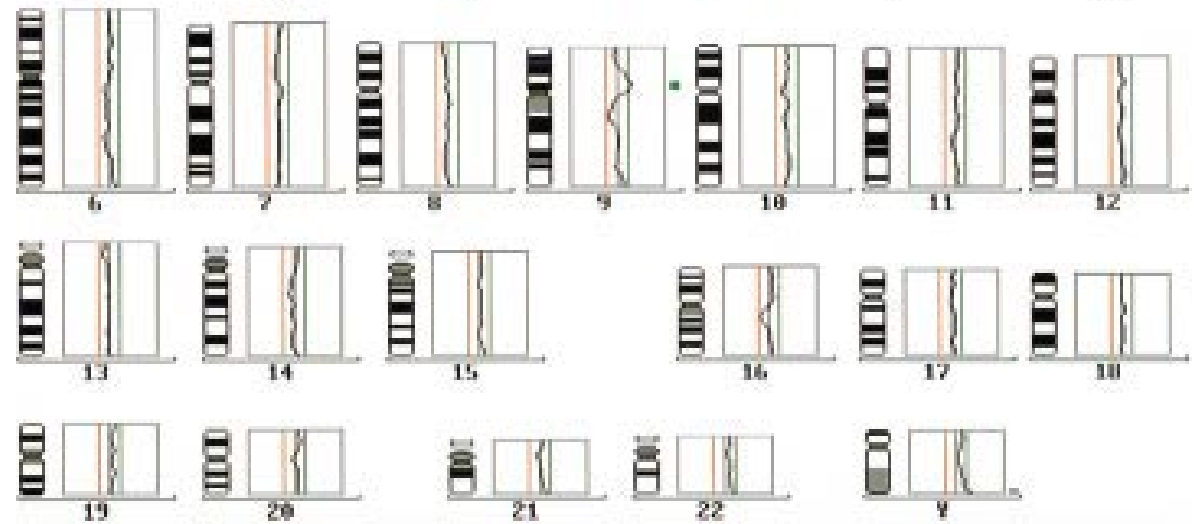


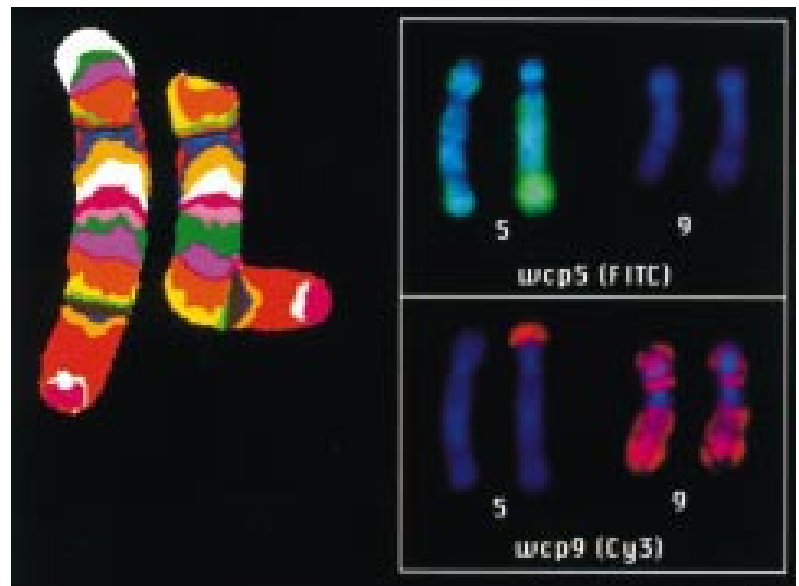

Figure 5 Chromosome $5 \mathrm{mBand}$-FISH determined the chromosome 5 insertion breakpoint in III. 1 at 5 p 13. ${ }^{4}$ WCP 5 and WCP 9 showed the breakpoint of the $5 p$ deletion in the inserted region.

deleted chromosome 5 occurred in the inserted region of the paternally inherited derivative chromosome 5 . The chromosome 5 breakpoint could be determined by mBand at $5 \mathrm{pl} 3.3$ (fig 5). Therefore, patient III.l has a partial monosomy (5) (pl4pter) and a partial trisomy 9p. The origin of the der(5) telomere remains unclear.

Chromosome analyses of the mother (I.2) and the brother (II.3) of II.2 showed a balanced insertion of material from the short arm of chromosome 9 into the short arm of chromosome 5 (ins(5;9)(p13.3;p12p21)). The GTG banding results were confirmed by FISH using chromosome 5 and chromosome 9 specific whole chromosome painting probes (fig 6).

For a better characterisation of the trisomic region, microsatellite analysis with seven markers from chromosome $9 \mathrm{p}$ and one marker from chromosome $9 \mathrm{q}$ was performed on DNA from I.2, II.2, II.3, and III.1. Most markers in the critical region were not informative. Only microsatellite marker D9S104 showed three different alleles in III.1, confirming a trisomy for the subband 9p2l (data not shown). Therefore, YAC-FISH was performed to determine the trisomic region in more detail.

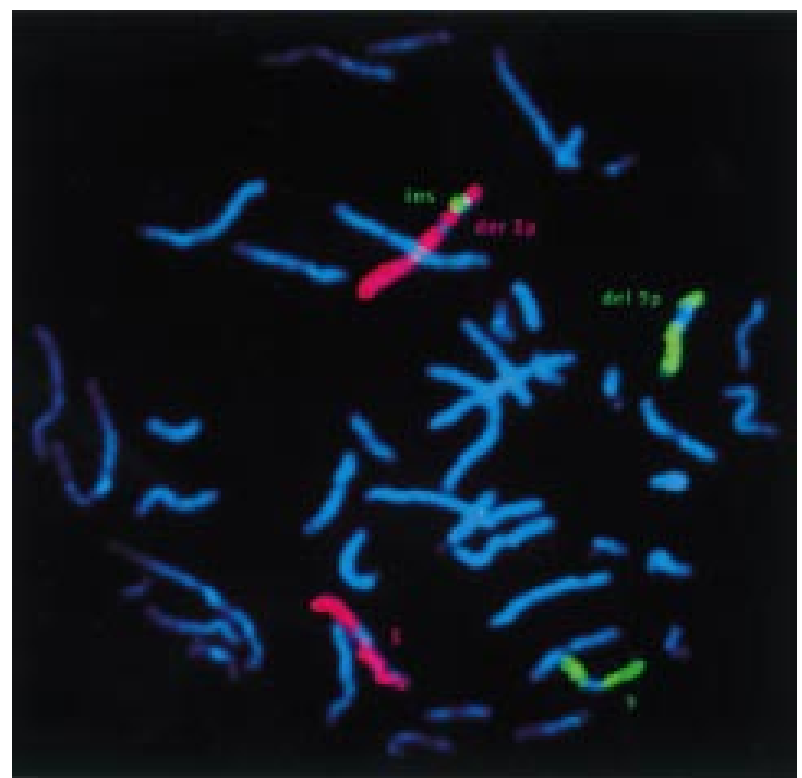

Figure 6 Metaphase of I.2 showing a whole chromosome painting with specific probes for chromosomes 5 (red) and 9 (green). A shortened chromosome 9 specific signal is visible on $\operatorname{der}(9)$. The missing segment is inserted in the short arm of the der(5).
Table 1 Results of the YAC-FISH with probes spanning the chromosomal region 9p12 to 9p24

\begin{tabular}{lllll}
\hline YAC & Localisation* & Chr 9 (1) & Chr 9 (2) & ins $(5 ; 9)$ \\
\hline 961 le04 & $9 p 23-24$ & + & + & - \\
835 e12 & $9 p 23$ & + & + & - \\
$942 f 10$ & $9 p 21-22$ & + & + & + \\
$785 f 08$ & $9 p 13-21$ & + & + & + \\
$854 d 10$ & $9 p 13$ & + & + & + \\
$926 b 09$ & $9 p 13$ & + & + & + \\
$902 g 06$ & $9 p 12$ & + & + & + \\
\hline
\end{tabular}

According to the GTG banding and CGH results, the trisomic segment was postulated to include the chromosomal subbands 9p12-9p21.3. Five different YAC probes localised within and two YAC probes localised outside this region were hybridised to metaphases of II.2 (table 1). All YACs from the critical region 9p12-p21.3 resulted in three specific signals, two on the normal chromosomes 9 and one on the derivative chromosome 5. In contrast, the YACs which are localised in 9p23 and 9p24 only showed signals on both chromosomes 9 .

Taking all the cytogenetic results together, II.2 is a carrier of an unbalanced maternally inherited inserted translocation $(5 ; 9)(\mathrm{pl} 3.3 ; \mathrm{pl} 2 \mathrm{p} 21.3)$ resulting in a partial trisomy $9 \mathrm{pl2}-$ p21.3. This case shows the efficient use of CGH, WCP, and mBand for the correct identification of chromosomal material of unknown origin and of the mechanisms generating structural chromosome aberrations.

\section{DISCUSSION}

Chromosomal insertions, with an estimated frequency of less than 1 in 5000 newborns, are relatively rare chromosome rearrangements. ${ }^{7}$ Only a few reports of inherited interchromosomal insertions have been published and most cases have arisen de novo. Insertions may lead to disruption of genes, position effects with alterations of gene function, or loss or acquisition of chromosomal segments that cannot be detected by cytogenetic methods. Unbalanced transmission of insertion chromosomes results in partial trisomies and/or monosomies. We report on an unbalanced inherited maternal insertion $(5 ; 9)(\mathrm{p} 13.3 ; \mathrm{p} 12 \mathrm{p} 21.3)$ resulting in partial trisomy 9p12-p21.3. To the best of our knowledge, this is the first report of partial trisomy $9 \mathrm{p}$ and a normal phenotype. The normal phenotype is unexpected, because the unbalanced insertion includes a trisomic segment of about $21 \mathrm{Mb}$ (Entrez Map View Chromosome 9, Genes on Sequence Map), harbouring about 280 genes (Entrez Map View, Chromosome 9, Genes on Cytogenetic Map). It is usual that such large autosomal trisomies result in mental retardation and morphological anomalies. In particular, partial trisomy 9p is a well described phenotype and results in a complex clinical malformation pattern. Haddad et $a l^{8}$ reviewed the phenotypic effects of different trisomic regions of chromosome $9 \mathrm{p}$. They compared the cytogenetic and clinical findings of 144 previously published cases with partial or complete trisomy 9p. The majority of these cases were caused by an unbalanced translocation involving another chromosome. Phenotypic effects of these additional segments could not be excluded in these cases. Therefore, the authors confined their analysis to 11 patients with direct duplications of 9p. There was a remarkable consistency in the facial and digital anomalies, which were present in all patients. A general trend towards a milder phenotype in cases with smaller and more distal duplications could be suspected. Furthermore, the characteristic trisomy 9p phenotype showed the best correlation with the 9p22 region. FISH analyses by Fujimoto et al and Guanciali Franchi et $\mathbf{l}^{10}$ suggest that the segment 9p22 may be the critical region for the duplication 9p syndrome. Band 9 p22 
was shown to be duplicated in all patients with de novo duplications of $9 p$ without involvement of another chromosome abnormality. Just one patien $t^{11}$ showed a duplication without involvement of 9p22. Very limited information is available on this patient and the precise breakpoint must be questioned because chromosome analysis was performed at a low banding level. ${ }^{9}$ These findings could also explain why our proband showed no phenotypic abnormalities, because the "critical" region 9p22-9p24 does not seem to be involved in the partial trisomy 9. However, the normal phenotype in II.2 suggests that the genes located in the trisomic segment may not be subject to dosage effect.

A further case with a combination of cri du chat syndrome and partial trisomy $9 \mathrm{p}$ was described by Sigmund et al..$^{12}$ In this case, the combination resulted from an unbalanced translocation $(5 ; 9)(\mathrm{pl} 3.3 ; \mathrm{pl} 3.1)$. The patient harboured the "critical" segment 9p22 and showed typical clinical features of both chromosomal abnormalities.

Imprinting effects may also be an explanation for the unexpected phenotype in our patient. However, clear imprinted regions on chromosome 9 have not been confirmed so far (Imprinted Gene Catalogue Records, 2000).

It is difficult to estimate the reproductive risk for further children of II.2, because he has an interchromosomal duplication resulting from an unbalanced inherited maternal insertion. Insertions can be associated with a very high reproductive risk. The average risk of insertion carriers to have a child with an abnormal phenotype is in the range of $10-50 \%$. Two possibilities of segregation in meiosis have to be considered in our case. Firstly, the risk for the transmission of the rearranged chromosome 5 in II.2 is a priori $50 \%$, which is higher than the risk for a straightforward insertion. However, the risk for an abnormal phenotype must be lower, because II.2 has a normal phenotype. Secondly, there is also a risk for a deletion in $5 p$, which can be best explained by a synapsing of the homologous chromosomes 5 in meiosis I, followed by a looping out of the insertional segment and a break inside the loop. ${ }^{7}$ However, this deletion risk is difficult to estimate and no specific published data are available. All in all, a detailed risk estimation cannot be given in the present case, but a prenatal diagnosis should be performed in further pregnancies of II.2, as well as of his brother.

For further analysis of the unexpected genotype-phenotype correlation of patient II.2, we have established a lymphoblastoid cell line of this patient. Expression analysis by array technologies may show whether the trisomic segment alters the gene expression profile in these cells.

\section{ACKNOWLEDGEMENTS}

The authors thank Mrs R Drange, Mrs B Bütow, and Mrs B Plückthun for excellent technical assistance. We also thank Dr J Wirth from the Molecular Cytogenetic and Positional Cloning Centre of the MPI of
Molecular Genetics in Berlin for providing YAC-DNA and Mrs K Saar from the Microsatellite Centre of the Max-Delbrück-Zentrum in Berlin for performing microsatellite analysis. Furthermore, we thank Metasystems for paying for the colour figures.

Electronic database information. Entrez Genome: http:// www.ncbi.nlm.nih.gov/Entrez/ Imprinted Gene Catalogue Records: http://cancer.otago.ac.nz/IGC/Web/home.html The Molecular Cytogenetic and Positional Cloning Center: http://www.molgen.mpg.de

\section{Authors' affiliations}

M Stumm, J Müsebeck, M Volleth, P Wieacker, Institute of Human

Genetics, Otto von Guericke University, Magdeburg, Germany

H Tönnies, Institute of Human Genetics, Charité, Campus

Virchow-Klinikum, Berlin, Germany

J Lemke, Institute of Human Genetics and Anthropology, Friedrich Schiller University, Jena, Germany

I Chudoba, MetaSystems Inc, Altlussheim, Germany

Correspondence to: Dr M Stumm, Institut für Humangenetik Universitätsklinikum, Leipziger Strasse 44, 39120 Magdeburg, Germany; Markus.Stumm@medizin.uni-magdeburg.de

\section{REFERENCES}

1 Young RS, Reed T, Hodes ME, Palmer CG. The dermatoglyphic and clinical features of the 9p trisomy and partial 9p monosomy syndromes. Hum Genet 1982:62:31-9.

2 Wilson GN, Raj A, Baker D. The phenotypic and cytogenetic spectrum of partial trisomy 9. Am J Med Genet 1985;20:277-82.

3 Réthoré MO, Larget-Piet L, Abonyi D, Boeswillwald M, Berger R, Carpentier S, Cruveiller J, Dutrillaux B, Lafourcade J, Penneau M, Lejeune J. Sur quatre cas de trisomie pour le bras court du chromosome 9. ndividualisation d'une nouvelle entité morbide. Ann Genet 1970;13:217-32

4 Stumm M, Tönnies H, Mandon U, Götze A, Krebs P, Wieacker PF. Mosaic tetrasomy $9 p$ in a girl with multiple congenital anomalies: cytogenetic and molecular-cytogenetic studies. Eur J Pediatr 1999; 158:571-5

5 Stumm M, Kessel-Weiner E, Pascu F, Ottolenghi C, Theile U, Wieacker $\mathrm{PF}$. Deletion of the DM-domain gene cluster in a fetus with ring chromosome 9 and sex reversal. Pediatr Pathol Mol Med 2000;19:415-23

6 Chudoba I, Plesch A, Lörch T, Lemke J, Claussen U and Senger G. High resolution multicolor-banding: a new technique for refined FISH analysis of human chromosomes. Cytogenet Cell Genet 1999:84:156-60.

7 Gardner RJM, Sutherland GR, eds. Chromosome abnormalities and genetic counseling. Oxford monographs on medical genetics No 29 Oxford: Oxford University Press, 1996.

8 Haddad BR, Lin AE, Wyandt H, Milunsky A. Molecular cytogenetic characterisation of the first familial case of partial 9p duplication (p22p24). J Med Genet 1996:33:1045-7.

9 Fujimoto A, Ming SL, Schwartz S. Direct duplication of 9p22p24 in a child with duplication 9p syndrome. Am J Med Genet 1998;77:268-71.

10 Guanciali Franchi P, Calabrese G, Morizio E, Modestini E, Stuppia L, Mingarelli R, Palka G. FISH analysis in detecting 9p duplication (p22p24). Am J Med Genet 2000;90:35-7.

11 Coco R, Penchaszadeh VB. Cytogenetic findings in 200 children with mental retardation and multiple congenital anomalies of unknown cause. Am J Med Genet 1982;1 2:155-73.

12 Sigmund J, Frisch $\mathrm{H}$, Heinz-Erian $\mathrm{P}$, Rhomberg K, Wegner RD. Cri du chat-syndrome in combination with partial trisomy 9p. Pädiatr Pädol 1986;21:61-7 


\title{
Craniofacial anomalies, cataracts, congenital heart disease, sacral neural tube defects, and growth and developmental retardation in two sisters: a new autosomal recessive MCA/MR syndrome?
}

\author{
J Siegel-Bartlet, A Levin, A S Teebi, S J Kennedy
}

J Med Genet 2002;39:145-152

$\mathrm{N}$ eural tube defects are usually multifactorial. They can also be associated with a number of underlying monogenic or chromosomal conditions. These include autosomal recessive disorders, such as Meckel-Gruber, Roberts, and Walker-Warburg syndromes, and chromosomal anomalies, such as microdeletion $22 \mathrm{ql} 1 .^{1}$ Also, teratogenic conditions, such as valproate embryopathy, may also have an association with neural tube defects. ${ }^{2}$ We present an apparently autosomal recessive, syndromic form of sacral neural tube defects resulting in tethered cord in two female sibs.

\section{CASE REPORTS}

Patient 1 was born to a G4, P3 mother and has three healthy, older maternal half sibs who have a different father. Her parents are of mixed European descent and non-consanguineous. The pregnancy history was negative for maternal illness or known teratogen exposure. Labour began spontaneously at 38 weeks. The delivery was complicated by fetal bradycardia following artificial rupture of the membranes. An emergency caesarian section was performed because of abruptio placentae. The birth weight was $1750 \mathrm{~g}$ ( $<3 \mathrm{rd}$ centile), head circumference was 30.5 $\mathrm{cm}$ ( $<3$ rd centile), and length $45.5 \mathrm{~cm}$ ( $<3$ rd centile). Apgar scores were 3 at one minute and 8 at five minutes. Two vessels were present in the umbilical cord. The placenta was found to have areas of calcification with a few foci of intravillous thrombosis and mild acute chorioamnionitis.

Atrial and ventricular septal defects, detected in infancy, were repaired at 10 months. A sacral dimple prompted an MRI of the spine which showed a low lying conus medullaris at the lower aspect of L2 (fig 1). The patient's tethered cord was surgically repaired at 30 months. The patient has required a fundoplication and is fed by gastrostomy tube. She has also had surgical release of her heel cords and the tendons behind her knees.

She had her first ophthalmological examination at our institution at 18 months of age. Two weeks before this examination she had a left nasolacrimal duct probing at another centre for presumed obstruction. No external lacrimal system anomalies were present. At our initial examination, she showed normal visual responses for her age, clear lenses, and a normal eye examination with the exception of moderate, bilateral, symmetrical hyperopia ( +5.50 sphere OU) for which spectacles were prescribed. By 23 months of age, she had developed a small accommodative esotropia that was well controlled with her hyperopic spectacles. At 30 months, her eye examination was once again normal. However, two months later her mother noted a white abnormality in the pupils. Examination showed bilateral, dense, white cataracts with a clear zone at the Y sutures. At surgery, the cortical portion of the cataracts had a very wispy consistency and was very adherent to the surrounding capsule. Retinal examination before the presence of cataracts had always been normal. At the time of presentation with cataracts, it was difficult to view the retina although there was an impression of possible optic atrophy. Postoperatively, she has been noted to have mild retinal vessel tortuosity and bilateral temporal pallor of each optic nerve. She subsequently developed bilateral aphakic glaucoma that is controlled medically.

In view of the rapid onset of the cataract, a laboratory evaluation was undertaken. Sodium, potassium, chloride, calcium, creatinine, cholesterol, thyroid function studies, serum and urine amino acids, urine reducing substances, and serum lactate levels were all normal. MRI of the brain, chromosomes, FISH for microdeletion $22 \mathrm{ql}$, very long chain fatty acids, urine organic acids and oligosaccharides, mucopolysaccharide screen, and carbohydrate deficient glycoprotein testing have been normal. Subtelomeric FISH and SKY were later performed to search for cryptic chromosomal rearrangements and the results were normal.

A spine $x$ ray at 5 years of age showed multiple compression deformities of the spine resulting in thoracolumbar dextroscoliosis, thoracic kyphosis, and lumbar lordosis. Generalised decreased bone density and borderline delayed bone age were also noted. Her growth has continued to be delayed. At 8.6 years, her height was $97 \mathrm{~cm}$ ( $<3$ rd centile), weight was $16.8 \mathrm{~kg}$ ( $<3$ rd centile), and head circumference $46.5 \mathrm{~cm}(<3 \mathrm{rd}$ centile). She has a low anterior hairline with widow's peak, persistent drooling, and a short philtrum with full lips (fig 2A, B). She has a geographic tongue with white lines. Her central incisors are prominent and widely spaced (fig 2C). She has micrognathia. Her ears are small but similar to her mother's. Her chest is barrel shaped and prominent. She has bilateral inverted nipples. She has thoracic kyphosis, with some lordosis, mild scoliosis and mild gibbus. The veins in the shoulder region are prominent. Longitudinal grooves were noted on both the fingernails and the toenails. There was no limitation of movement of the upper limbs and hands. There was limitation of movement of both knees but this may be secondary to her neurological abnormalities. She has central hypotonia with peripheral hypertonia. This patient has remained preambulatory and preverbal. At the age of 8 , she was recognised to be having seizures by EEG and was started on carbamazepine.

Patient 2, the younger sib of patient 1 , was noted to have normal fetal growth on ultrasound at 20.9 weeks' gestation. However, by 33 weeks' gestation the fetus was noted to be small for gestational age. The placenta was noted on ultrasound to have prominent venous lakes and possible degenerative changes. Amniotic fluid volume was mildly increased. The baby was born at 36 weeks' gestation with a birth weight of $1800 \mathrm{~g}$ ( $<3$ rd centile). A muscular ventricular septal defect with patent foramen ovale was diagnosed in infancy, but subsequently closed spontaneously. A tethered cord was repaired at 13 months of age.

Her first eye examination at our centre at 13 months of age showed clear lenses. She had mild hyperopia $(+2.00$ diopters $)$

Abbreviations: $M C A / M R$, multiple congenital anomalies/mental retardation 


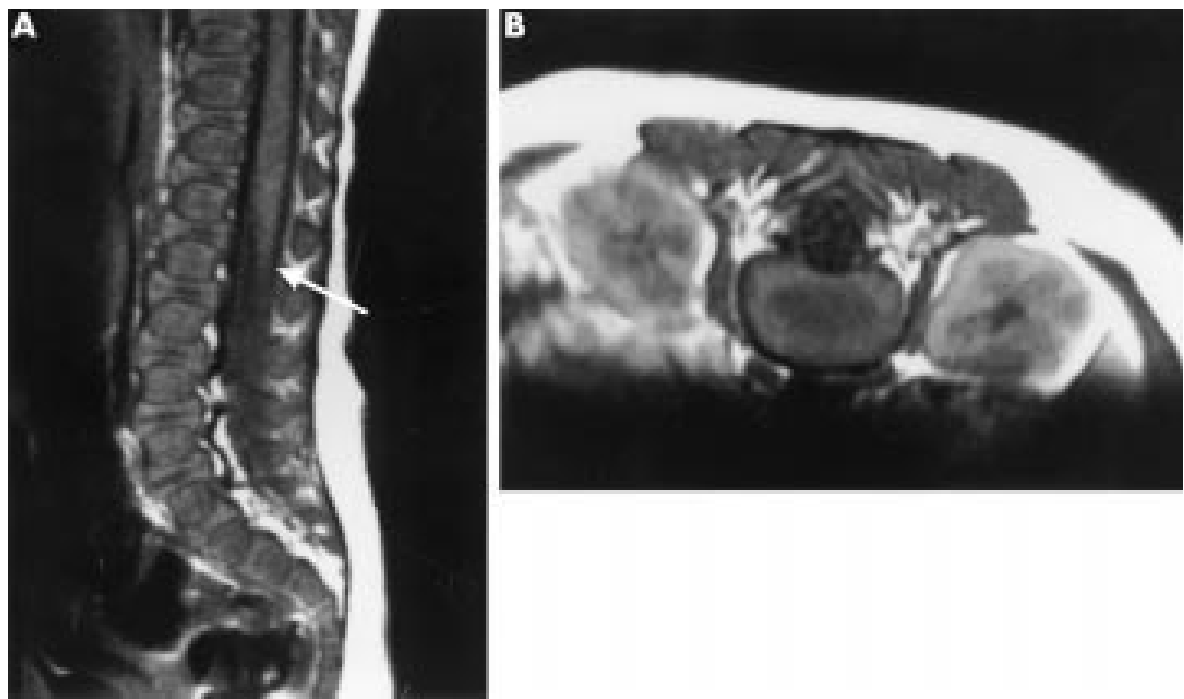

Figure 1 (A, B) Patient 1. T1 (TR540/TE 10) sagittal and axial image of the cord shows the conus extending to the L2-3 disc level.

and astigmatism $(+1.00$ diopters $)$. Retinal examination was normal with the exception of bilateral temporal peripapillary atrophy. In view of her sister's history, she was followed every six months. At 20 months of age, she was noted to have multiple, globular, anterior, cortical dot lens opacities which were worse in the right eye (fig 3). Six weeks later, the opacities had increased in size and she also had new posterior subcapsular cataracts that were worse in the left eye along with an opacified lamella within each lens. Cataract surgery was performed at which time the same subcapsular cortical material was noted. At 3 years of age, she shows good corrected visual function in both eyes with an alternating exotropia of 20-25 prism diopters and chronic bilateral blepharitis. She has also developed bilateral aphakic glaucoma which is controlled medically.

Her serum lactate was normal. A spine $x$ ray at 2 years of age showed mild, generalised decreased bone density and borderline delayed bone age. Chromosomes, FISH for microdeletion $22 q 11$, very long chain fatty acids, urine organic acids and oligosaccharides, mucopolysaccharide screen, and carbohydrate deficient glycoprotein testing have all been normal. Subtelomeric FISH and SKY were normal.

Like her sister, her growth has remained delayed. At 6 years of age, her weight was $16.4 \mathrm{~kg}$ (3rd centile), length was $95 \mathrm{~cm}$ ( $<3$ rd centile), and head circumference was $46.5 \mathrm{~cm}(<3 \mathrm{rd}$ centile). Her facies are similar to her older sister (fig 2D, E). She has central hypotonia with peripheral hypertonia. She has a low frontal hairline with a widow's peak. Her eyebrows are broad, but have sparse hair. Her philtrum is short and she has prominent, widely spaced central incisors. She has micrognathia. Her ears are small. She has stiff joints in her upper limbs and hands. In her lower limbs, there is limitation in the movement of her knees. Her nails are normal. Examination of her genitalia showed pubic hair. Unlike her sib, this patient was almost walking by the age of 2 years. Unfortunately, she had a near drowning bathtub accident that aggravated her neurodevelopmental injury and she never regained this ability. Like her sister, she cannot talk. Following the accident, this patient developed seizures that are controlled medically.

\section{DISCUSSION}

The hallmark manifestations in this family include a characteristic craniofacial appearance, atrial ventricular septal heart defects, sacral neural tube defects, cataracts developing in early childhood, and growth and developmental retardation (table 1).

The combination of eye abnormalities and neural tube defects is well documented in several disorders that include warfarin embryopathy, ${ }^{3}$ Walker-Warburg syndrome, ${ }^{4}$ oculocerebrocutaneous syndrome, Meckel-Gruber syndrome, ${ }^{5}$ and Knobloch vitreoretinopathy. ${ }^{6}$ However, only Walker-Warburg and Knobloch syndromes occasionally have cataracts as a component and in those circumstances other ocular malformations not present in our patients are invariably present. Also, the neural tube defect present in this family is specific, sacral neural tube defect with tethered cord. Kousseff ${ }^{7}$ reported sibs with sacral neural tube defects and conotruncal heart defects, but without cataracts. A similar case was subsequently reported. ${ }^{8}$ The pattern of anomalies seen in Kousseff syndrome is different from that seen in this family.

The cataracts observed in these children had a distinctive morphology. Earlier diagnosis of patient 2 allowed for definition of the phenotype, whereas we presume that complete progression had already occurred in patient 1 at the time of diagnosis. The cataracts had rapid onset in the third year of life with multifocal heterogeneous involvement of the cortex including anterior globular opacities, posterior subcapsular opacities, a lamellar component, and an unusual, subcapsular, diffuse, wispy consistency noted at surgery. To our knowledge, these cataracts do not fit any previously described phenotype that would encompass all of the findings observed. Posterior subcapsular and lamellar cataracts are non-specific and non-diagnostic. They can be seen as isolated idiopathic disorders, heritable cataracts, or secondary to a multitude of causes especially in the case of posterior subcapsular opacity that can be the result of trauma, steroids, or intraocular inflammation. The acute onset of cataracts may suggest a metabolic derangement that we were unable to identify. Most developmental cataracts have a slower progressive onset. Neither child had an acute event that could be identified as a precipitating factor.

The unusual constellation of findings suggests to us that these sisters share a single genetic aetiology with early onset indicated by the presence of malformations occurring in embryogenesis, cardiac and neural tube defects. Perhaps the continued growth and developmental retardation and the onset of cataracts in early childhood would suggest an ongoing metabolic effect as part of this syndrome. In the absence of cryptic chromosomal rearrangements, this disorder is probably inherited in an autosomal recessive manner.

\section{ACKNOWLEDGEMENTS}

We thank the family for their cooperation. We also thank Rozmin Visram for her secretarial assistance. 
A
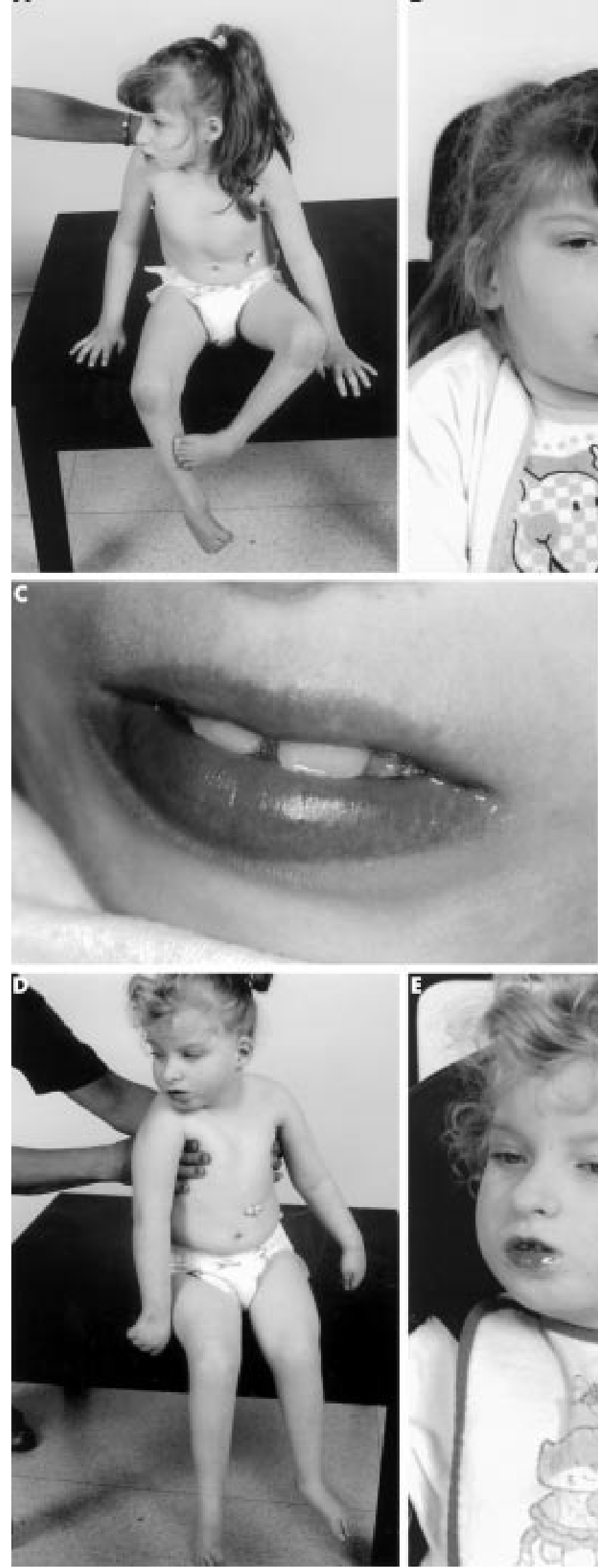

B

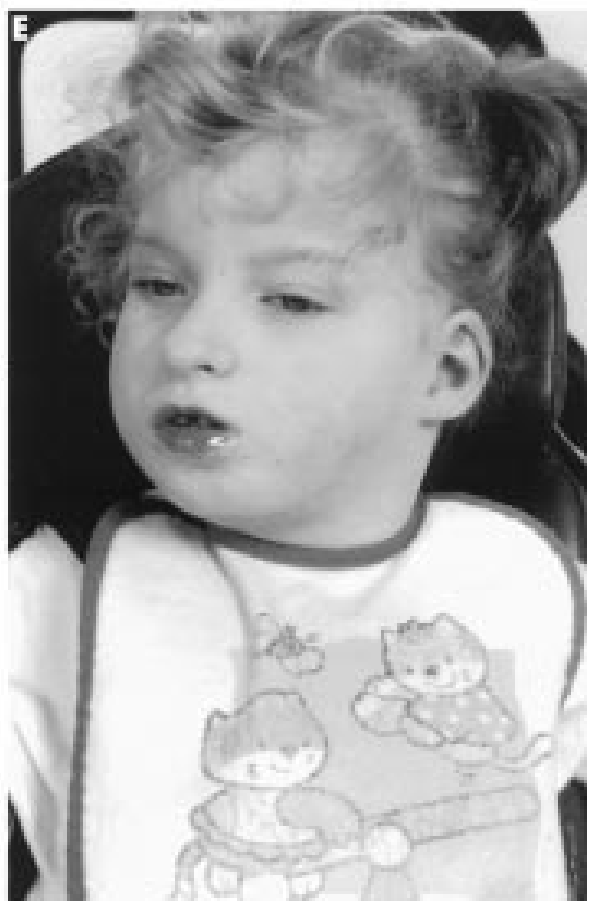

Figure 2 (A, B, C) Patient 1. Whole body and close up of face and mouth. Note the broad central incisors. (D, E) Patient 2. Whole body and close up of face. Note the

remarkable similarity to patient 1 .

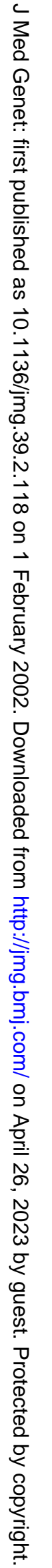




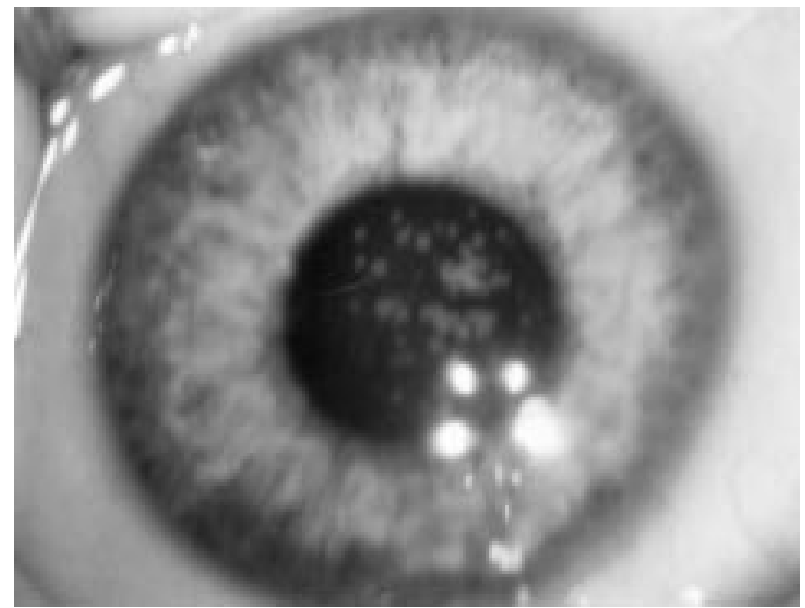

Figure 3 Patient 2. Cataract. Note multiple, globular, anterior, cortical dot lens opacities.

\section{Authors' affiliations}

J Siegel-Bartlet*, A S Teebi, S J Kennedy, Section of Clinical Genetics and Dysmorphology, Division of Clinical and Metabolic Genetics, The Hospital for Sick Children, 555 University Avenue, Toronto, ON M5G $1 \times 8$, Canada

A Levin, Department of Ophthalmology, The Hospital for Sick Children, 555 University Avenue, Toronto, ON M5G 1X8, Canada

Correspondence to: Professor A S Teebi, Section of Clinical Genetics and Dysmorphology, Division of Clinical and Metabolic Genetics, The Hospital for Sick Children, 555 University Avenue, Toronto, ON M5G 1X8, Canada; ateebi@sickkids.on.ca

*Present address: Genetics Department, Alfigen, Pasadena, California, USA

\section{REFERENCES}

1 Jones KL. Recognizable patterns of human malformations. 5th ed. Philadelphia: Saunders, 1997

2 Kozma C. Valproic acid embryopathy: report of two siblings with further expansion of the phenotypic abnormalities and a review of the literature. Am J Med Genet 2001;98:68-175

3 Kaplan LC. Congenital Dandy-Walker malformation associated with first trimester warfarin: a case report and literature review. Teratology $1985 ; 32: 333-7$
Table 1 Manifestations of the new MCA/MR

syndrome in two female sibs

\begin{tabular}{|c|c|c|}
\hline & Patient 1 & Patient 2 \\
\hline IUGR & + & + \\
\hline Microcephaly (primary) & + & + \\
\hline Short stature/growth delay & + & + \\
\hline \multicolumn{3}{|l|}{ Craniofacial anomalies } \\
\hline Low anterior hairline/widow's peak & + & + \\
\hline Short philtrum & + & + \\
\hline $\begin{array}{l}\text { Prominent, widely spaced central } \\
\text { incisors }\end{array}$ & + & + \\
\hline Geographic tongue & + & + \\
\hline Full lips & + & - \\
\hline Micrognathia & + & + \\
\hline Small ears & + & + \\
\hline Eye abnormalities & + & + \\
\hline Hyperopia/astigmatism & + & + \\
\hline Early childhood cataracts & + & + \\
\hline Nasolacrimal duct stenosis & + & - \\
\hline Strabismus & + & + \\
\hline VSD/ASD & + & + \\
\hline Inverted nipples & + & - \\
\hline Sacrococcygeal dimple/tethered cord & + & + \\
\hline Delayed bone age & + & $+($ Borderline $)$ \\
\hline Joint limitation/stiff joints & + & + \\
\hline Longitudinal grooves of nails & + & - \\
\hline Hypotonia & + & + \\
\hline Seizures & + & + \\
\hline Developmental delay & + & + (Milder) \\
\hline Single umbilical artery & + & ? \\
\hline $\begin{array}{l}\text { Placental calcification/degenerative } \\
\text { changes }\end{array}$ & + & + \\
\hline
\end{tabular}

4 Dobyns WB, Pagon RA, Armstrong D, Curry CJ, Greenberg F, Grix A Holmes LB, Laxova R, Michels VV, Robinow M, Zimmerman RL. Diagnostic criteria for Walker-Warburg syndrome. Am J Med Genet 1989:32:195-210

5 Salonen R, Paavola P. Meckel syndrome. J Med Genet 1998;35:497-501.

6 Sniderman LC, Koenekoop RK, O'Gorman AM, Usher RH, Sufrategui MR, Moroz B, Watters GV, Der Kaloustian VM. Knobloch syndrome involving midline scalp defect of the frontal region. Am J Med Genet 2000;90:146-9.

7 Kousseff BG. Sacral meningocele with conotruncal heart defects: a possible autosomal recessive trait. Pediatrics 1984;74:395-8.

8 Toriello HV Sharda JK, Beaumont EJ. Autosomal recessive syndrome of sacral and conotruncal development field defects (Kousseff syndrome). Am J Med Genet 1985;22:357-60.

\title{
Dysmorphism, variable overgrowth, normal bone age, and severe developmental delay: a "Sotos-like" syndrome?
}

\author{
J Amiel, L Faivre, L Wilson, M Le Merrer, A Munnich, R Winter, S Lyonnet, \\ V Cormier-Daire
}

S otos syndrome (MIM 117550) is an overgrowth syndrome first described by Sotos et al in 1964 with over 200 cases reported to date. The syndrome is characterised by preand postnatal overgrowth, macrocephaly, advanced bone age, and distinctive facial features. ${ }^{2}$ In a review of 79 patients diagnosed as Sotos syndrome, Cole and Hughes ${ }^{3}$ showed that the overall gestalt was as efficient as clinical and radiological criteria for the diagnosis. The vast majority of cases are sporadic.
Concordant and discordant monozygotic twins have been reported. ${ }^{45}$ In rare instances, familial cases with autosomal dominant or autosomal recessive inheritance have been suspected and chromosomal rearrangements have also been reported. ${ }^{46}$ However, the aetiology of Sotos syndrome remains unknown. A hypothalamic origin was first suspected but extensive endocrinological testing failed to show significant anomalies. More recently, chromosomal uniparental disomy has been 

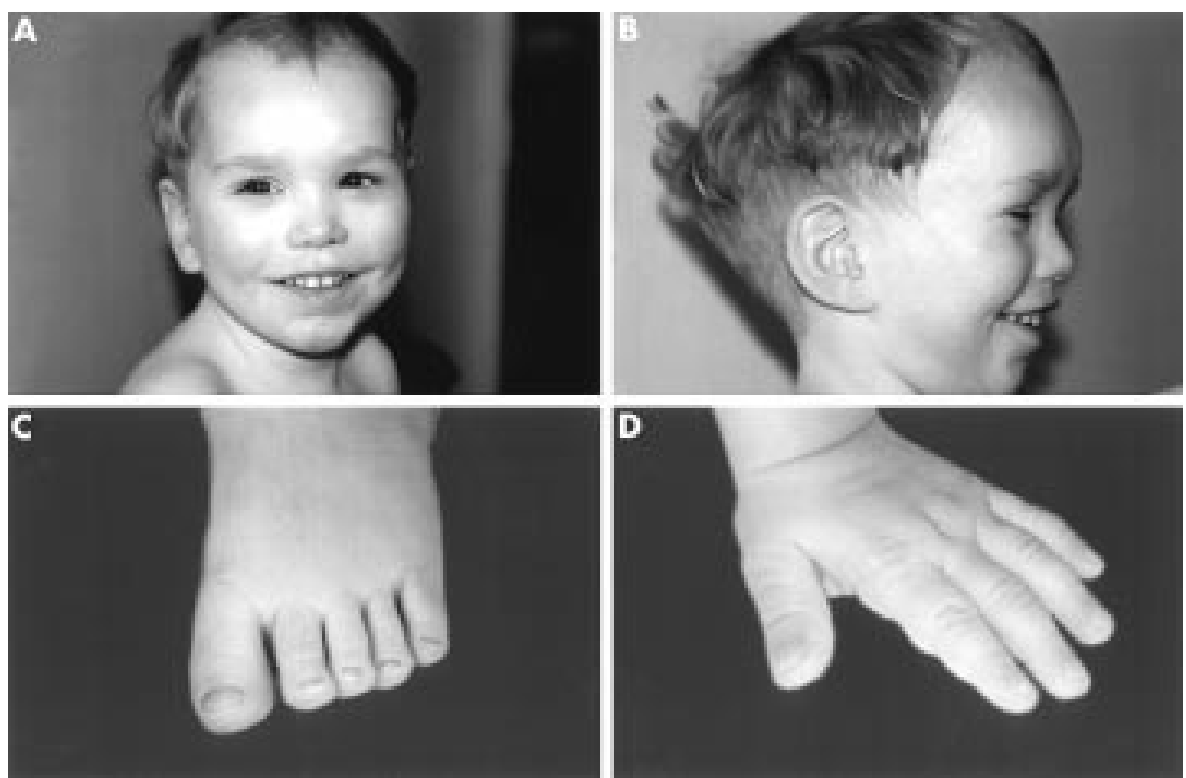

Figure 1 Case 1. (A) Note the long face with pointed chin, high forehead with receding frontal hairline, fine hair, mild hypertelorism, and convergent strabismus. (B) Note dolichocephaly. (C) Note large feet and flat, brittle, deep set nails. (D) Note large hands and loose skin

ruled out. ${ }^{7}$ Here, we report on five unrelated cases with a Sotos facial gestalt, severe developmental delay, moderate to absent overgrowth, and normal bone age. We propose a separate Sotoslike syndrome.

\section{CASE REPORTS}

\section{Case 1}

Case 1, a male, was the third child of healthy, nonconsanguineous parents, aged 31 and 33 years at the time of birth. The mother's height was $1.57 \mathrm{~m}$ (25th centile) and the father's $1.72 \mathrm{~m}$ (between the 25th and 50th centile). Amniocentesis was performed for at risk maternal serum screening and fetal chromosomes were normal 46,XY. Bilateral vesicoureteral reflux was diagnosed prenatally and surgically repaired at 9 months of age. He was born at term with normal birth parameters (birth weight $3360 \mathrm{~g}$, 25th centile; length $51 \mathrm{~cm}$, 50th centile; OFC $35 \mathrm{~cm}$, 50th centile). He had hypotonia and psychomotor delay (sat at 12 months, walked at 24 months, no words at 24 months). He was first investigated at 9 months; hypsarrythmia was diagnosed and treated with Vigabatrin. He was admitted to hospital eight days later with Streptococcus pneumoniae meningitis. When first seen, at 22 months of age, growth was in the normal range (weight $14 \mathrm{~kg}$, 75th centile; height 90 $\mathrm{cm}$, 75th centile; OFC $50.5 \mathrm{~cm}$, 75th centile). Facial features included a long face with a pointed chin, dolichocephaly, a high forehead with receding frontal hairline, fine hair, mild hypertelorism, convergent strabismus, and a high arched palate (fig 1A, B). The hands and feet were large with flat, brittle, deep set nails (fig 1C, D). Examination of the skin showed loose skin on the extremities and two punctiform scars across one arm. He stands with kyphosis, bent knees, and pes planus. Peripheral reflexes were brisk. Fundi were normal.

EEG showed hypsarrythmia and MRI of the brain showed a right parietofrontal cavity, a cyst of the septum pellucidum, and mild ventriculomegaly. At 22 months of age, bone age was 2 years for carpal bones, phalanges, and metacarpals according to Greulich and Pyle. Supernumerary epiphyses were present at the base of the second and third metacarpals. High resolution chromosomes were normal $(46, \mathrm{XY})$ on lymphocytes with no fragile site on the $\mathrm{X}$ chromosome.

\section{Case 2}

Case 2, a male, was the third child of healthy, nonconsanguineous parents aged 38 and 43 years at the time of birth. The mother's height was $1.70 \mathrm{~m}$ (90th centile) and the father's $1.87 \mathrm{~m}$ (>97th centile). The mother's OFC was $57 \mathrm{~cm}$ (97th centile). The older brother's and sister's heights were above the 97th centile $(1.81 \mathrm{~m}$ at 14 years and $1.78 \mathrm{~m}$ at 13 years, respectively). Amniocentesis for maternal age showed normal fetal chromosomes, 46,XY. The mother had hypertension in the third trimester of the pregnancy. He was born at term with normal birth parameters (birth weight $3570 \mathrm{~g}$, 75th centile; length $54 \mathrm{~cm}$, 90th centile; OFC $36.5 \mathrm{~cm}$, 75th centile). There was a unilateral cleft lip and upper gum, feeding difficulties, hypotonia, hyperbilirubinaemia, and hypoglycaemia at birth. He showed psychomotor delay (sat at 12 months, walked at 24 months, no words at 6 years). When first seen, at 26 months of age, growth was above the mean (weight $16 \mathrm{~kg}$, 90 th centile; length $100 \mathrm{~cm}$, 97th centile; OFC $54.5 \mathrm{~cm},>97$ th centile). Facial features included a long face with pointed chin, dolichocephaly, a high forehead with receding frontal hairline, fine hair, mild hypertelorism, epicanthic folds, and downward slanting palpebral fissures (fig 2A, B). The hands and feet were large with flat, brittle, deep set nails (fig 2C, D). The skin was velvety. He stands with kyphosis, bent hips and knees, and pes planus. Fundi were normal. At 6 years of age, height is above the 97th centile, weight is between the 90th and 97 th centile, and OFC is above the 97th centile.

MRI of the brain showed mild ventriculomegaly. At 26 months of age, bone age was 2 years 8 months according to Greulich and Pyle. Pseudoepiphyses were present at the base of the second and fifth metacarpals. High resolution chromosomes were normal $(46, \mathrm{XY})$ on lymphocytes with no fragile site on the $X$ chromosome. Auditory evoked potentials and abdominal ultrasound were normal.

\section{Case 3}

Case 3, a male, was the first child of healthy, nonconsanguineous parents aged 28 and 42 years at the time of birth. The mother subsequently had two miscarriages. The mother's height was $1.60 \mathrm{~m}$ (50th centile) and the father's $1.72 \mathrm{~m}$ (25th centile). Case 3 was born at 33 weeks of gestation (birth weight $2100 \mathrm{~g}, 50$ th centile; length $44 \mathrm{~cm}, 50$ th centile; OFC $32 \mathrm{~cm}$ ). He had ventricular septal defect and a patent ductus arteriosus that closed spontaneously. Psychomotor development was delayed (sat at 14 months, walked at 3 years, three words at 2 years 10 months). At 11.5 years of age, height and weight were on the 97th centile and OFC $>97$ th centile. 

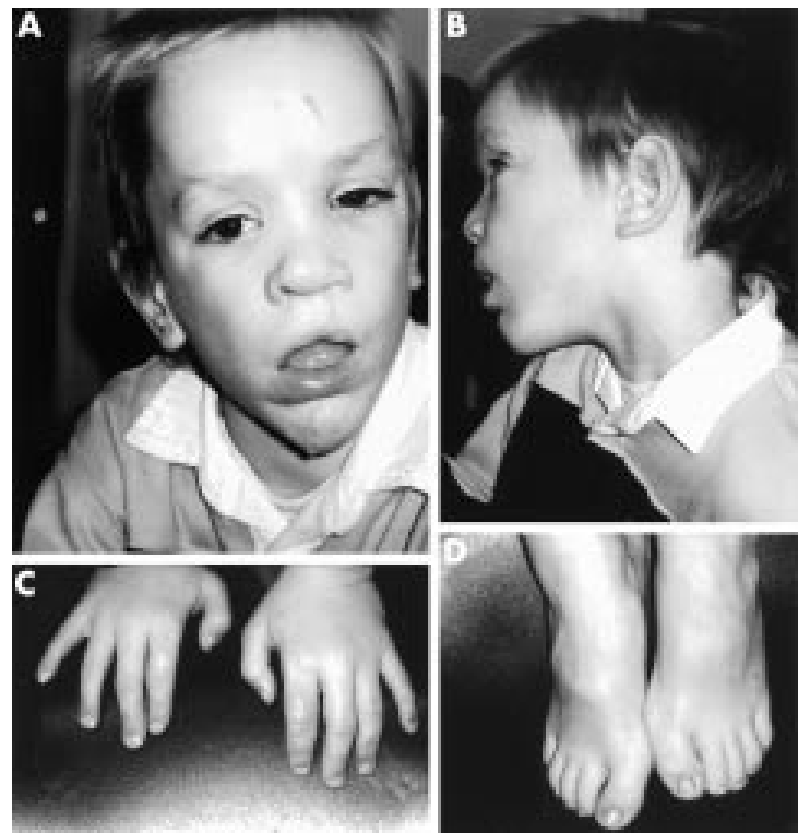

Figure 2 Case 2. (A) Note the long face with pointed chin, high forehead with receding frontal hairline, fine hair, mild hypertelorism, epicanthic folds, downward slanting palpebral fissures, and repaired cleft lip. (B) Note dolichocephaly. (C) Note large hands. (D) Note large feet and flat, brittle, deep set nails.

He attended normal school with two years delay. Facial dysmorphic features included a long face with a pointed chin, a high forehead with receding frontal hair line and fine hair (fig 3A, B). The hands and feet were large (>97th centile) with flat, deep set nails that required surgery.
Brain CT scan showed mild ventriculomegaly. At 3 years of age, bone age is 3 years 6 months according to Greulich and Pyle. High resolution chromosomes were normal $(46, \mathrm{XY})$ in lymphocytes. Fragile $\mathrm{X}$ was ruled out by molecular testing.

\section{Case 4}

Case 4, a female, was the first of two children of healthy, non-consanguineous parents aged 30 and 22 years at the time of birth. The mother's height was $1.53 \mathrm{~m}$ (10th centile) and the father's $1.74 \mathrm{~m}$ (50th centile). The mother had two healthy children from a previous union. She was born at term after an uneventful pregnancy with birth parameters as follows: birth weight $3140 \mathrm{~g}$, 50th centile; OFC $36.5 \mathrm{~cm}$, 90th centile (length not recorded). Psychomotor development was slow and she was hyperactive with temper tantrums and obsessional behaviour (sat at 9 months, walked at 18 months, no words at 3 years 10 months). Seizures occurred at 7 months of age and were treated by carbamazepine. Patent ductus arteriosus was surgically repaired at 1 year. Growth followed the 50th centile until the age of 3.5 years. Growth acceleration started at that age with height on the 90th centile; weight and OFC were above the 97th centile at 5 years of age. Facial dysmorphic features included a long face with a pointed chin, a high forehead, dolichocephaly, hypertelorism, epicanthic folds, downward slanting palpebral fissures, strabismus, a low nasal bridge, and a narrow, high palate (fig 3C, D). Extremities were large with bilateral 2-3 syndactyly of the toes. Examination of the skin was normal.

A brain CT scan and MRI showed mild ventriculomegaly. Electroencephalography was normal. At 3 years 10 months of age, bone age was between 3 years and 3 years 8 months according to Greulich and Pyle. Blood karyotype showed normal chromosomes $(46, \mathrm{XX})$ in lymphocytes. Fragile X was ruled out by molecular testing.

\section{Case 5}

Case 5, a male, was the second child of healthy, unrelated parents. Both parents were of average stature but their heights
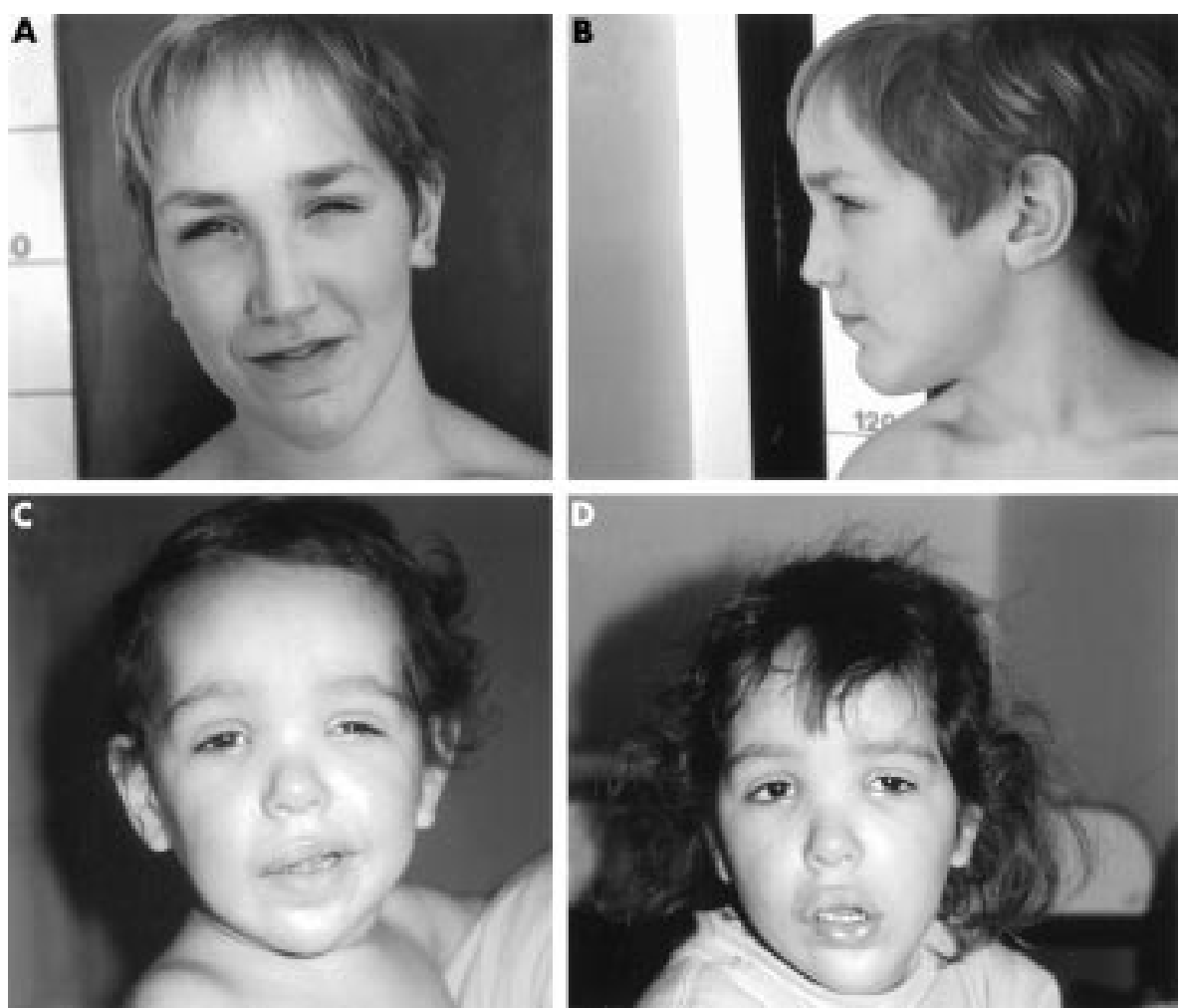

Figure 3 (A, B) Case 3. Note the long face with pointed chin, high forehead with receding frontal hair line, and fine hair. (C, D) Case 4 Note the long face with pointed chin, high forehead, hypertelorism, epicanthic folds, and downward slanting palpebral fissures. Facial asymmetry is not a feature. 
were not recorded. He was born at term with a normal birth weight $(3300 \mathrm{~g})$. At 21 months of age, growth was in the normal range (weight $12.9 \mathrm{~kg}$, 75th centile; height $86.4 \mathrm{~cm}$, 75th centile; OFC $52.1 \mathrm{~cm}$, 97th centile). Psychomotor development was delayed (standing with support, one word). Facial dysmorphic features included dolichocephaly, a high forehead with frontal bossing and receding frontal hair line, a long face with a pointed chin, downward slanting palpebral fissures, strabismus, a high palate, and a unilateral ear pit. He had large hands and feet. The skin was lax and he had three café au lait patches.

Brain CT scan showed partial agenesis of the corpus callosum. Blood karyotype showed normal chromosomes $(46, \mathrm{XY})$ on lymphocytes and fragile $\mathrm{X}$ was ruled out by molecular testing. At 21 months of age, bone age was 2 years 8 months according to Greulich and Pyle while his distal radial epiphysis was not yet visible.

\section{DISCUSSION}

Here we report five unrelated patients with the combination of similar and distinctive facial features, loose skin on the extremities with brittle, deep set nails (3/5), moderate to severe developmental delay, moderate to absent overgrowth, normal bone age, and mild ventriculomegaly (tables 1 and 2). The five cases we report are sporadic and no consanguinity was observed. There was no known exposure to drugs or toxins during the pregnancies. Fragile $\mathrm{X}$ syndrome was ruled out

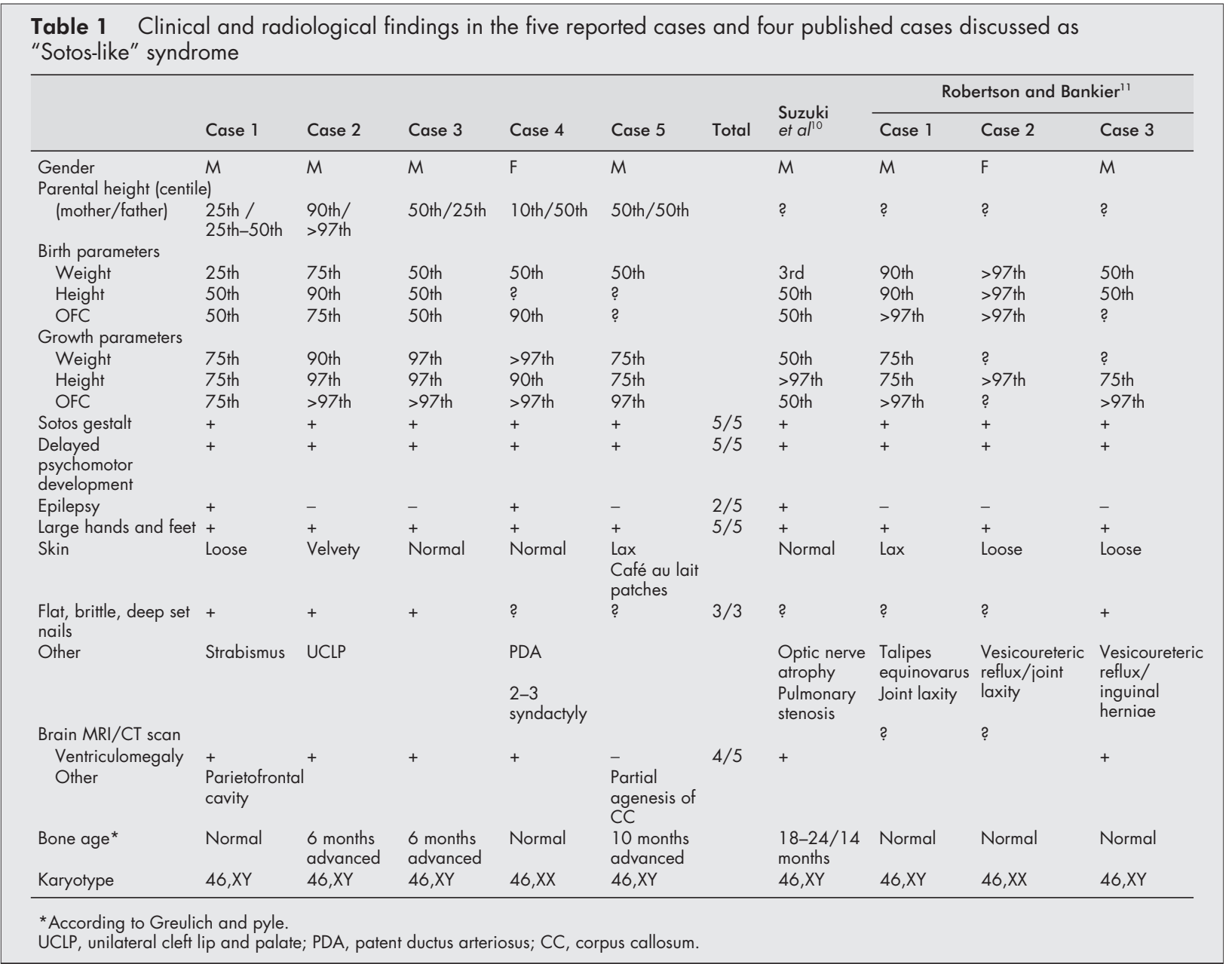

Table 2 Facial dysmorphic features in the five reported cases and four published cases compared to distinctive facial features in a series of patients with Sotos syndrome*

\begin{tabular}{|c|c|c|c|c|c|c|c|c|c|c|c|c|}
\hline \multirow[b]{2}{*}{ Facial features } & \multirow{2}{*}{$\begin{array}{l}\text { Sotos } \\
\text { syndrome* }\end{array}$} & \multirow[b]{2}{*}{ Case 1} & \multirow[b]{2}{*}{ Case 2} & \multirow[b]{2}{*}{ Case 3} & \multirow[b]{2}{*}{ Case 4} & \multirow[b]{2}{*}{ Case 5} & \multirow[b]{2}{*}{ Total } & \multirow{2}{*}{$\begin{array}{l}\text { Suzuki } \\
\text { et allo }\end{array}$} & \multicolumn{3}{|c|}{ Robertson and Bankier ${ }^{11}$} & \multirow[b]{2}{*}{ Total } \\
\hline & & & & & & & & & Case 1 & Case 2 & Case 3 & \\
\hline Frontal bossing & $97.5 \%$ & + & + & + & + & + & $5 / 5$ & + & + & + & + & $4 / 4$ \\
\hline High frontal hairline & $97.5 \%$ & + & + & + & + & + & $5 / 5$ & + & + & + & + & $4 / 4$ \\
\hline Prominent jaw & $95 \%$ & + & + & + & + & + & $5 / 5$ & - & $?$ & + & + & $2 / 3$ \\
\hline $\begin{array}{l}\text { Downward slanting palpebral } \\
\text { fissures }\end{array}$ & $90 \%$ & - & + & + & + & + & $4 / 5$ & + & - & + & - & $2 / 4$ \\
\hline Facial flushing & $85 \%$ & + & ? & ? & + & $?$ & $2 / 2$ & ? & ? & $?$ & ? & ? \\
\hline Dolichocephaly & $80 \%$ & + & + & ? & + & + & $4 / 4$ & ? & ? & ? & ? & ? \\
\hline High palate & $70 \%$ & + & $\mathrm{CL}$ & $?$ & + & + & $3 / 3$ & + & + & + & + & $4 / 4$ \\
\hline
\end{tabular}


in all patients and there was no identified chromosomal rearrangement on blood karyotyping.

Features consistently observed in our patients have been described in Sotos syndrome, namely facial gestalt, large extremities, brittle, deep set nails, and loose skin. Similarly, mild, non-specific ventriculomegaly and corpus callosum agenesis are frequently found in Sotos syndrome. ${ }^{8}$ Therefore, although the five patients have the Sotos syndrome facial gestalt, they share features that make Sotos syndrome unlikely, namely absence of overgrowth and macrocephaly at birth, growth acceleration of late onset that remained moderate (from 26 months to 6 years of age, patients 2-4), normal bone age, and severe psychomotor delay. Macrocephaly-cutis marmoratatelangiectatica congenita syndrome was considered in case 4 and ruled out because of absent overgrowth and macrocephaly at birth, absence of segmental overgrowth and hydrocephalus, and normal skin examination. ${ }^{9}$ Finally, none of the syndromes included in the differential diagnosis of Sotos syndrome seem satisfactory, namely Weaver-Smith (MIM 277590), autosomal dominant macrocephaly (MIM 153470), and ZonanaBannayan (MIM 153480) syndromes.

Sotos syndrome remains of unknown aetiology and may have been overdiagnosed. ${ }^{3}$ Reviewing published reports, we found four cases which may be similar to the cases reported here. Suzuki et $_{\text {al }}{ }^{10}$ reported a male patient diagnosed as Sotos syndrome who showed the combination of increased height, large extremities, normocephaly, hypsarrythmia, and moderately advanced bone age (table 1). Because of the ethnic origin, dysmorphic features are difficult to appreciate. Nevertheless, the patient showed a high forehead with receding frontal hair line, downward slanting palpebral fissures, and a high arched palate (table 2). Robertson and Bankier ${ }^{11}$ reported three unrelated cases with the combination of an overall Sotos gestalt, macrocephaly, moderate to absent overgrowth, developmental delay, and normal bone age (tables 1 and 2). They put emphasis on symptoms suggestive of a connective tissue disorder, namely cutis laxa, joint hypermobility, and vesicoureteric reflux. Cole and Hughes ${ }^{3}$ reviewed 79 cases diagnosed as Sotos syndrome and categorised 22 patients as "definitely not Sotos" (28\%). Among this group, two sisters were described as combining "significant developmental delay and characteristic facies with normal bone age and chromosomal analyses". They may represent the Sotoslike syndrome. Goldstein et $a l^{12}$ reported two unrelated patients with overgrowth, macrocephaly, advanced bone age, developmental delay, nystagmus, and dysmorphic facial features with epicanthic folds, a depressed nasal bridge, and anteverted nares. The authors raised the question of a variant of Sotos syndrome. We believe that they represent a distinct entity from the cases we report.

In the absence of definitive genetic tests, one should be cautious with the diagnosis of Sotos syndrome. We propose a Sotos-like syndrome for the association of Sotos facial gestalt, moderate overgrowth and macrocephaly, severe developmental delay, and normal bone age. We do not know whether the Sotos-like syndrome is allelic to Sotos syndrome or genetically distinct if of genetic origin, the cases we report being sporadic. It would be of interest to know whether other clinicians have encountered similar patients and experienced the same diagnostic difficulties.

\section{ACKNOWLEDGMENTS}

We thank the families for their cooperation and Professor Brunelle for reviewing the patients' $x$ rays and for helpful discussion.

\section{Authors' affiliations}

J Amiel, L Faivre, M Le Merrer, A Munnich, S Lyonnet, V Cormier-Daire, Département de Génétique, Hôpital Necker-Enfants Malades, 149 rue de Sèrres, 75743 Paris, France

L Wilson, R Winter, Mothercare Department of Paediatric Genetics, Institute of Child Health, 30 Guilford Street, London WCIN 1EH, UK

Correspondence to: Dr Cormier-Daire, Département de Génétique, Hôpital Necker-Enfants Malades, 149 rue de Sèvres, 75743 Paris, France; cormier@necker.fr

I Chudoba, MetaSystems Inc, Altlussheim, Germany

Correspondence to: Dr M Stumm, Institut für Humangenetik, Universitätsklinikum, Leipziger Strasse 44, 39120 Magdeburg, Germany; Markus.Stumm@medizin.uni-magdeburg.de

\section{REFERENCES}

1 Sotos JF, Dodge PR, Muirhead D, Crawford JD, Talbot NB. Cerebral gigantism in childhood. N Engl J Med 1964;271:109-16.

2 Cole TR, Hughes HE. Sotos syndrome. J Med Genet 1990;27:571-6.

3 Cole TR, Hughes HE. Sotos syndrome: a study of the diagnostic criteria and natural history. J Med Genet 1994;31:20-32.

4 Gorlin RJ, Cohen MM, Levin LS. Syndromes of the head and neck. 3rd ed. Oxford: Oxford University Press, 1990.

5 Brown WT, Wisniewski KE, Sudhalter V, Keogh M, Tsiouris J, Miezejeski C, Schaefer GB. Identical twins discordant for Sotos syndrome. Am J Med Genet 1998:79:329-33.

6 Faivre L, Viot G, Prieur M, Turleau C, Gosset P, Romana S, Munnich A, Vekemans M, Cormier-Daire V. Apparent Sotos syndrome (cerebral gigantism) in a child with trisomy 20p1 1.2-p12.1 mosaicism. Am J Med Genet 2000:91:273-6.

7 Smith M, Fullwood P, Qi Y, Palmer S, Upadhyaya M, Cole T. No evidence for uniparental disomy as a common cause of Sotos syndrome. J Med Genet 1997;34: 10-12.

8 Schaefer GB, Bodensteiner JB, Buehler BA, Lin A, Cole TR. The neuroimaging findings in Sotos syndrome. Am J Med Genet 1997:68:462-5

9 Robertson SP, Gattas M, Rogers M, Ades LC. Macrocephaly-cutis marmorata telangiectatica congenita: report of five patients and a review of the literature. Clin Dysmorphol 2000;9:1-9.

10 Suzuki N, Kyo K, Kano K. Sotos syndrome associated with West syndrome and a visual disorder. Pediatr Int 1999;41:395-8.

11 Robertson SP, Bankier A. Sotos syndrome and cutis laxa. J Med Genet 1999;36:51-6.

12 Goldstein DJ, Ward RE, Moore E, Fremion AS, Wappner RS. Overgrowth, congenital hypotonia, nystagmus, strabismus, and mental retardation: variant of dominantly inherited Sotos sequence? Am J Med Genet 1988;29:783-92 